\title{
HACIA UNA CULTURA ORGANIZACIONAL AUTOCTONA \\ QUE FOMENTE EL DESARROLLO ECONÓMICO
}

\author{
AUTORES:
}

Pablo Enrique Fierro López | Natali del Rocío Torres Peñafiel Rosa Elis Bell Heredia | Jhonny Santiago Torres Peñafiel 


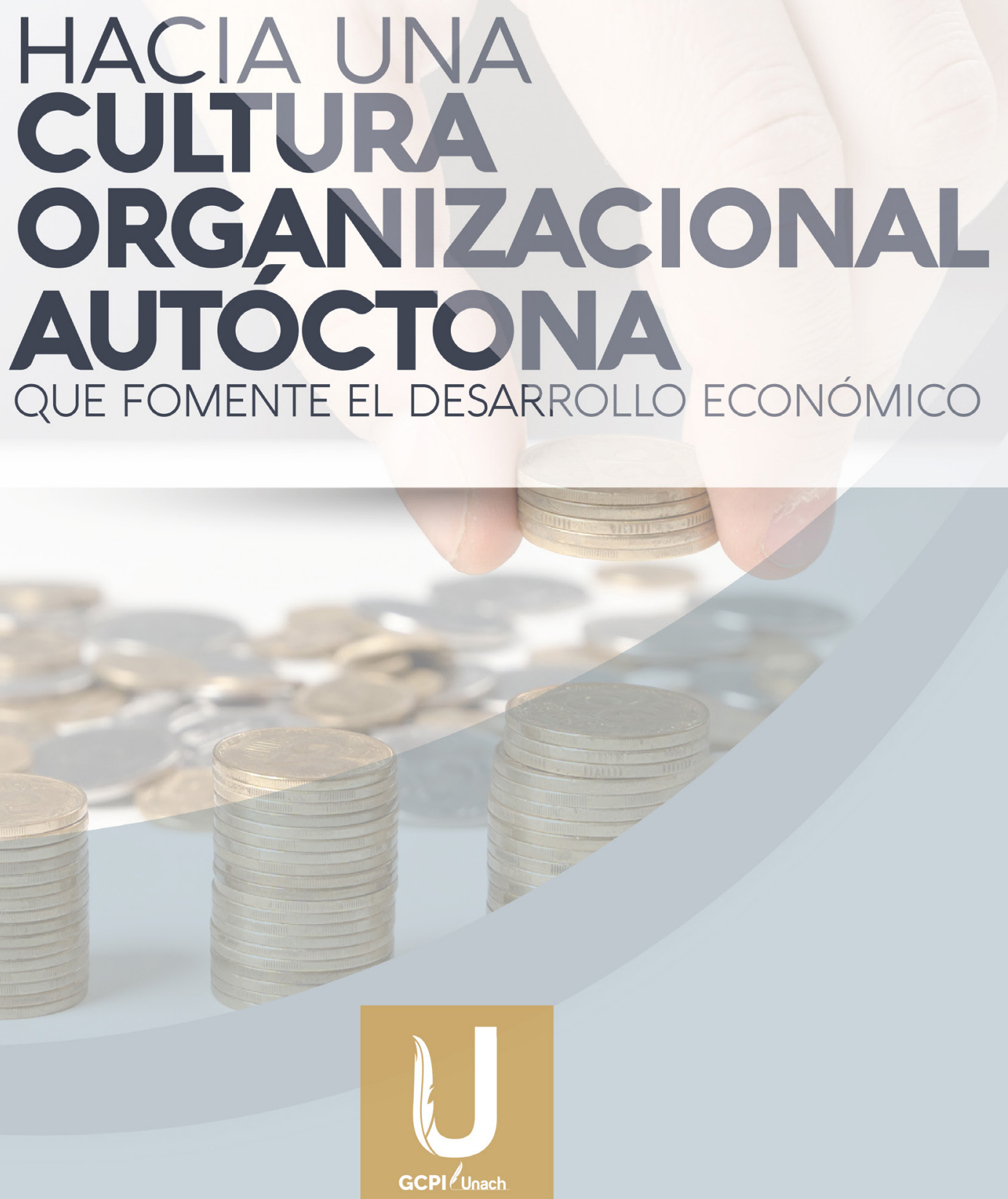


\section{UNIVERSIDAD NACIONAL DE CHIMBORAZO}

Rector

Ph.D. Gonzalo Nicolay Samaniego Erazo

Vicerrectora Académica

Ph.D. Ángela Calderón Tobar

Vicerrector de Investigación, Vinculación y Posgrado

Ph.D. Lexinton Cepeda Astudillo

Vicerrectora Administrativa

Ph.D. Anita Ríos Rivera

\section{Comité Editorial:}

Presidente: Ph.D. Lexinton Cepeda Astudillo

Secretaria: Ing. Sandra Zúñiga Donoso

Miembros: Ph.D. Margarita Pomboza Floril; Ph.D. Gerardo Nieves Loja; Ph.D. Carmen Varguillas Carmona; Ph.D. Cristhy Jiménez Granizo; Msc. Clara Mayorga Mazón; Ph.D. Diego Pinilla Rodríguez.

Título de la obra: HACIA UNA CULTURA ORGANIZACIONAL AUTÓCTONA QUE FOMENTE EL DESARROLLO ECONÓMICO

Nombres de los autores: Pablo Enrique Fierro López | Natali del Rocío Torres Peñafiel | Rosa Elis Bell Heredia | Jhonny Santiago Torres Peñafiel; Riobamba, 2020

CUNACH, 2020

Ediciones: Universidad Nacional de Chimborazo (UNACH)

Diseño Gráfico: UNACH

Primera edición - noviembre 2020

Riobamba - Ecuador

Se prohíbe la reproducción total o parcial de esta obra, sea cual fuere el medio, sin la anuencia por escrito del titular de los derechos.

ISBN: 978-9942-835-25-3

ISBN: 978-9942-835-26-0 (DIGITAL)

DOI: https://doi.org/10.37135/u.editorial.05.21

Depósito legal: 059232

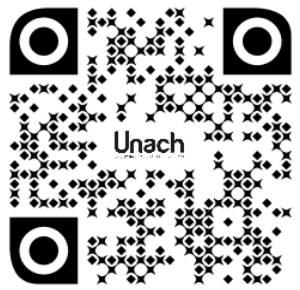




\section{HACIA UNA CULTURA ORGANIZACIONAL AUTOCTONA \\ QUE FOMENTE EL DESARROLLO ECONÓMICO}

Filiación autores:

Pablo Enrique Fierro López

Universidad Nacional de Chimborazo

pfierro@unach.edu.ec

Natali del Rocío Torres Peñafiel

Escuela Superior Politécnica de Chimborazo natali.torres@espoch.edu.ec

Rosa Elis Bell Heredia Universidad de la Habana - Cuba rosa@fec.uh.cu

Jhonny Santiago Torres Peñafiel Universidad Nacional de Chimborazo jhonny.torres@unach.edu.ec

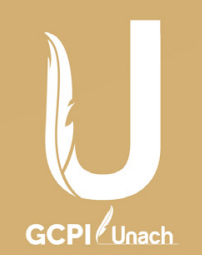



ÍNDICE

CAPÍTULO I.

EL CONOCIMIENTO Y EL CAPITAL HUMANO .......................11

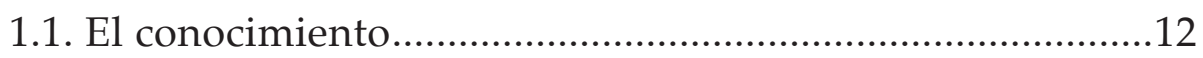

1.2. La gestión del conocimiento ..............................................13

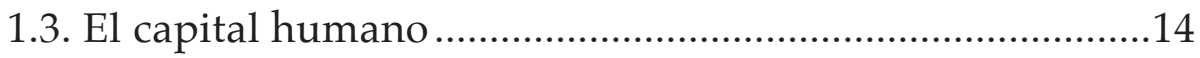

1.4. El conocimiento y el capital humano..................................25

1.5. La sociedad del conocimiento ........................................28

CAPÍTULO II.

LA GESTIÓN Y LA ORGANIZACIÓN ...........................................31

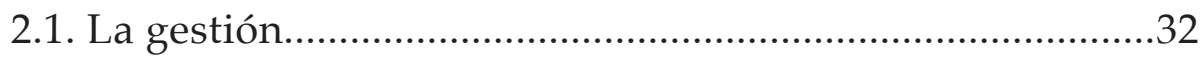

2.2. Funciones del proceso de gestión .......................................33

2.3. Eficacia, eficiencia y efectividad..........................................36

2.4. Teorías administrativas y Cultura Organizacional ............37

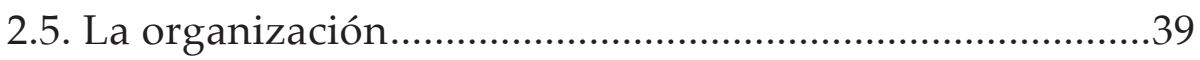

2.6. Teorías de las organizaciones .............................................41

2.7. El concepto de organización desde el punto de vista sistémico

CAPÍTULO III.

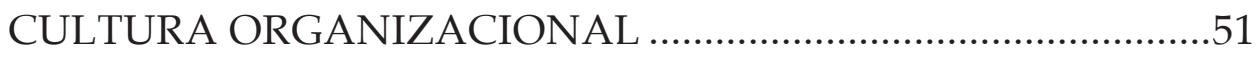

3.1. La Conceptualización de Cultura Organizacional .............52

3.1.1. Hacia una Cultura Organizacional Autóctona ................59

3.2. Variables de la Cultura Organizacional .............................62

3.3. Tendencias sobre la Cultura Organizacional......................82 
CAPÍTULO IV.

DESARROLLO ECONÓMICO LOCAL.

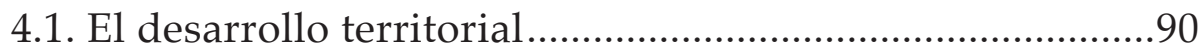

4.2. Experiencias sobre desarrollo económico local ...................96

CAPÍTULO V.

PROCEDIMIENTO PARA FOMENTAR UNA CULTURA ORGANIZACIONAL AUTÓCTONA EN CHIMBORAZO

5.1. Caracterización de la provincia de Chimborazo 104

5.2. Procedimiento para fomentar una Cultura Organizacional Autóctona en los GAD Municipales de la provincia de Chimborazo.

5.3. Caso de estudio: Gobierno Autónomo Descentralizado Municipal del cantón Colta.

CAPÍTULO VI.

ACCIONES PARA EL FOMENTO DE UNA CULTURA

ORGANIZACIONAL AUTÓCTONA EN LOS GAD DE LA

PROVINCIA DE CHIMBORAZO

6.1. Acciones para fomentar un Cultura Organizacional Autóctona

6.2. Evaluación y control de la gestión ......................................144

6.3. Validación del procedimiento ............................................146

CONCLUSIONES GENERALES

REFERENCIAS BIBLIOGRÁFICAS 


\section{INTRODUCCIÓN}

Esta obra contempla resultados importantes que parten del proyecto de investigación titulado "Lineamientos para Fomentar una Cultura Organizacional exitosa" de la Universidad Nacional de Chimborazo (Unach) y de la investigación "Fomento de una Cultura Organizacional Autóctona en aras de una mejor gestión para los Gobiernos Autónomos Descentralizados Municipales de la provincia de Chimborazo", los cuales contribuyen a las ciencias administrativas y económicas, pues la fundamentación teórica de esta investigación, se centra en concebir una Cultura Organizacional que rescata cualidades y características propias de los territorios, con culturas ancestrales, que reconozcan el accionar de los actores locales, en los cantones del Ecuador.

El objetivo de esta investigación es establecer las acciones para que, a través del fomento de una Cultura Organizacional Autóctona en los Gobiernos Autónomos Descentralizados Municipales del Ecuador, y el enfoque de trabajo de los funcionarios públicos, dé como resultado un impacto positivo promoviendo el desarrollo de los pueblos.

En el primer capítulo se desarrolla el conocimiento, posteriormente se aborda el "capital humano" como una forma nueva de concebir a la persona dentro de la organización; en base a estos temas se analiza la combinación de estas dos variables como son: el conocimiento y el capital humano, para determinar lo que es la sociedad del conocimiento.

El capítulo dos analiza la gestión y la organización, la primera, conociendo las funciones del proceso de la misma, y distinguiendo: qué es la eficiencia, eficacia y efectividad; también examinando varias teorías administrativas que dan sustento a este trabajo y su relación con la Cultura Organizacional. Consecutivamente se 
describen las diferentes teorías de la organización enfocando el trabajo a un marco conceptual de organización desde el punto de vista sistémico.

En el capítulo tres, se aborda la Cultura Organizacional, en primera instancia se recogen criterios de una revisión bibliográfica para elaborar una conceptualización de la Cultura Organizacional Autóctona, definiendo y proponiendo un nuevo concepto, que se adapte a las particularidades de los territorios.

En el capítulo cuatro, se considera al desarrollo económico local, analizando el desarrollo territorial a través de varias experiencias de desarrollo económico local, concluyendo en un atisbo crítico sobre el desarrollo local.

En el capítulo cinco, titulado procedimientos para fomentar una Cultura Organizacional exitosa en Chimborazo, se realiza una caracterización de dicha provincia, que permite tener un diagnóstico de esta región del Ecuador, y por último, el estudio de caso del Gobierno Autónomo Descentralizado Municipal del cantón Colta.

En el capítulo seis, se desarrollan acciones necesarias para fomentar una Cultura Organizacional Autóctona en un gobierno local, también se propone la evaluación y control de las diferentes acciones y por último se valida el procedimiento con expertos. 


\section{CAPÍTULO I.}

\section{El CONOCIMIENTO \\ $\underline{Y}$ EL CAPITAL HUMANO}




\subsection{El conocimiento}

Una de las características distintivas de las nuevas teorías del crecimiento, desarrolladas en los últimos años, ha sido el enriquecimiento del concepto relevante de capital, las contribuciones más recientes han atribuido una importancia creciente a la acumulación de "capital humano" y conocimientos productivos, así como a la interacción entre estos dos factores intangibles.

Las posiciones, interpretaciones y concepciones alrededor del "capital humano", comienzan a desarrollarse desde mediados del siglo pasado. Varios autores con un fuerte enfoque neoclásico se refieren a este, como una economía basada en el conocimiento, capital intelectual, recursos humanos, etc.

Lo mejor que puede poseer una organización, es el conocimiento que se encuentra en ella; pero, lo importante es desarrollarlo para el bien de la organización, "el conocimiento existe en todas las organizaciones actuales, pero solo aquellas que desean prosperar lo visualizan como un capital competitivo, generador de valor" (Aportela,et. al. 2008).

El conocimiento genera valor para todos en la organización, desde los mandos superiores hasta los clientes o usuarios del bien o servicio, si se sabe aprovechar para el propio bien, se puede convertir en la mejor ventaja competitiva, que trae múltiples beneficios que podrían ser difíciles de imitar por la competencia, debido a que cada institución es única, al igual que su conocimiento, tácito o explícito, pero ¿cómo se puede visualizar este conocimiento?

La organización debe buscar las formas para que las personas aporten su conocimiento para bien de todos. "Si bien, la clave sigue residiendo en el conocimiento individual, son las entidades las que deben conceder a las personas la suficiente garantía, de que ese conocimiento depositado en la empresa sea realmente motivante y gratificante" (Aportela, et. al. 2008). 
El "conocimiento" es uno de los activos más valiosos de la organización, el cual puede ser una ventaja competitiva de gran valor. La empresa que no aprende a sacar el mayor provecho a la información que tiene a su poder y a capitalizar eficazmente el conocimiento que se genera de ella, estará en desventaja considerable con relación a otras empresas del entorno.

Este conocimiento organizacional debe cubrir todas las áreas estratégicas de la organización del capital humano, como son la estructural, relacional, organizativa, tecnológica y de mercado para poder sacarle provecho al conocimiento poseído. Estas áreas estratégicas son tomadas en consideración en el artículo "Agregación de valor a los servicios de información para la gestión del conocimiento en la creación de servicios y productos informáticos", en donde las autoras (Pérez, et.al, 2009), señalan que el capital humano se compone de estas áreas.

\subsection{La gestión del conocimiento}

Para (Guillen, 2018), "si se pretende comprender una situación susceptible de intervenirse para solucionar o mejorar, es necesario observar el todo, pues analizar sus partes de forma independiente no basta", por lo que es de suma importancia que los gerentes de las organizaciones tomen en cuenta los beneficios que conlleva una planificación de la gestión del conocimiento, dentro de su estrategia ya que es un recurso desperdiciado en muchas instituciones. También es importante recalcar que la implementación de una estrategia basada en el conocimiento adquirido previamente puede permitir incrementar el valor de los bienes y servicios para satisfacer de mejor manera las necesidades de los clientes, fomentando la innovación para poder lograrlo y obteniendo como resultados una mayor productividad.

La gestión del conocimiento debe ser considerada en la planificación de los recursos humanos y así conseguir la retención y atracción de los colaboradores con talento e incentivarlos a que compartan su 
conocimiento con el resto de la organización. Por medio del capital humano se crea conocimiento y con este capital humano se transmite y se renueva el conocimiento creado.

\subsection{El capital humano}

La educación superior juega un papel protagonista en la sociedad del conocimiento, pues con sus actividades académicas y de investigación generan un sistema nacional de innovación para que el conocimiento científico y tecnológico produzca sus mayores beneficios a futuro en las organizaciones, que juntamente con las habilidades demostradas se lo denominará "capital humano". Sin embargo, antes de conceptualizar al capital humano es necesario conocer el significado de Recursos Humanos.

El término recursos humanos (abreviado como RRHH, RH, RR.HH) se originó en el área de economía política y ciencias sociales, donde se utilizaba para identificar a uno de los tres factores de producción, también conocido como trabajo (los otros dos son tierra y capital); como tales, durante muchos años se consideraba un recurso más: predecible y poco diferenciable.

El concepto de recursos humanos surge en la década de 1920, en reacción al enfoque de "eficiencia" de Taylor. Los psicólogos y expertos en empleo iniciaron el movimiento de recursos humanos, que comenzó a ver a los trabajadores en términos de su psicología y adecuación a la organización, más que como partes intercambiables.

Este movimiento creció a lo largo del siglo XX, poniendo cada día mayor énfasis en: el liderazgo, la cohesión y la lealtad que jugaban un papel importante en el éxito de la organización. Como se puede evidenciar en las conceptualizaciones anteriores, el entorno organizacional sufrió transformaciones importantes en la economía y la sociedad, producto del proceso de globalización; de ahí que existe un consenso de que el trabajador es mucho más que trabajo, y 
que podía aportar más que eso a la empresa y a la sociedad, es así que se creó el concepto de capital humano, que engloba la complejidad de este recurso.

Para Susana Delgado, recursos humanos "es el departamento dentro de una empresa que se encarga de la gestión y a la administración del personal, en sus orígenes de esta rama de la administración se encargaba de funciones de la administración de personal, ahora con el paso del tiempo ha ido asumiendo progresivamente funciones que se relacionan con la misión del personal" (Delgado, 2008).

Según el Diccionario Ilustrado de la Lengua Española, "Recursos Humanos es el conjunto del capital humano que está bajo el control de la empresa en una relación directa de empleo, en este caso personas, para resolver una necesidad o llevar a cabo una empresa" (Albizu, 2000).

De la literatura anteriormente señalada, se puede analizar que Delgado y Albizu coinciden en que, recursos humanos enfatiza a la administración o dirección de las personas que laboran dentro de una organización.

Cuando se utiliza en singular, "recurso humano", generalmente se refiere a las personas empleadas en una empresa u organización, es sinónimo de "personal". Cuando se habla en plural, "recursos humanos", suele referirse al área de la administración que se ocupa de gerenciar al personal de la empresa; esto incluye contratar, desarrollar, adiestrar y despedir, entre otras funciones.

Es importante mencionar que el potencial del trabajador, juega un papel muy importante para considerarlo como un recurso dentro de la organización.

A medida que el mundo empresarial se daba cuenta que un empleado era mucho más que "trabajo", y que podía aportar más que eso a la 
empresa y a la sociedad, se creó el concepto de capital humano, que engloba la complejidad de este recurso.

El “capital humano", actualmente es una expresión muy utilizada a partir de los cambios organizacionales y el rol preponderante, que el conocimiento y el talento humano juega en la nueva economía.

El profesor de la Facultad de Economía de la Universidad de La Habana, Carlos Lazcano Herrera, en su artículo "capital humano, en busca de su contexto", en el año 2006, señala que el origen del término "capital" procede del latín "caput", y humano procede del Latín "human", que significa cabeza; por tanto, el "capital humano" en Latín significa "cabeza humana", que es donde se concentra la inteligencia humana, la psiquis y los valores fundamentales de los hombres, además de los aspectos físicos y biológicos.

En el artículo mencionado, Lazcano, plantea que "en la actualidad el término de "capital" no es patrimonio de economistas, filósofos, educadores, etc., es de todas las ciencias, y ha pasado a formar parte de la cultura expresiva del ser humano; según el contexto donde se emplea; es por ello que encontramos expresiones como "capital de mi país" refiriéndose en términos geográficos, "pena capital" refiriéndose en términos jurídicos; "pecado capital" en términos religiosos, y así sucesivamente” (Lazcano y Font, 2006).

Para abordar el término de "capital" hay que tener en cuenta los escritos de Carlos Marx, sobre todo el primer tomo de su gran obra, "El capital", analiza primero la mercancía, después el dinero y luego el capital destacando que "... es un valor que se auto acrecienta, un valor que crea plusvalía”. Y más adelante señala “... no es una cosa material, sino una determinada relación social de producción, correspondiente a una determinada formación histórica de la sociedad, que toma cuerpo en una cosa material" (Marx, 1973). 
Los economistas clásicos anteriores a Marx, consideran al "capital" como la riqueza utilizada en la producción de más riqueza, o riqueza en proceso de intercambio. No llegaban a desentrañar la verdadera esencia del problema dado en las relaciones sociales y como, el trabajo, es la fuente del valor de las riquezas.

El término "capital humano" apareció por primera vez en "Investment in Human Capital", un artículo del Premio Nobel en Economía, Theodore Schultz, publicado en 1961 en la American Economic Review, desde entonces los economistas han cargado con muchos términos la maleta actual del capital humano.

La mayoría de autores coincide en que el capital humano comprende habilidades, experiencias y conocimientos, algunos como el Economista Gary Becker (Premio Nobel), añaden personalidad, apariencia, reputación y credenciales. Y todavía otros como el consultor de Gestión Richard Crawford, equiparan al "capital" con sus propietarios, señalando que el capital humano consiste en personas hábiles e instruidas.

Es así que el concepto actual de capital humano se recaba de los autores clásicos, quienes pusieron de manifiesto que las cualidades humanas tales como los conocimientos o habilidades adquiridas por los trabajadores, su salud, educación, motivación, influyen en la actividad económica de la organización, a continuación, se mencionan algunos conceptos importantes.

El economista Schultz, ha señalado cinco factores quehan contribuido a mejorar la capacidad humana:

1) Equipos y servicios de salud, ampliamente concebidos para que incluyan todos los gastos que afectan la expectativa de: vida, fuerza, resistencia, vigor, y vitalidad de un pueblo.

2) Formación en el puesto de trabajo, incluyendo el aprendizaje al viejo estilo, organizado por las empresas. 
3) La educación formal organizada en el nivel elemental, secundario y superior.

4) Los programas de estudio para adultos que no están organizados por las empresas, incluyendo los programas de extensión.

5) La emigración de individuos y familias para ajustarse a las cambiantes oportunidades de trabajo.

Para Schultz, "la adquisición de los elementos educativos que permiten el aprendizaje complejo en grados crecientes, es el punto de partida de un proceso de acumulación de capital humano, donde la complejidad de los conocimientos y destrezas necesarios evolucionan de acuerdo con los progresos tecnológicos. En vista de estos planteamientos es necesario que el capital humano encuentre una aplicabilidad económica a través del mercado, para que las personas, como consecuencia, de una mayor formación, encuentren las oportunidades que le permitan, mejorar su desempeño en el trabajo, incrementen la productividad e impulsen el crecimiento de la economía. En este sentido, la política económica debe concebir el capital humano como un activo que contribuye al crecimiento, y promueve la "empleabilidad" de la mano de obra, creando las condiciones necesarias para que las personas lleven a la práctica su "capacidad de emprender". Y que el progreso tecnológico económico conduzca hacia una dinámica de cambio acelerado de las características de "empleabilidad", que retribuya sus capacidades laborales, las cuales, se transforman cada vez que se completa un ciclo tecnológico en la economía" (Schultz, 1983).

Mientras que Gary Becker, define el capital humano como: "el conjunto de las capacidades productivas que un individuo adquiere por acumulación de conocimientos generales o específicos que puede ser acumulado, o usarse. Es una opción individual, una inversión. Se evalúa por la diferencia entre el coste de los gastos de educación 
y los gastos correspondientes (compra de libros...), y el coste de productividad, es decir, el salario que, recibiría si estuviera inmerso en la vida activa, y sus rentas futuras actualizadas" (Becker, 1983).

En este sentido los autores contemplan que la definición de Schultz y la definición de Becker se complementan, ya que hoy en día, el individuo hace una valoración arbitrada entre trabajar y continuar una formación, que le permita en el futuro, percibir salarios o inclusive realiza un esfuerzo mayor al prepararse y trabajar al mismo tiempo con la finalidad de obtener mejores réditos a futuro e impulsar la economía garantizando la empleabilidad.

Dentro de este análisis no podemos dejar de lado el pensamiento Marxista, pues, sirve de referente directo al "capital humano", como concepto es "trabajo complejo". "Esta noción de Marx es la sustancia del "capital humano", la que explica cómo un trabajo altamente calificado demanda mayor salario y de aquí la falsa idea de que cesa la explotación y la supeditación del trabajo al capital pero a la vez, multiplica varias veces la ganancia de los dueños de esa mercancía especial" (García, 2005).

Es así, que el término capital humano se menciona, en ocasiones, como una forma de capital, indicando con ello "aprovechamiento al máximo del aporte humano", al que como activo intangible se le asigna un valor y se considera como capital.

Para los economistas clásicos, el capital es riqueza utilizada en la producción de más riqueza, o riqueza en proceso de intercambio, mientras que, para los marxistas, capital es una relación social de producción, en la cual el trabajo es fuente y valor de las riquezas.

Estas dos diferentes definiciones han ocasionado polémica entre dos posiciones contrapuestas acerca del capital, por lo que la palabra capital, en el contexto del análisis teórico, trae las mayores contradicciones y discusiones. 
Lo sobresaliente del análisis del capital humano no radica en la denominación del concepto, sino en la definición que dé a este. Pues, la identificación del término "Capital" con vocablos sustitutos como "riqueza", "patrimonio" o "caudal", entre otros, puede ser interpretado como la idea de que el ser humano es tratado como un elemento meramente material.

Sin embargo, para varios autores la relevancia del concepto de capital humano radica en la interpretación del mismo.

En nuestro criterio se considera al capital humano como una de las características, valores y cualidades de las personas (aspectos intangibles como: la formación, educación, escolarización, el conocimiento, la salud, responsabilidad, lealtad) o el nivel de conocimiento que posee cada ser humano, es decir la fuerza mental que seamos capaces de desarrollar para contribuir a los objetivos de las organizaciones, sin embargo se cree necesario que además de los conocimientos se requiere tener la actitud adecuada para estar dispuestos a crecer dentro de las empresas y por tanto, a mostrar una conducta de excelencia a la hora de desarrollar nuestro trabajo día a día pues desde mi punto de vista personal: ACTITUD (entusiasmo, valores, responsabilidad, patriotismo, lealtad, etc.) + APTITUD (conocimientos, talento, competencia, etc.) = ÉXITO, PRODUCTIVIDAD, RENTABILIDAD, etc.

Entre las investigaciones realizadas a la utilización del término capital humano, Odriozola (2013), sintetiza sus argumentos en las razones siguientes: 
Tabla 1: El capital humano.

- El hecho de que detrás de la identificación del término "capital" con vocablos sustitutos como "riqueza", "patrimonio" o "caudal" entre otros similares. Subyace un tratamiento al ser humano como elemento meramente material.

- El hecho de que mantener la nomenclatura existente conlleva un aplazamiento en la conformación de un sistema categorial propio.

- El lugar central que ocupa en las concepciones marxistas lo concerniente al "capital" como sistema de relaciones de explotación capitalista.

Fuente: (Odriozola, 2013).

Tomando en cuenta estas consideraciones, Odrizola plantea una alternativa para sustituir al término "capital humano" por "potencial humano".

El concepto de potencial humano en el mundo laboral cobra importancia, debido a que la gerencia, al ser consciente que todos sus colaboradores cuentan con un gran potencial para llevar a cabo las tareas encomendadas, que pueden emplear estratégicamente, tanto para el logro de los objetivos particulares del trabajador, como para la consecución de los objetivos, metas y propósitos de la propia organización.

Según el Diccionario Ilustrado de la Lengua Española, el potencial humano se describe como "la aptitud intelectual de los hombres de una organización, valorada para su capacidad natural o adquirida para su desempeño" (Albizu, 2000).

Para la doctora Silvia Odriozola, potencial humano, "se define como el conjunto de conocimientos y valores asimilados por las personas, que contribuyen al mejoramiento de sus habilidades productivas y creativas, a la ampliación de sus capacidades para participar de forma consciente en el proyecto social del cual forman parte y a su realización plena como individuos" (Odriozola, 2013). 
De ahí que surge la alternativa, para lo que hoy en día se conoce como "capital humano", considerado como "potencial humano". Dos razones básicas fundamentan la propuesta. La primera de ellas: inclusión de valores, lo cual según Odriozola constituye un rasgo distintivo con respecto al concepto de capital humano. La segunda está relacionada con el rendimiento esperado del potencial humano. Esto último se refiere a que, en la concepción del capital humano, el rendimiento que se espera obtener en su inversión está vinculado, en lo fundamental, al plano individual. Es decir, las personas invierten tiempo y recursos en aumentar su nivel de formación, pero con el propósito de obtener beneficios individuales.

La concepción del potencial humano que propone Odriozola, son los valores alcanzados por la sociedad, los que permiten que este potencial humano pueda ser aprovechado en beneficio de la propia sociedad.

Los autores consideran que el concepto de "capital humano" incluye también a los valores humanos además del conocimiento del trabajador, y que estos aplicados conjuntamente en las labores diarias, permitirá alcanzar el éxito empresarial el cual engloba, mejores utilidades, mejores participaciones a los trabajadores, mejores contribuciones impositivas con el estado, etc., implementado un proceso de integración social entre los trabajadores y empoderamiento hacia sus organizaciones.

El análisis teórico acerca de la importancia del conocimiento, permite adentrarse en los conceptos esenciales que facilitan comprender y revelar los principales elementos para desarrollar estudios con un fundamento científico general; pero en ellos se precisa, la necesidad de particularizarlo a las características de la organización y al contexto concreto en que esta se forma y desarrolla. Ciertas organizaciones definen sus propósitos y otras los tratan como parte de la cultura de estas. Dentro de economía se ha considerado un nuevo eje, que toma forma en relación al conocimiento denominado economía del conocimiento, cuyo sustento ya no se basa solamente en el trabajo, 
capital, materiales y energía, sino en el capital intangible, que a través de un cambio tecnológico aumenta la capacidad productiva de las demás funciones, todo esto aplicado a una sociedad del conocimiento, en donde los países buscan el desarrollo a través de la educación y la adquisición de conocimientos, aplicables a la ejecución diaria de las actividades laborales en las diferentes áreas de producción. Todo ello tiene su raíz anclada en el proceso de globalización.

Un análisis del concepto de "capital humano" en cuanto a su evolución y conceptualización nos ha permitido constatar que, aunque existen varias definiciones al respecto, hay un acuerdo generalizado entre los autores e investigadores en el sentido de que es necesario cambiar los enfoques tradicionales de tratamiento a los recursos humanos, otorgándole el significado por el aporte a los resultados de la empresa, ya que la ventaja competitiva básica de las entidades radica en el nivel de preparación y de gestión del capital humano.

El término capital humano muchas veces es utilizado para referirse a los recursos humanos o potencial humano y viceversa, sin embargo, es importante conocer que en el capital humano se suman las actitudes y el potencial humano del recurso humano, en otras palabras, al conocimiento se lo identifica con capital humano, a las habilidades como potencial humano y al trabajador como recurso humano.

Portanto, el capital humanoesun conceptoamplioy multidimensional que recoge muchas formas distintas de inversión en seres humanos. La salud y la nutrición son ciertamente aspectos importantes de esta inversión, especialmente en los países en desarrollo donde deficiencias en estos aspectos pueden limitar severamente la capacidad de la población de participar en actividades productivas. Desde el punto de vista de los autores, el aspecto clave del capital humano tiene que ver con los conocimientos y habilidades de la fuerza laboral que se acumulan como resultado de la escolarización, 
la formación continua y la experiencia, y que resultan útiles en la producción de bienes, servicios y nuevos conocimientos.

Para comprender la relación entre globalización y conocimiento, conceptualicemos a la globalización, pues, según Pérez "es un fenómeno objetivo, derivado del desarrollo del mecanismo económico capitalista, es la manifestación del desarrollo de la esencia del sistema donde el nivel de concentración y centralización del trabajo, el capital y la propiedad, toman magnitudes acordes con el desarrollo extraordinario de las fuerzas productivas" (Perez, 2000).

De la literatura anterior podemos sintetizar que la globalización es el conjunto de cambios integrales que afectan a todas las esferas de la sociedad. De estos cambios han surgido fenómenos al interior de la estructura socioeconómica mundial, entre ellos una profundización y expansión del conocimiento, el cual se constituye en el determinante de las ventajas comparativas de los países.

Estas ventajas ya no se basan en la dotación de recursos naturales, la mano de obra barata o la ubicación geográfica, sino en el desarrollo del talento humano, cuyos "conocimientos y habilidades no solo hacen posible mejorar las ventajas competitivas en la economía mundial, sino también encontrar alternativas de solución a los problemas económicos y sociales de los entornos nacionales y locales" (Chaparro, 2015). A este proceso ha contribuido en forma notoria la llamada revolución de la información.

Sin embargo, a pesar de que el conocimiento se ha convertido en la única fuente de ventaja competitiva en el largo plazo, este sólo puede ser utilizado cuando existen condiciones apropiadas, como la formación de un recurso humano calificado, con determinadas habilidades para su empleo. 
Tomando en cuenta estas consideraciones, la globalización del conocimiento impone el reto de buscar y aplicar estrategias de mejoramiento continuo apropiadas a las condiciones específicas de las organizaciones, con miras a potenciar ventajas competitivas, que les permitan posesionarse en el mercado local, nacional o internacional, evitando tener que convertirse en un simple apéndice tecnológico de las empresas transnacionales. Para lograr este objetivo se requiere un gran esfuerzo en materia de investigación y desarrollo, capacitación continua, y mucha creatividad en el desarrollo de las funciones laborales.

Es por ello, que en este análisis se plantea un modelo conceptual con base empírica del tema del capital humano, que ayude a implementar políticas más integrales en el ámbito global, pero también y especialmente en el regional y local.

Considerando que para Navarro (2005), se precisa entender al capital humano contemplando su naturaleza intangible que plantea una mediación entre lo global y lo local que ayude a las personas a responder a las exigencias del medio con respecto a la competitividad y productividad regulados por el bien común.

\subsection{El conocimiento y el capital humano}

De la transición de la fase industrial a la posindustrial del capitalismo se han originado cambios en el ambiente económico, político, social y cultural, de forma global.

En el ámbito económico, "la producción de bienes pierde importancia en la estructura económica a favor del sector servicios, así como el mercado de productos, ante los mercados globalizados de divisas, finanzas y capitales. Las estructuras ocupacionales sufren un cambio radical por la aparición creciente de las categorías profesionales altamente cualificadas y la disminución de las menos cualificadas. Las empresas se ven en la necesidad de introducir sistemas 
adecuados de gestión del conocimiento y de adaptar sus estructuras organizativas a otras más flexibles y de gestión para hacer frente a los cambios" (Askenazy, 2014).

En el ámbito político las decisiones requieren cada vez más de la legitimación. Además, los márgenes de decisión han disminuido manifestándose, por una parte, en la capacidad del sistema político para gestionar procesos sociales y por la otra el sistema económico depende menos de las decisiones políticas debido a la globalización de los procesos económicos.

En el ámbito social se observa que los cambios en la estructura ocupacional han generado un impulso a la educación, reflejándose en un nivel de educación más alto de la población. Las universidades dejan de ser instituciones de educación superior elitista para convertirse en instituciones de educación superior masificada.

Y en el ámbito cultural el uso de las nuevas tecnologías de información y comunicación y los avances de las tecnologías de tráfico, indican cambios en los procesos culturales y las interacciones sociales.

Es en estas condiciones, en donde se gesta la nueva economía, que en palabras de Didriksson se describe como "el proceso de relaciones económicas globales (o locales) que ocurre de forma desigual y contradictoria a nivel internacional, y que se caracteriza por estar sustentado en el uso extensivo e intensivo de nuevas tecnologías, aprendizajes y conocimientos organizados o aplicados en los sistemas de informatización y de las telecomunicaciones, de la biotecnología y de las ciencias genómicas, entre otras innovaciones, y que empieza a tomar forma bajo la forma de un nuevo Modo (articulado económico, político y socio institucional) de Producción de Conocimientos" (Didrikson, 2006).

A esa nueva economía algunos especialistas y académicos la denominan economía del conocimiento, sustentada ya no en las 
funciones de producción tradicionales: trabajo, capital, materiales y energía, sino en el capital intangible que a través de un cambio tecnológico aumenta la capacidad productiva de las demás funciones. La nueva teoría de crecimiento intenta explicar la relación que existe entre conocimiento- tecnología y productividad-crecimiento económico.

Esta teoría sostiene que el conocimiento puede aumentar la rentabilidad de las inversiones y a la vez acumular conocimiento, mediante métodos más eficaces de organización de la producción, así como nuevos y mejorados productos y servicios; a través de la educación y entrenamiento de la fuerza de trabajo, la inversión en investigación y desarrollo y la creación de nuevas estructuras de gestión y organización del trabajo.

Por su parte Hirst sostiene que economía del conocimiento es un "sistema en el que el procesamiento de la información se ha convertido en la característica principal en la mayoría de los sectores, y específicamente en donde se ha dado un importante cambio en los mercados: de bienes materiales hacia los de información" (Hirst, 2000).

Por otra parte, la Organización de Cooperación Económica y Desarrollo (OCDE) menciona en un estudio del Banco Mundial que el término economía del conocimiento se usa para dibujar la atención a la importancia del conocimiento en todas las actividades económicas.

De las ideas expresadas se deduce que Hirst enfatiza sobre el término de información, mientras que el Banco Mundial lo hace sobre el conocimiento, diferencia que se explica a continuación. La existencia de la tecnología de la información da lugar a la codificación de determinados tipos de conocimiento.

Todos los conocimientos que pueden ser codificados y convertidos en información pueden ser transmitidos a grandes distancias con 
muy pocos gastos. El aumento en la codificación del conocimiento es lo que ha dado lugar a la sociedad de la información; en la que muy pronto los trabajos serán la producción, manipulación y distribución de información o conocimiento codificado.

\subsection{La sociedad del conocimiento}

Es así como la economía del conocimiento se caracteriza más por la necesidad de aprendizaje continuo de la información y de la codificación de las competencias para el uso de la información. En este contexto la sociedad ha tenido que desarrollar la capacidad para producir, seleccionar, adaptar, usar y comercializar el conocimiento para lograr el crecimiento económico sostenido y mejorar los estándares de vida de la población. El resultado es el surgimiento de la sociedad del conocimiento.

La noción sociedad de conocimiento tiene sus orígenes en los años 1960 cuando se analizaron los cambios en las sociedades industriales y se acuñó la noción de la sociedad post-industrial.

El sociólogo Peter F. Drucker, pronosticó la emergencia de una nueva capa social de trabajadores de conocimiento y la tendencia hacia una sociedad de conocimiento. Para Drucker, "este tipo de sociedad está caracterizada por una estructura económica y social, en la que el conocimiento ha substituido al trabajo, a las materias primas y al capital como fuente más importante de la productividad, crecimiento y desigualdades sociales" (Druker, 1969).

Los autores coinciden con Drucker en el sentido de que se reconoce como sociedades del conocimiento a los países que han alcanzado un mayor desarrollo económico o industrial y cuya característica principal es otorgarle al conocimiento y a la información un gran valor; a tal grado que se les considera los motores del crecimiento. Por tanto, estas sociedades se caracterizan por la introducción de nuevas tecnologías de la información y la comunicación en todos los ámbitos de la vida. 
Sus dimensiones sociales reconocen la importancia de uno de sus elementos centrales: el enfoque de desarrollo humano y la autonomía que permite poner en práctica los derechos universales y las libertades fundamentales, mejorando la eficacia de las políticas de desarrollo y la lucha contra la pobreza.

Sin embargo en la construcción de la sociedad del conocimiento es necesario enfrentarse a la brecha digital ocasionada por la falta de Internet en los países subdesarrollados o en territorios en los cuales destacan los problemas socioeconómicos ocasionados por la falta de recursos económicos y el empleo, que hacen difícil la adquisición de computadoras y el acceso a las telecomunicaciones, lo que también dificulta la geografía; también está la edad de los usuarios que en su mayoría son jóvenes lo que no les permite pagar los servicios o adquirir una computadora.

Una de las alternativas posibles para reducir esa brecha digital es combinar las nuevas tecnologías: telefonía móvil, el Internet, la telecomunicación con aquellas clásicas que permiten los medios de comunicación masiva como la prensa, la televisión, y la radio.

En síntesis, la construcción de una sociedad del conocimiento, no es tarea fácil, pues se deberá poner especial atención en el papel que juega la investigación, actividad por excelencia generadora del conocimiento, y al uso que se le dará al mismo, de tal manera que se garantice que sea el adecuado, pero además que se difunda a través de publicaciones los resultados de la investigación para que todos los demandantes de esta información tengan acceso a él. La sociedad del conocimiento impactará la geopolítica del siglo XXI. El conocimiento y la información se convertirán en un factor estratégico que cada país usará para impulsar su desarrollo. 



\section{CAPÍTULO II.}

\section{LA GESTIÓN Y LA ORGANIZACIÓN}




\subsection{La gestión}

Durante los últimos cincuenta años, el término Gestión ha sido utilizado para referirse a la Administración, Gerencia, Dirección, Dirección Integrada, Gestión Integrada y Management (Rodríguez, 2010). Por esta razón, se ha dado diferentes definiciones de gestión, aceptándose como regla general, que es sinónimo de administración, gerencia o dirección; esto es interesante ya que la gestión es en realidad las tres cosas a la vez (Comisión Económica para América Latina y el Caribe, CEPAL 2003, Ochoa, 2007; Sanabria, 2007 y Garzón, 2011). Bajo esta consideración, los autores se centran en la gestión, para el desarrollo de la investigación.

El término Gestión, proviene del latín gestio-gestionis que significa ejecutar, lograr un éxito con medios adecuados (Corominas, 1995). Heredia (1985:25), define a la gestión como "la acción y efecto de realizar tareas con cuidado, esfuerzo y eficacia, que conduzcan a una finalidad". Mientras que para Rementeria (2008:1) es una "actividad profesional tendiente a establecer los objetivos y medios de su realización, a precisar la organización de sistemas, a elaborar la estrategia del desarrollo y a ejecutar la gestión del personal"; este autor, manifiesta la importancia y constante capacidad de influir positivamente en la situación dada dentro de la organización, definición que no difiere con la de Heredia el momento de considerar los objetivos y metas.

Sin embargo, la definición con la que se identifica esta autora está dada por Rodríguez (2010:67) y radica en que "la gestión se asume como el conjunto de procesos y acciones que se ejecutan sobre uno o más recursos para el cumplimiento de la estrategia de una organización, a través de un ciclo sistémico y continuo, determinado por las funciones básicas de planificación, organización, dirección o mando y control". 


\subsection{Funciones del proceso de gestión}

Considerando esta última definición, los autores coinciden con Rodríguez, en el hecho de que la gestión se manifiesta y evidencia a través del desarrollo del proceso de gestión de Fayol y otros autores, el cual está dado a través de cuatro funciones básicas: planeación, organización, dirección y control. ${ }^{1}$ A continuación, se realiza un análisis sobre el criterio de varios autores con respecto a la clasificación de las fases del proceso de gestión, las cuales varían en consideración al momento histórico en el que fueron planteados, tal como se puede observar en la tabla 2.

Tabla 1: El capital humano.

\begin{tabular}{ll}
\hline Autores & Funciones del proceso de Gestión \\
\hline Fayol (1949) & Planeación, organización, dirección, y control \\
\hline Druker (1954) & Planear, organizar, dirigir y controlar. \\
\hline Nogueira (2002) & $\begin{array}{l}\text { Planificar, Organizar, Dirigir, Motivación, } \\
\text { Controlar }\end{array}$ \\
\hline Robbins y Coulter, (2005) & Planeación, Organización, Dirección y Control \\
\hline Arnoleto y Díaz, (2009) & Planificación, Organización, Dirección y Control \\
\hline Amaru, (2009) & Planeación, organización, liderazgo, dirección \\
& y control \\
\hline Koontz, Weihrich y Cannice (2012) & Planeación, Organización, Integración del \\
& Personal, Dirección y Control \\
\hline
\end{tabular}

Fuente: (Odriozola, 2013).

Como se puede observar, el planteamiento de Fayol es la base para que otros autores propongan ciertos elementos o funciones, como es el caso de Nogueira (2002), quien considera a la motivación como otra función o elemento del proceso de gestión, al igual que Amaru (2009), propone el liderazgo y Koontz, et al. (2012), incluye a la integración del personal, elementos considerados como intangibles dentro de la gestión (Fombrun, 2008). A continuación, se realiza una breve aproximación conceptual a cada una de las funciones del proceso de gestión de Fayol, y su relevancia en la optimización de los resultados organizacionales, que es la finalidad de la gestión.

1 Proceso administrativo o proceso de gestión: Planificar, Organizar, Dirigir y Controlar. (Fayol, 1949; Druker, 1954; Robbins y Coulter, 2005; Ivancevich et al. 1997; Arnoleto y Diaz, 2009; Carreño, 2011) 
La planeación

Según Chiavenato (2009:503), la planeación es "la que identifica objetivos y lo que debe hacerse para alcanzarlos". Definición que coincide con la que plantean Robbins y Coulter (2005), al considerar a la planeación como la fijación de metas y establecimiento de estrategias para alcanzarlas, mediante la implementación de planes para coordinar organizadamente las actividades.

En base a lo citado, se concluye que la planeación es un proceso sistemático y estructurado que incluye elegir misiones, objetivos y acciones en la búsqueda de respuestas a preguntas vitales para su diseño, estructura, dirección y control, que considera la dinámica del cambio social tanto en el entorno actual como en un escenario futuro.

\section{Organización}

La organización es la segunda fase del proceso de gestión. Para Koontz, et al. (2012:30), es aquella que "supone el establecimiento de una estructura intencional de funciones que las personas desempeñen en una organización; es intencional en el sentido de asegurarse que todas las tareas necesarias para lograr las metas se asignen, en el mejor de los casos, a las personas más aptas para realizarlas".

Por su parte Franklin (2009), considera que la organización como parte del proceso de gestión, es la fase en la que se define la estructura organizacional, la forma de delegar facultades y el enfoque para manejar los recursos humanos y clima organizacional.

Atendiendo al criterio de los autores citados, se define a la organización, como aquella que establece un orden y estructura de las funciones que las personas realizan en una organización hacia la consecución de resultados. 


\section{Dirección}

Para Robbins y Coulter (2005:493), la dirección es aquella que "interpreta los objetivos y los planes para alcanzarlos y conduce y orienta a las personas hacia ellos. La dirección se ejerce por medio de la comunicación, el liderazgo y la motivación".

Según Franklin (2009:14), "la dirección es el proceso de guiar y proveer de soporte necesario a las personas para que contribuyan con efectividad al logro de las metas de la organización".

Se puede concluir que, la dirección es el proceso de guiar y proveer de soporte necesario a las personas para que contribuyan con efectividad al logro de las metas de la organización, se atribuye a la dirección, un buen liderazgo, mediante una buena comunicación y motivación.

\section{Control}

Según Stoner (1996:610), "el control administrativo es el proceso que permite garantizar que las actividades reales se ajusten a las actividades proyectadas"; definición que coincide con la de Franklin (2009), quien asume que el control es el proceso que utiliza una persona, un grupo o una organización para regular sus acciones y hacerlas congruentes en base a las expectativas definidas en los planes, en las metas y en los estándares de desempeño planificados.

En este sentido se considera al control como la medición y corrección de las actividades laborales individuales y organizacionales para asegurar que los hechos se desarrollen acorde a los planes (Franklin, 2009; Koontz, et al. 2012).

A continuación, en la figura 1, se muestra los componentes esenciales que constituyen las fases del proceso de gestión en una organización en base a la revisión de la literatura especializada. 
PLANEACIÓN

Objetivos, metas

Filosofía, valores

Ritos, creencias, tradiciones

Planes

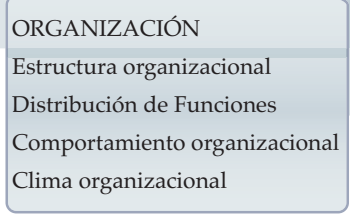

Clima organizaciona

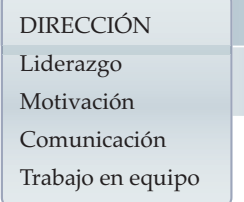

CONTROL

Medidas

Indicadores

Estándares

Figura 1. Proceso de gestión.

Fuente: Elaboración a partir de la revisión bibliográfica: Franklin (2009); Coulter (2010);

Koontz, et al. (2012); Robbins y Coulter (2005).

\subsection{Eficacia, eficiencia y efectividad}

Es así que, se considera a la gestión, como el eje fundamental de la organización, el cual permite su consolidación y proyección, con eficiencia, eficacia y efectividad. Varios autores, como Chiavenato (2009); Robbins y Coulter (2005); Koontz, et al. (2012), Cesca et al. (2012) coinciden en que la eficiencia es alcanzar los objetivos y metas planteadas, utilizando la mínima cantidad de recursos posibles. Por su parte la eficacia indica la medida en que se han alcanzado resultados, es decir, la capacidad para lograr los objetivos y metas planteadas. Mientras que la efectividad involucra la eficiencia y eficacia, es decir, el logro de los resultados programados en el tiempo y con los costos más razonables posibles, es decir hacer lo correcto con gran exactitud y sin desperdicio de tiempo o dinero.

La intención de mantener estos tres factores en un mundo donde lo único constante es el cambio, puede garantizar la supervivencia organizacional y para ello se requiere de la gestión a través de un profundo conocimiento del entorno inmediato y el ambiente interno de la organización.

Es necesario reconocer que en la gestión se ha dado mayor importancia a la cuantificación de recursos tangibles, elementos que cuantitativamente son más propensos a un análisis. Pues aquellos factores con mayor complicación para evaluar son los valores, comportamientos o clima, y han quedado en un segundo plano. 
Estos valores vinculados a los aspectos humanos, por ser intangibles suelen ser los más difíciles de medir o evaluar, sin embargo, son los aspectos fundamentales para fomentar un cambio cultural y mejorar la gestión (Chiavenato, 2009, Franklin, 2009).

En este sentido se considera que para lograr una mejor gestión organizacional se debe conjugar la eficacia y eficiencia, aunque estos dos aspectos estén condicionados por factores intangibles como la cultura organizacional (Dessler, 1993).

\subsection{Teorías administrativas y Cultura Organizacional}

“En la década de los noventa, en la que empieza a verse al cambio cultural como una oportunidad para agregar valor y establecer ventajas competitivas" (Rodríguez, 2009:2), considerándose así a la Cultura Organizacional como una variable o un medio que puede ser fomentado para mejorar la gestión logrando eficaz y eficientemente los objetivos y metas propuestas.

En la literatura especializada sobre el tema, se han planteado varias teorías administrativas, las cuales enfatizan la importancia de considerar a intangibles como la motivación hasta llegar a la, para alcanzar los objetivos y metas organizacionales; en este capítulo se citan las más conocidas a fin de considerarlas para desarrollar este trabajo de investigación, tal como se muestra en la figura 2. 

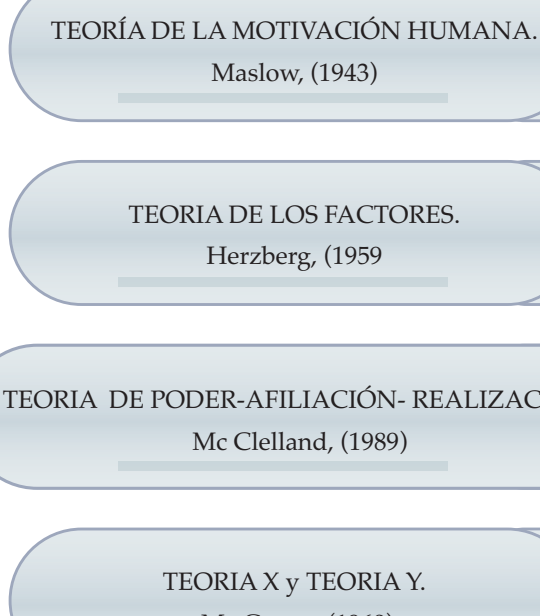

Mc Gregor (1960)

TEORIA Z

(Ouchi, 1982)
Fisiológicas

Seguridad

Estima

Amor, afecto y pertenencia

Factores Higiénicos

Factores de Motivación
El poder

La afiliación y

La realización

La teoría $X$, Es necesaria una supervisión constante La teoría $Y$, crear un clima favorable para el crecimiento de la autonomía.

Figura 2. Teorías de la administración.

Fuente: Chiavenato (2008).

Las teorías presentadas, abordan la relevancia que tiene el trabajador dentro de la organización y la satisfacción de sus necesidades, toda vez que se convertirá en el impulsador para asumir responsabilidades y encaminar su conducta laboral a alcanzar metas que permitirán a la organización lograr su razón de ser, mejorando notablemente su gestión.

Maslow (1943), en su Teoría de la Motivación Humana, estudia la jerarquía de la satisfacción de las necesidades de las personas siendo estas: 1. Fisiológicas, 2. Seguridad, 3. Amor, 4. Estima y 5. Realización. Por su parte Herzberg (1959), plantea la Teoría de los Factores, la cual aborda que la satisfacción laboral de las personas depende de dos clases de factores. Factores de satisfacción (motivadores/satisfacientes) y factores de insatisfacción (factores de higiene/ cosas que generan insatisfacción).

Es así como, para Chiavenato (2009), el recurso humano debe trabajar dentro de una estructura organizacional adecuada y de una 
Cultura Organizacional que le brinde impulso y apalancamiento, pues cuando estos tres elementos (talentos, organización y comportamiento) se conjugan, se tiene todas las condiciones para que la organización mejore su gestión en términos excepcionales.

Hofstede (1980), afirma que la gestión y la organización están penetradas por la cultura desde el principio hasta el final. Según Mancera, aumenta el sentimiento de pertenencia, cuando las personas se sienten identificadas con la organización (Mancera, 2013). Todo esto se logra a través de una Cultura Organizacional que encamine a la institución a mejorar su gestión a través de sus expresiones de manifestaciones en las fases del proceso administrativo.

\subsection{La organización}

Las organizaciones han nacido con una finalidad concreta, las primeras evidencias fueron organizaciones para el desarrollo de tareas artesanales, oficios que contribuían a la supervivencia y economía cotidiana de las tribus y clanes. Posteriormente la razón de organizarse fue defender territorios o conservar el poder en los territorios conquistados.

Las organizaciones han buscado siempre solucionar los problemas que son esenciales al entorno que las rodea, pero como el entorno cambia con el transcurso del tiempo, también han cambiado la forma de las organizaciones, la forma de plantear los problemas y de resolverlos de manera efectiva, dilucidando diferentes enfoques sobre su conceptualización, especialmente al considerarla como un sistema.

La Teoría de los Sistemas propuesta por Ludwing (1989), fue planteada como una herramienta amplia que podría ser compartida por muchas ciencias distintas, contribuyendo a la aparición de nuevo paradigma científico basado en la interrelación entre los elementos que forman los sistemas, ya que se consideraba que los sistemas en 
su conjunto eran iguales a la suma de sus partes, y que podían ser estudiados a partir del análisis individual de sus componentes; este autor, puso en duda tales creencias.

El vocablo organización se deriva del griego "organon", que significa instrumento.

Para Koontz y O’donell, organizar es "agrupar las actividades para alcanzar ciertos objetivos, asignar a cada grupo un administrador con autoridad necesaria para supervisarlo y coordinar tanto en sentido vertical como horizontal toda la estructura de la empresa" (Koontz y O’donell, 1985).

Mientras que para Robbins y Coulter una organización es "un conjunto sistemático de personas encaminadas a realizar un propósito específico" (Robbins y Coulter, 1996).

Dentro de la problemática organizacional, uno de los temas que más debatibles, es el concepto de organización, en este sentido para Bueno, la dificultad del concepto radica en que este "constituye un silogismo y que se debe poner el acento en la triple dimensión que él representa" (Bueno, 1997).

Haciendo referencia al planteamiento anterior, la palabra organización, puede significar un sistema que persigue un fin, el cual se estructura en base a sus recursos y el cumplimiento de la normativa vigente; también puede expresar, el proceso de organizar, es decir, el acto de coordinar, ordenar, disponer sobre los recursos y actividades buscando la eficacia y eficiencia respecto a los fines propuestos y finalmente, puede hacer referencia a la teoría o al conocimiento científico que estudia y explica los dos significados anteriores que expresan la medición de la calidad.

Morgan define a las organizaciones a través de las siguientes características: 
- "Son sistemas en el que participan dos o más personas,

- Tienen ciertas características como poseer una estructura,

- Se rigen bajo normas y valores

- Ofrecen bienes o servicios

- Se garantizan con el propósito de cumplir los objetivos específicos.

- Pueden ser grandes, medianas o pequeñas" (Morgan, 1998).

Para Chiavenato, la organización es "la coordinación de diferentes actividades de contribuyentes individuales, con la finalidad de efectuar intercambios planteados con el ambiente" (Chiavenato, 2009).

Particularmente se coincide con varias ideas planteadas por los autores citados en párrafos anteriores, pues se considera que las organizaciones son unidades sociales cuya intencionalidad para su creación, radica en la consecución de los objetivos y metas planteadas en base al involucramiento y optimización eficiente y eficaz de los recursos (financieros, materiales, humanos).

\subsection{Teorías de las Organizaciones}

Para varios autores, la apreciación sobre la evolución del pensamiento organizacional, se constituye aún un paradigma muy complejo, en base a la amplia literatura existente; por esta razón se recopila información relevante, encaminada a la orientación de una percepción a esta evolución, la cual se plasma en la tablas 3 y 4. 
Tabla 3. Teorías clásicas de la organización.

\begin{tabular}{|c|c|c|}
\hline \multicolumn{3}{|c|}{ TEORÍAS CLÁSICAS } \\
\hline TEORÍA & AUTORES & CARACTERÍSTICAS \\
\hline $\begin{array}{l}\text { Teoría } \\
\text { Científica }\end{array}$ & $\begin{array}{l}\text { Town, Taylor. } \\
\text { 1900) }\end{array}$ & $\begin{array}{l}\text { Debate sobre considerar "científica" a esta } \\
\text { corriente de pensamiento administrativo. } \\
\text { Concepto con sentido moderno. } \\
\text { Conclusión: La mejor forma de organización es la } \\
\text { que permite medir el esfuerzo individual. }\end{array}$ \\
\hline Teoría Funcional & (Fayol, 1916) & $\begin{array}{l}\text { Pensamiento administrativo: toda organización } \\
\text { estaba basada en cinco funciones básicas: } \\
\text { seguridad, producción, contabilidad, } \\
\text { comercialización y administración. } \\
\text { Las organizaciones pequeñas de tipo familiar eran } \\
\text { las más comunes. } \\
\text { Conclusión: La mejor forma de organización está } \\
\text { basada en una distribución de funciones, que se } \\
\text { subdividen en subfunciones y procedimientos, los } \\
\text { cuales a su vez son desarrollados por uno o más } \\
\text { puestos. }\end{array}$ \\
\hline $\begin{array}{l}\text { Teoría } \\
\text { Burocrática }\end{array}$ & (Weber, 1924) & $\begin{array}{l}\text { Se caracteriza por reglas, controles y jerarquías, y } \\
\text { es impulsada por la burocracia. } \\
\text { Este modelo también es conocido como racional } \\
\text { - legal. } \\
\text { Conclusión: la mejor forma de organización es } \\
\text { la que tiene reglas claras y racionales, decisiones } \\
\text { impersonales y excelencia técnica en sus } \\
\text { empleados y gestores. }\end{array}$ \\
\hline $\begin{array}{l}\text { Teoría de las } \\
\text { Relaciones } \\
\text { Humanas }\end{array}$ & $\begin{array}{l}\text { (Mayo, 1920; } \\
\text { Follet, Maslow, } \\
\text { 1954; Mcgregor, } \\
\text { 1957; Herzberg, } \\
\text { 1966) }\end{array}$ & $\begin{array}{l}\text { La participación social de los trabajadores es un } \\
\text { componente fundamental de la productividad. } \\
\text { Descubrir las motivaciones de los individuos y los } \\
\text { grupos. } \\
\text { Psicología humanista a las organizaciones. } \\
\text { Conclusión: La mejor forma de organización es la } \\
\text { que considera e integra a las personas que la hacen } \\
\text { funcionar. }\end{array}$ \\
\hline
\end{tabular}




\begin{tabular}{|c|c|c|}
\hline $\begin{array}{l}\text { Teoría de } \\
\text { los Sistemas } \\
\text { Cooperativos }\end{array}$ & (Barnard, 1938) & $\begin{array}{l}\text { Teoría organizacional que concebía a las } \\
\text { organizaciones como sistemas cooperativos, } \\
\text { no como productos mecánicos de diseños de } \\
\text { ingenieros de la eficiencia. } \\
\text { Conclusión: La mejor forma de organización es la } \\
\text { que asegura la cooperación de los miembros que } \\
\text { la conforman, mediante un trato justo y beneficios } \\
\text { recíprocos. }\end{array}$ \\
\hline $\begin{array}{l}\text { Teoría del } \\
\text { Comportamiento }\end{array}$ & $\begin{array}{l}\text { (March y } \\
\text { Simon, 1961; } \\
\text { March, 1965; } \\
\text { Simon 1979 y } \\
\text { 1984) }\end{array}$ & $\begin{array}{l}\text { La toma de las decisiones es el punto fundamental } \\
\text { de la administración. } \\
\text { Conclusión: La mejor forma de organización } \\
\text { es la que permite que los empleados de todos } \\
\text { los niveles tomen decisiones y colaboren en el } \\
\text { cumplimiento de los objetivos, de acuerdo a su } \\
\text { nivel de influencia y autoridad. }\end{array}$ \\
\hline Teoría Política & $\begin{array}{l}\text { (Selznick, } \\
\text { Pfeffer, } \\
\text { Croazier) }\end{array}$ & $\begin{array}{l}\text { Las organizaciones son fuentes constantes de } \\
\text { intereses de grupo. } \\
\text { Gestión del conflicto y la negociación. } \\
\text { Conclusión: La mejor forma de organización es la } \\
\text { que crea colaciones entre los diferentes grupos de } \\
\text { interés que existen en ella, y gestiona de manera } \\
\text { positiva el conflicto. }\end{array}$ \\
\hline $\begin{array}{l}\text { Teoría del } \\
\text { Desarrollo } \\
\text { Organizacional }\end{array}$ & $\begin{array}{l}\text { (Lewin, } \\
\text { Mcgregor) }\end{array}$ & $\begin{array}{l}\text { Las actividades de mejoramiento que propone el } \\
\text { desarrollo organizacional sean aplicadas en varios } \\
\text { niveles: individual, interpersonal, por grupos e } \\
\text { inter grupos. } \\
\text { Conclusión: La mejor forma de organización es } \\
\text { la que promueve el cambio planeado basado en } \\
\text { intervenciones, en las que la colaboración entre } \\
\text { distintos niveles organizacionales es posible. }\end{array}$ \\
\hline $\begin{array}{l}\text { Teoría de la } \\
\text { Contingencia }\end{array}$ & $\begin{array}{l}\text { (Burns, Slater, } \\
\text { Woodward, } \\
\text { Child) }\end{array}$ & $\begin{array}{l}\text { La creciente importancia del estudio del medio } \\
\text { ambiente en las organizaciones como una de las } \\
\text { variables fundamentales del éxito de un negocio. } \\
\text { Conclusión: La mejor forma de organización } \\
\text { depende de la tecnología, tamaño y medio } \\
\text { ambiente. }\end{array}$ \\
\hline
\end{tabular}

Fuente: $\quad$ Torres, et al. (2018).

Las nueve teorías clásicas mencionadas difieren mucho entre sí, sin embargo hay ciertos criterios en los que varios autores coinciden, o simplemente sus teorías relacionan, es el caso de Fayol y Weber, pues para Fayol la mejor forma de organización radica en el establecimiento 
y distribución de funciones y procesos; mientras que Weber cree que el éxito de una organización radica en el establecimiento de reglas y la toma de decisiones claras, si analizamos estas dos teorías se puede observar que los dos autores tienen un punto de intersección muy importante: establecimiento y distribución de funciones, aspecto fundamentar de las organizaciones que debe ampararse en reglas para su cumplimiento.

Otro punto importante en el que coinciden los autores de la teoría clásica a excepción de Fayol, Weber, Burns, Slater, Woodward y Child, es que la mejor forma de organización se establece con el involucramiento de las personas.

Es necesario analizar que, dentro de las teorías clásicas, la teoría de contingencia, propuesta por Burns, Slater, Woodward, Child, plantea una percepción totalmente diferente a las demás, toda vez que sostiene que la mejor forma de organización depende de la tecnología, tamaño y medio ambiente.

Se considera que los aportes de cada uno de los autores clásicos señalados son muy certeros y han ido evolucionando e involucran conceptualizaciones que recalcan la necesidad e importancia de la participación de las personas para determinar una mejor forma de organización, de ahí que se derivan otras características o estrategias como el establecimiento y distribución de funciones en base a una nomenclatura justa, la solución de conflictos, la tecnología, etc.

Se han analizado también otras teorías que han surgido en la actualidad; en la tabla 4, se mencionan las "teorías modernas de la organización" más utilizadas académicamente en las cuatro últimas décadas según Torres, et al. (2018) quien cita a Rivas (2009): 
Tabla 4. Teorías modernas de la organización.

\begin{tabular}{|c|c|c|}
\hline \multicolumn{3}{|c|}{ TEORÍAS MODERNAS } \\
\hline TEORÍA & AUTORES & CARACTERÍSTICAS \\
\hline $\begin{array}{l}\text { Teoría de la } \\
\text { Población } \\
\text { Ecológica }\end{array}$ & $\begin{array}{l}\text { (Hannan y } \\
\text { Freeman, 1977, } \\
\text { 1984) }\end{array}$ & $\begin{array}{l}\text { Enfatizar la importancia del entorno en la } \\
\text { subsistencia. } \\
\text { Conclusión: La mejor forma de organización es } \\
\text { la que consigue adaptarse al entorno y seguir } \\
\text { operando con eficiencia. }\end{array}$ \\
\hline $\begin{array}{l}\text { Teoría } \\
\text { Institucional }\end{array}$ & $\begin{array}{l}\text { (Di Maggio, } \\
\text { Powell, 1983; } \\
\text { Meyer, Rowan, } \\
\text { 1977) }\end{array}$ & $\begin{array}{l}\text { La organización debe ser estudiada como un todo. } \\
\text { Importancia a la distinción entre instituciones } \\
\text { públicas y organizaciones privadas. } \\
\text { Conclusión: La mejor forma de organización es la } \\
\text { que considera e integra a las personas que la hacen } \\
\text { funcionar. }\end{array}$ \\
\hline $\begin{array}{l}\text { Teoría del costo } \\
\text { de Transacciones }\end{array}$ & $\begin{array}{l}\text { (Williamson, } \\
\text { 1975, 1985) }\end{array}$ & $\begin{array}{l}\text { El costo de búsqueda del producto, el costo por } \\
\text { diferenciar el precio relevante, el costo por negociar } \\
\text { los contratos para llevar a cabo transacciones, y el } \\
\text { de garantizar que lo pactado se cumpla. } \\
\text { Conclusión: La mejor forma de organización es la } \\
\text { que minimiza los costos de transacción. }\end{array}$ \\
\hline $\begin{array}{l}\text { Teoría de los } \\
\text { Recursos y } \\
\text { Capacidades }\end{array}$ & (Barney, 1991) & $\begin{array}{l}\text { Fortalezas y debilidades internas de la } \\
\text { organización. } \\
\text { Conclusión: La mejor forma de organización es } \\
\text { la que gestiona más racionalmente sus recursos y } \\
\text { capacidades }\end{array}$ \\
\hline $\begin{array}{l}\text { Teoría de la } \\
\text { Agencia }\end{array}$ & $\begin{array}{l}\text { (Rumelt, } \\
\text { Schendel y } \\
\text { Teece, 1991) }\end{array}$ & $\begin{array}{l}\text { En la teoría de la agencia se observa un } \\
\text { rompimiento con el carácter universal de la teoría } \\
\text { de la organización } \\
\text { Su objeto de estudio son las organizaciones } \\
\text { privadas. } \\
\text { La teoría de la agencia estudia las formas óptimas } \\
\text { para formalizar contratos entre un agente y el } \\
\text { principal. } \\
\text { Conclusión: La mejor forma de organización es } \\
\text { la que crea los mecanismos que previenen que } \\
\text { el agente actúe a favor de sus propios intereses y } \\
\text { lo premia si actúa a favor de los intereses de la } \\
\text { organización. }\end{array}$ \\
\hline
\end{tabular}




\begin{tabular}{|c|c|c|}
\hline $\begin{array}{l}\text { Teoría del Caos } \\
\text { Determinista }\end{array}$ & (Cambell, 1993) & $\begin{array}{l}\text { Es una colección de técnicas conceptuales, } \\
\text { matemáticas y geométricas que permiten definir a } \\
\text { los sistemas complejos. } \\
\text { Conclusión: La mejor forma de organización } \\
\text { es la que gestiona la variabilidad caótica de la } \\
\text { organización a través de su complejidad. }\end{array}$ \\
\hline $\begin{array}{l}\text { Teoría de los } \\
\text { Sistemas Alejados } \\
\text { del Equilibrio }\end{array}$ & (Prigonine) & $\begin{array}{l}\text { Explicar las conductas de las leyestermodinámicas, } \\
\text { rápidamente fue adaptada a la organización. } \\
\text { Conclusión: La mejor forma de organización es la } \\
\text { que puede adaptarse y auto-organizarse. }\end{array}$ \\
\hline $\begin{array}{l}\text { Teoría de } \\
\text { los Sistemas } \\
\text { Complejos } \\
\text { Adaptativos }\end{array}$ & $\begin{array}{l}\text { (K a u f f } m \text { a } n, \\
\text { 1995) }\end{array}$ & $\begin{array}{l}\text { La complejidad es el estudio de los sistemas } \\
\text { complejos adaptativos (SCA) } \\
\text { Conclusión: La mejor forma de organización es la } \\
\text { que permite ajustes continuos de sus elementos } \\
\text { entre sí y con su entorno. }\end{array}$ \\
\hline $\begin{array}{l}\text { Teoría de la } \\
\text { Autocriticabilidad } \\
\text { Organizada }\end{array}$ & $\begin{array}{l}\text { (Maturana y } \\
\text { Varela, 1980) }\end{array}$ & $\begin{array}{l}\text { Conciben a los seres vivos como sistemas vivientes } \\
\text { que se producen a sí mismos de modo indefinido. } \\
\text { Conclusión: La mejor forma de organización es la } \\
\text { que crea una red de procesos u operaciones que } \\
\text { pueden crear o destruir elementos del mismo } \\
\text { sistema, como respuesta a las perturbaciones del } \\
\text { medio. }\end{array}$ \\
\hline
\end{tabular}

Fuente: Torres, et al. (2018).

Al respecto, se puede concluir que las teorías: de la población ecológica, de la agencia, de los sistemas complejos adaptativos y de la autocriticabilidad organizada, tienen en común que la mejor forma de organización tiene que ver exclusivamente con los diferentes aspectos generados en un entorno que persigue el bienestar institucional.

Sin embargo, las teorías del costo de transacción y de los recursos y capacidades se centra en que la mejor forma de organización radica en el manejo eficiente y reducción de costos de los recursos empleados para lograr fines propuestos, estas teorías no priorizan al ser humano como el factor elemental para formar organizaciones exitosas. 
Se ha analizado también las teorías del caos determinista, de los sistemas alejados del equilibrio y de los sistemas complejos adaptativos, cuyos planteamientos están direccionados al manejo de los procesos organizacionales de acuerdo con su complejidad.

Los autores comparten los criterios expuestos por las teorías analizadas en el primer grupo, las cuales enfatizan su trabajo en el entorno, el mismo que involucra la optimización de todos los recursos priorizando al ser humano para alcanzar el éxito en una organización ya sea pública o privada.

\subsection{El concepto de organización desde el punto de vista sistémico}

La conceptualización de organización vista desde el enfoque sistémico, involucra tener una definición clara de "sistemas". En este sentido, según Chiavenato "es un conjunto de elementos, relacionados de modo dinámico, que desarrollan una actividad para alcanzar determinado objetivo o propósito" (Chiavenato, 1999).

Las organizaciones como "sistemas sociales diseñados para lograr metas y objetivos por medio de los recursos humanos y de otro tipo. están compuestas por subsistemas interrelacionados que cumplen funciones especializadas. convenio sistemático entre personas para lograr algún propósito específico" (Díaz, 2009).

La teoría de las organizaciones en la administración, ha sufrido ciertos cambios importantes en últimos años. Las investigaciones sobre conceptualizaciones no siempre suelen ser certeras, sin embargo, surgió un enfoque que permite construir un concepto de organización desde otro punto de vista, el enfoque de sistemas, que está implícito en la unificación de muchos campos del conocimiento. Según Martínez, el enfoque sistémico en la organización puede descomponerse en tres niveles de análisis: 
1. nivel de comportamiento social o bien conocido como macrosistemas el cual permite visualizar la compleja interacción entre (ambiente y sociedad),

2. nivel de comportamiento organizacional: como tal el sistema, el cual visualiza la organización como una totalidad.

3. nivel de comportamiento individual: el cual permite conocer al individuo (intereses, motivación, aprendizaje, etc.) (Martínez, 2011).

Sin embargo, para Chiavenato "las organizaciones funcionan como sistemas abiertos, esto significa que están en un proceso continuo de intercambios con el entorno... las organizaciones, como sistema abierto es parte de una sociedad mayor, constituida por partes menores... las organizaciones son sistemas que operan dentro de otros sistemas; son conjuntos de elementos que interactúan entre sí y que buscan alcanzar objetivos" (Chiavenato, 2009:37).

En base al criterio de este autor, el sistema abierto necesita recursos, material y energía, los mismos que se obtienen a través del entorno que rodea a las personas, lo cual le permitirá obtener de ellos lo que se conoce como insumos o entradas, y que posteriormente serán procesados de tal manera que dará como resultado salidas a la organización.

Las entradas dentro de un sistema constituyen la fuerza de arranque que suministra al mismo sus necesidades operativas. Por su parte, el proceso es lo que transforma una entrada en salida, por ejemplo, una tarea realizada por un miembro de la organización. Mientras que una salida representa el producto final obtenido del procesamiento de las entradas.

Es así que, partiendo de la consideración de que las organizaciones son instrumentos indispensables para el desarrollo y desenvolvimiento 
del hombre; y un sistema es un conjunto de elementos que se interrelacionan con la finalidad de alcanzar un objetivo, surge el concepto de organización desde un enfoque sistémico.

La organización desde el punto de vista sistémico se conceptualiza como un sistema social, integrado por personas y más recursos que se deben a una estructura que se desarrolla en base a un determinado contexto, con la finalidad de alcanzar o lograr objetivos comunes.

Por esta razón, mediante la implementación didáctica de la figura 3, se pretende evidenciar la construcción del concepto de organización desde el punto de vista sistémico:

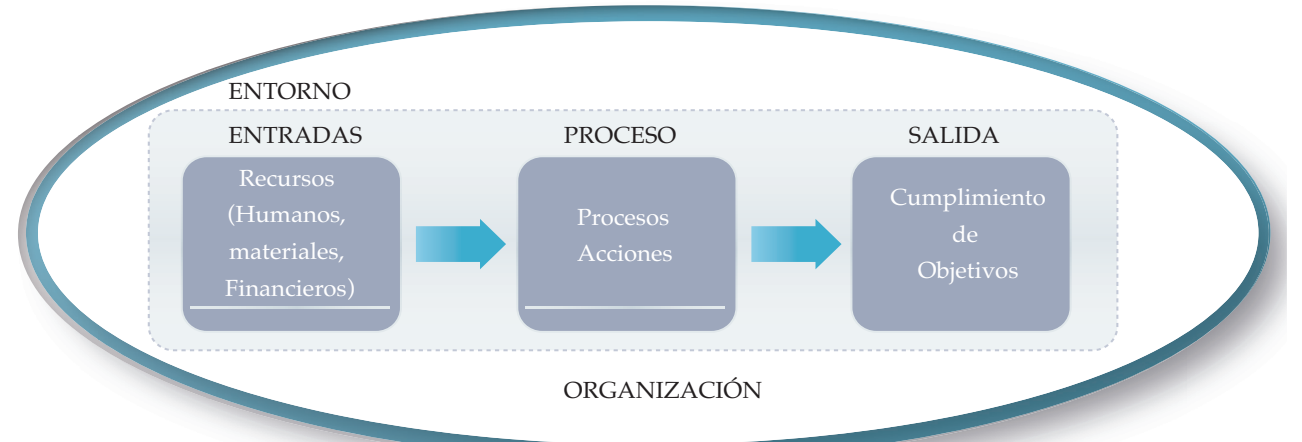

Figura 3. Conceptualización de organización desde el punto de vista sistémico.

Fuente: Torres, et al. (2018).

Las organizaciones constituyen espacios sistémicos que funcionan desde perspectivas interrelacionadas e interdependientes. Interdependencia porque al ser parte el todo, cada una de las partes responde a los mismos objetivos funcionales trazados por quienes diseñaron la organización. Cada acción que realiza un componente de la organización es ejecutada desde una lógica que, aunque tenga su propia autonomía de funcionamiento, depende de los otros componentes para ser ejecutada. Interrelación porque se refiere al hecho de que cualquier cosa que acontezca en un punto de la organización, tendrá diversos efectos en los otros subsistemas de esta (Quiroga, et al, 2011). 
Por ello la ciencia administrativa adopta el pensamiento sistémico para entender las diferentes interacciones entre los elementos que componen las organizaciones. La visión de las organizaciones como sistemas deben ubicarse dentro de los sistemas abiertos, es decir aquellos que se caracterizan por su constante interacción con el ambiente, una relación dentro hacia afuera y viceversa; tienen capacidad de crecimiento, adaptación al ambiente en el que se desenvuelven. Su estado actual, futuro o final, no está necesariamente determinado por su estado inicial. Como todo sistema social, las organizaciones tienden al caos, es decir a una entropía negativa, y son necesarios mecanismos de gestión para estabilizarlas. 


\section{CAPÍTULO III.}

\section{CULTURA ORGANIZACIONAL}




\subsection{La Conceptualización de Cultura ${ }^{2}{ }^{\text {Organizacional }}$}

Todas las organizaciones tienen características distintas, como sus valores, visión, prestigio, estilos de vida, etc., la mayoría de estas, intangibles que se derivan de su cultura. Santos (2014), manifiesta que la cultura es un proceso progresivo de auto liberación del hombre, que le caracteriza como un ser de mutación y un ser de proyecto que se afirma como tal en la medida en que trasciende la existencia. Una cultura se hace con el hombre a través de un proceso continuo de creación y establecimiento de principios y valores.

La concepción de la cultura, ha sido desarrollada por la Antropología, Sociología, Psicología y por la Administración, esta última, como disciplina, a diferencia de las otras ciencias mencionadas, estudia la cultura de las organizaciones con el propósito de diseñar modelos de organización para mejorar la gestión, pero sobre la base de las experiencias y conocimientos adquiridos en sus propias investigaciones (Rodríguez, 2009).

Los autores definen a la cultura como el conjunto de expresiones, formas, tradiciones que con el transcurso del tiempo se constituyen como las características de una población determinada.

De la misma manera que la persona tiene una cultura, las organizaciones también la tienen, pues se constituye en uno de los primeros pasos para tener una apreciación corporativa clara. En la actualidad el ser humano está consciente de que, para cumplir con los objetivos propuestos, es imprescindible la organización ${ }^{3} \mathrm{y}$ coordinación eficaz y eficiente de sus capacidades.

2 La palabra cultura proviene del latín que significa cultivo, agricultura, instrucción, y sus componentes son "cults" (cultivado) y "ura" (acción, resultado de una acción); pertenece a la familia "cotorce" (cultivar, morar) y "colows (colono, granjero, campesino) Recuperado de: Alta Dirección Empresarial de Negocios.

$\backslash$ http:/ / altadireccionempresarialdenegocios.bligoo.com.mx/cultura-organizacional\#. VjvAJdIrJdg. 12-04-15.

3 El vocablo organización se deriva del griego "organon", que significa instrumento. 
Para Chiavenato, la organización es la coordinación de diferentes actividades de contribuyentes individuales, con la finalidad de efectuar intercambios planteados con el ambiente (Chiavenato, 2009). Haciendo énfasis en el proceso de gestión, la organización “es la etapa en la que se define la estructura organizacional, la forma de delegar facultades, el enfoque para manejar los recursos humanos, la cultura y el cambio organizacional; como unidad productiva, una organización es una entidad social orientada hacia la consecución de metas con base en un sistema coordinado y estructurado vinculado con el entorno" (Franklin, 2009:4).

Particularmente los autores consideran que, las organizaciones son unidades sociales cuya intencionalidad para su creación radica en la consecución de los objetivos y metas planteadas en base al involucramiento y optimización eficiente y eficaz de los recursos. Uno de esos recursos son las personas dentro de la organización, quienes día a día articulan con sensibilidad actitudes, valores, hábitos, costumbres, supuestos y formas de hacer las cosas en diferentes dimensiones; la conjugación de estas percepciones se conoce como cultura organizacional (Torres, 2018).

La cultura de una organización es un concepto derivado de la intersección de dos teorías: la de la cultura y la de la organización (Smircich, 1983). La primera definición de cultura organizacional y la utilización del término, se debe a Andrew M. Pettigrew en su artículo "On studying Organizational Cultures". El interés de Pettigrew era estudiar el papel del liderazgo en la creación y desarrollo de las organizaciones, este autor entiende por cultura organizacional, un conglomerado de creencias, ideologías, lenguaje, rituales y mitos iniciados y consolidados a partir de la acción de líderes. Pettigrew, en su esfuerzo por considerar a las organizaciones como instituciones sociales, no duda en incorporar términos y métodos tomados de la antropología y la sociología. La contribución de Pettigrew fue la de señalar que la conducta organizativa estaba formada por universos simbólicos singulares, creados a través de la acción de líderes en el contexto de la propia organización. Estos universos solamente eran considerados desde el punto de vista teórico y metodológico desarrollado por la antropología y la sociología (Torres, 2018). 
Otras teorías culturales relacionadas con las organizaciones empiezan a aparecer un poco antes de mediados del siglo XX; en esta época Barnard, presidente de una organización muy reconocida en ese entonces, propuso que una de las principales tareas de los ejecutivos de la empresa era formular, definir e inculcar un propósito común a la organización (Martos, 2009).

Por su parte Drucker (1954), con su propuesta de dirección por objetivos, expone una racionalización de cómo deben dirigirse los esfuerzos de las personas en una misma dirección y contiene un primer puente de unión entre la escuela "cuantitativa" (orientada sólo a resultados) y los conceptos de trabajo en equipo y motivación personal defendido por los científicos del comportamiento organizacional (Torres, 2018).

Sin embargo, fue en los ochenta, que estas formulaciones tomaron una dimensión importante y ampliada. A esto se sumó el éxito adquirido en el aspecto académico y empresarial, de algunas propuestas novedosas como la "Teoría Z" de Ouchi (1982), “The art of Japanese Management" de Pascale y Athos (1981), y "En busca de la Excelencia" de Peters y Watterman (1982), entre otros, donde plantean que "la clave del éxito duradero no reside sólo en las estrategias o la eficiente gestión de recursos sino en un aspecto muy poco considerado hasta ese momento como lo era la cultura de las organizaciones o cultura organizacional" (Martos, 2009:36).

La organización, como tal, está afectada por lo que podemos denominar Cultura Organizacional y que Schein define como: el conjunto de valores normas, creencias y comportamientos, presunciones básicas que comparten los miembros de una empresa, los cuales operan de manera inconsciente y definen la visión que la empresa tiene de sí misma (integración interna) y de su entorno (integración externa) (Schein, 1988).

Para Aguirre (2004:89), la Cultura Organizacional es "un conjunto de elementos interactivos fundamentales, generados y compartidos 
por la organización como eficaces para alcanzar sus objetivos, que cohesionan e identifican, por lo que deben ser enseñados a los nuevos miembros". Para Alabart (2004:8), la Cultura Organizacional es "un conjunto de paradigmas, que se forman a lo largo de la vida de la organización como resultado de las interacciones entre sus miembros, de estos con las estructuras, estrategias, sistemas, procesos, y de la organización con su entorno, a partir de las cuales se conforma un conjunto de referencias, que serán válidas en la medida que garanticen la eficiencia, la eficacia y la efectividad de la organización".

Para Chiavenato (2009:126), la Cultura Organizacional "es una compleja mezcla de supuestos, creencias, comportamientos, historias, mitos, metáforas y otras ideas que, en conjunto, reflejan el modo particular de funcionar de una organización".

En la tabla 5, se recopila los criterios más relevantes sobre la conceptualización de Cultura Organizacional dadas por autores que han contribuido imperantemente a la ciencia.

Tabla 5. Conceptualizaciones de Cultura Organizacional.

\begin{tabular}{|l|l|}
\hline Autores & \multicolumn{1}{c|}{ Conceptos } \\
\hline $\begin{array}{l}\text { Goffman } \\
\text { Ma59), Van } \\
\text { Barnett (1960) }\end{array}$ & $\begin{array}{l}\text { Los comportamientos regularmente observados en la relación } \\
\text { entre individuos como el lenguaje y los rituales anejos a la } \\
\text { diferenciación y la conducta. }\end{array}$ \\
\hline Rocher (1985). & $\begin{array}{l}\text { Se trata de un conjunto trabajado de maneras de pensar, de } \\
\text { sentir y de obrar más o menos formalizadas, que, aprendidas } \\
\text { y compartidas por una pluralidad de personas, sirven de un } \\
\text { modo objetivo y simbólico a la vez, para constituir a esas } \\
\text { personas en una colectividad particular y distinta. Gracias a la } \\
\text { cultura, una organización es capaz de atender correctamente } \\
\text { sus procesos continuos de adaptación (externa) e integración } \\
\text { (interna) a través de la acción pertinente y coordinada de los } \\
\text { miembros fundadores y claves (directivos, mandos medios, } \\
\text { líderes). }\end{array}$ \\
\hline Schein (1988). & $\begin{array}{l}\text { El conjunto de valores normas, creencias y comportamientos, } \\
\text { presunciones básicas que comparten los miembros de una } \\
\text { empresa, los cuales operan de manera inconsciente y definen } \\
\text { la visión que la empresa tiene de sí misma (integración } \\
\text { interna) y de su entorno (integración externa). }\end{array}$ \\
\hline
\end{tabular}




\begin{tabular}{|l|l|}
\hline Denison (1990). & $\begin{array}{l}\text { Aporta los valores, creencias y principios que sirven como } \\
\text { fundamento para el sistema gerencial de una organización, } \\
\text { como también los patrones de comportamientos o prácticas } \\
\text { que tanto ejemplifican como refuerzan esos valores, creencias } \\
\text { y supuestos básicos. }\end{array}$ \\
\hline $\begin{array}{l}\text { Thevenet } \\
\mathbf{( 1 9 9 2 ) .}\end{array}$ & $\begin{array}{l}\text { La cultura es un concepto adecuado, que permite conocer el } \\
\text { funcionamiento de las organizaciones y permite resolver sus } \\
\text { problemas allí dónde otros estudios han sido ineficaces. }\end{array}$ \\
\hline $\begin{array}{l}\text { Werther y } \\
\text { Davis (1993). }\end{array}$ & $\begin{array}{l}\text { Es comola personalidad dela organización, producto de todos } \\
\text { sus aspectos, como su gente, objetivos, tecnologías, tamaños, } \\
\text { edades, sindicatos, políticas, éxitos y fracasos. considerando } \\
\text { a la cultura organizacional como cultura corporativa. }\end{array}$ \\
\hline
\end{tabular}

Aguirre (2002). Es un conjunto de elementos interactivos fundamentales, generados y compartidos por la organización como eficaces para alcanzar sus objetivos, que cohesionan e identifican, por lo que deben ser enseñados a los nuevos miembros.

Alabart (2003). Un conjunto de paradigmas, que se forman a lo largo de la vida de la organización como resultado de las interacciones entre sus miembros, de estos con las estructuras, estrategias, sistemas, procesos, y de la organización con su entorno, a partir de las cuales se conforma un conjunto de referencias, que serán válidas en la medida que garanticen la eficiencia, la eficacia y la efectividad de la organización.

Aguirre (2004). Es un conjunto de elementos interactivos generales y compartidos por los miembros de una organización al tratar de conseguir la misión que da sentido a su existencia.

Serra (2004). $\quad$ Es un generador invisible de energía que hace posible el desarrollo de estrategias, las estructuras y los sistemas de las empresas en general.

\begin{tabular}{l|l} 
Hellriegel y & $\begin{array}{l}\text { La cultura organizacional representa un patrón complejo de } \\
\text { creencias, expectativas, ideas, valores, actitudes y conductas }\end{array}$ \\
compartidas por los integrantes de una organización que \\
evoluciona con el paso del tiempo.
\end{tabular}

Vargas (2007). Comprende los códigos de conducta permitidos en las organizaciones los cuales son aprendidos por los individuos a través de procesos terciarios de socialización. 


\begin{tabular}{|c|c|}
\hline Zapata (2007). & $\begin{array}{l}\text { Es un esquema de referencia para patrones de información, } \\
\text { comportamiento y actitudes que compartimos con otros en } \\
\text { el trabajo y que determinan el grado de adaptación laboral; } \\
\text { en esta medida representan un aprendizaje continuo en el } \\
\text { cual la cultura organizacional se enriquece con los aportes de } \\
\text { los individuos, se perpetúa a través de ellos a la vez que las } \\
\text { personas enriquecen sus entornos. }\end{array}$ \\
\hline $\begin{array}{l}\text { Chiavenato } \\
\text { (2009). }\end{array}$ & $\begin{array}{l}\text { Es una compleja mezcla de supuestos, creencias, } \\
\text { comportamientos, historias, mitos, metáforas y otras ideas } \\
\text { que, en conjunto, reflejan el modo particular de funcionar de } \\
\text { una organización. }\end{array}$ \\
\hline $\begin{array}{l}\text { Frankllin } \\
\text { (2009). }\end{array}$ & $\begin{array}{l}\text { Conjunto de creencias, actitudes, valores, hábitos, costumbres } \\
\text { y formas de hacer las cosas que comparten los miembros de } \\
\text { una sociedad en función de su contexto social y valores que } \\
\text { la sustentan. }\end{array}$ \\
\hline Koontz (2012). & $\begin{array}{l}\text { La cultura puede inferirse a partir de lo que las personas } \\
\text { dicen, hacen y piensan dentro de un ambiente organizacional. } \\
\text { Incluye el aprendizaje y la transmisión de conocimientos, } \\
\text { creencias y modelos de comportamiento a lo largo de un } \\
\text { periodo, lo que significa que la cultura de una organización } \\
\text { es bastante estable y no cambia tan rápido. }\end{array}$ \\
\hline $\begin{array}{l}\text { Robbins y Jude } \\
\text { (2013). }\end{array}$ & $\begin{array}{l}\text { La cultura organizacional se refiere a un sistema de } \\
\text { significado compartido por los miembros, el cual distingue a } \\
\text { una organización de las demás. }\end{array}$ \\
\hline Díaz (2013). & $\begin{array}{l}\text { Es la unión de normas, hábitos y valores que, de una forma } \\
\text { u otra, son compartidos por las personas y/o grupos que } \\
\text { dan forma a una institución, y que a su vez son capaces de } \\
\text { controlar la forma en la que interactúan con el propio entorno } \\
\text { y entre ellos mismos. }\end{array}$ \\
\hline $\begin{array}{l}\text { Rodríguez } \\
\text { (2014). }\end{array}$ & $\begin{array}{l}\text { Es aquella que identifica a una organización y la diferencia } \\
\text { de otra haciendo que sus miembros se sientan parte de } \\
\text { ella ya que profesan los mismos valores, creencias, reglas, } \\
\text { procedimientos, normas, lenguaje, ritual y ceremonias. }\end{array}$ \\
\hline Autores & $\begin{array}{l}\text { Se define como un sistema, que se forma día a día en } \\
\text { la organización como resultado de las percepciones e } \\
\text { interacciones entre sus miembros con respecto al entorno e } \\
\text { interno de la misma. }\end{array}$ \\
\hline
\end{tabular}

Fuente: Torres (2017). 
Considerando los aportes citados anteriormente, y las definiciones dadas por los diferentes autores reflejada en la tabla 5, se aborda a la Cultura Organizacional como un elemento de importancia estratégica, pues es una fortaleza que dirige a las organizaciones a mejorar su gestión, y se define como un sistema, que se forma día a día en la organización como resultado de las percepciones, manifestaciones e interacciones entre sus miembros, respecto al entorno e interno de la misma.

Se considera adecuado el particular en el que coinciden la mayoría de los autores, en que cada Cultura Organizacional es única y que nace de la necesidad y expectativas de sus líderes, propietarios, gerentes, etc., así también como del resultado a la adaptación externa y la integración interna de organización (Torres, 2018).

En la adaptación externa deberán resolverse temas como la misión, visión, objetivos, metas, medios y control, mientras que en la integración interna se resolverán temas como la comunicación, trabajo en equipo, motivación, liderazgo, valores, comportamiento y clima organizacional.

Según Matamala (2015:67), "la cultura es el cultivo de lo propio. Tiene que ver con la forma de pensar, actuar y sentir de las organizaciones, es su personalidad distintiva. Cultura es sinónimo de civilización y hace referencia a cómo se comportan las personas de esa civilización, igual que en una compañía".

Para este autor existen tres tipos de cultura, la primera es la cultura responsable, orientada a los principios de ética, valores, igualdad, sostenibilidad y apasionamiento por el servicio a sus clientes. El segundo tipo de cultura es la competitiva, cuya orientación radica en el logro de metas y objetivos enfocados al cambio y la innovación permanente, con un liderazgo que acompaña a su equipo de trabajo para asegurar el logro de los resultados. El tercer tipo de cultura es la humanista, caracterizada por su orientación al talento humano y a la gente, la confianza, el ambiente, la transformación, solidaridad, 
promoviendo una comunicación amplia, abierta y transparente (Torres, 2018).

Los autores consideran que no sería optimo enfocarse en un solo tipo de las culturas mencionadas por Matamala, sino rescatar lo más importante de cada una de ellas para fomentar una cultura integral en base a las circunstancias y necesidades de cada organización, atendiendo a su caracterización en base a la identidad cultural de sus pueblos y otras características propias de cada institución, etc. (Torres, 2018).

Para Chiavenato existen dos tipos de culturas, las adaptables que se caracterizan por la maleabilidad, flexibilidad y la orientación hacia la innovación y el cambio, y las no adaptables o conservadoras caracterizadas por la rigidez y la orientación hacia el mantenimiento del status y el conservadurismo (Chiavenato, 2009).

Mientras que para Hellriegel y Slocum (2004), existen dos tipos de culturas, las flexibles que se dividen en culturas de clan y culturas emprendedoras y las estables que se dividen en burocráticas y de mercado.

Para los autores, los tipos de Cultura Organizacional que propician una mejor gestión, deben ser adaptables y flexibles de acuerdo a lo expuesto por Chiavenato y Hellriegel y Slocum respectivamente, toda vez que las organizaciones son sistemas sociales sujetas a procesos dinámicos y esto provoca que el cambio y la innovación sean algo constante que se debe sobrellevar estratégicamente.

\subsubsection{Hacia una Cultura Organizacional Autóctona}

La Cultura Organizacional expresa la forma en que cada organización aprende y adopta un conjunto de creencias, métodos, ideas, e historias como esencia corporativa. Cada organización, tiene una cultura diferente y que puede variar dependiendo las circunstancias 
externas de la misma, tales como: aspectos geográficos, climáticos, globalización, interculturalidad, multietnicidad, identidad de los territorios, etc. (Torres, 2017).

Existen patrones de comportamiento que son comunes a todos los miembros de una organización, pero muestran variaciones en otros aspectos importantes. Esta diversidad cultural puede ser creada por: “1) la organización y relacionadas con las actividades que realizan entorno a las diferencias culturales que resultan por la naturaleza de su trabajo y 2) aspectos relacionados con sus antecedentes socioeconómicos, étnicos, raciales, de sexo, etc" (Vargas, 2007:34).

En este sentido, surge la necesidad de concebir una cultura organizacional que impulse $y$ se fundamente en aquellos espacios que la demandan, donde el intercambio de principios y valores permitan la sustentación de aceptación y el respeto en organizaciones con características culturales que provienen de territorios plurinacionales, donde prevalecen sus ritos, costumbres y tradiciones ancestrales, con la finalidad de evitar un choque de culturas que debilite a la organización, y a la vez, que absorba en sus propios ritos creencias y tradiciones organizacionales la riqueza cultural del territorio.

En base a esta consideración intercultural, Cox (1991), clasifica a las organizaciones en tres tipos: el primer tipo abarca a las organizaciones monolíticas o casi homogéneas, con grupos minoritarios que se acoplan a la cultura dominante, el segundo tipo es la organización plural, que permite la presencia de grupos con diferencias culturales, esperando que simplemente se acojan a las normas institucionales; y por último en el tercer tipo se encuentran las organizaciones multiculturales, que son concebidas como aquellas que integran a todas las diversidades culturales permitiendo la expresión y eliminando prejuicios y discriminaciones.

Dentro de esta clasificación, se considera como organizacionesideales, a las correspondientes al tercer tipo, es decir las organizaciones 
multiculturales, haciéndose énfasis en las características culturales de cada localidad.

Para los autores la diversidad intercultural de los pueblos es una riqueza patrimonial que cada territorio debe rescatar, considerando los principios y valores de aceptación, respeto e inclusión. Es aquí donde juegan un papel importante las instituciones públicas asentad as en estas localidades reconocidas por su riqueza e identidad cultural, el cual radica en gestionar acciones para preservar estas características, trabajando y dando ejemplo desde los procesos internos de la organización, generando un sentido de pertenencia hacia la misma (Torres, 2017).

Por tal razón, las manifestaciones de la Cultura Organizacional tienen que formularse mediante un estudio de los rasgos particulares de un fenómeno construido históricamente donde se reflejan las manifestaciones de los fenómenos de reproducción social y cultural (Yuquilema, 2016).

No obstante, Torres (2017), en la figura 4, hace hincapié en su conceptualización de Cultura Organizacional, para dar paso al concepto de Cultura Organizacional Autóctona y definirla como un sistema, que se forma día a día en la organización como resultado de las percepciones e interacciones entre sus miembros, respecto al entorno e interno de la misma, rescatando las raíces, principios, valores y comportamientos propios que constituyen la riqueza pluricultural de sus pueblos. 


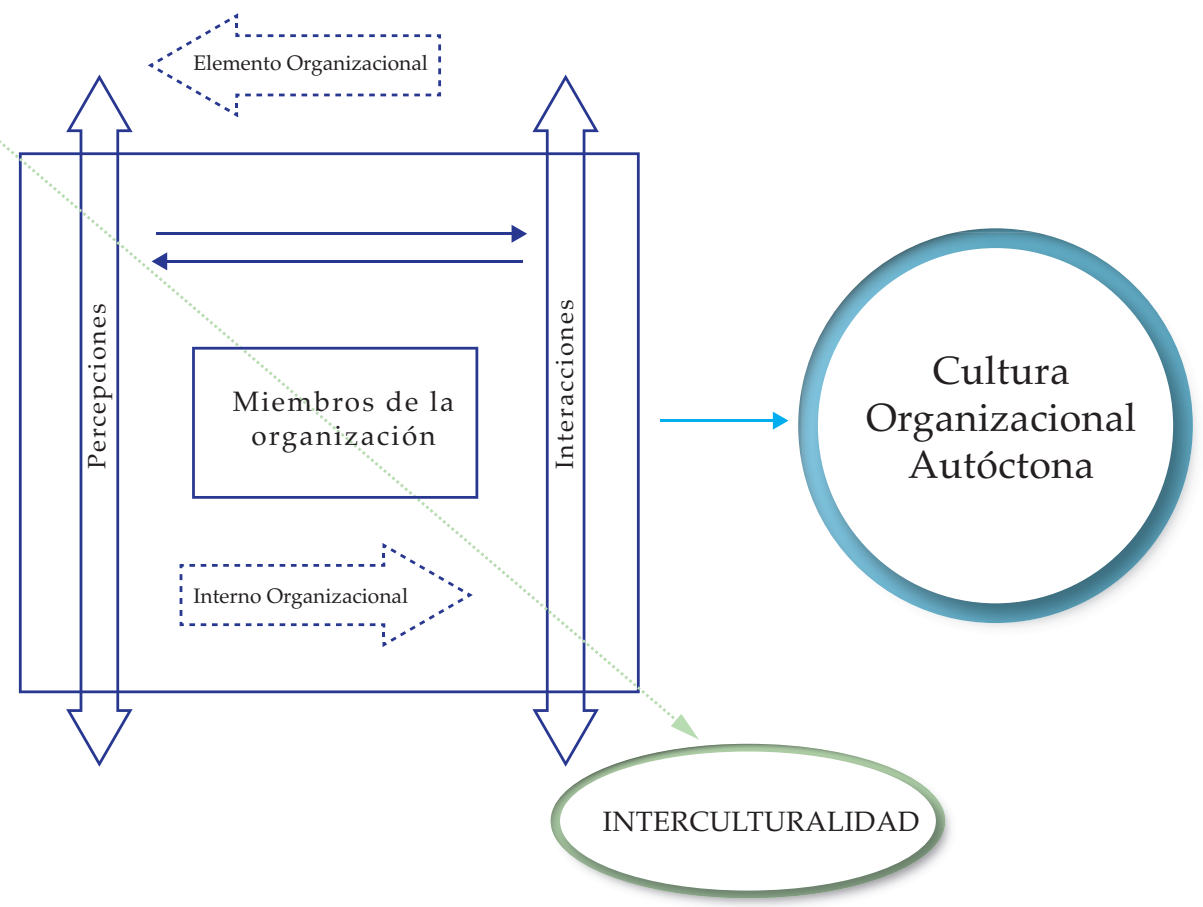

Figura 4 Conceptualización de la Cultura Organizacional Autóctona. Fuente: $\quad$ Torres (2017).

\subsection{Variables de la Cultura Organizacional}

El análisis de las variables sustenta aquellos elementos cuyas percepciones generan la cultura organizacional, en este sentido, Rao y Weintraub (2009) consideran seis pilares para alcanzar una Cultura Organizacional innovadora; recursos, procesos, valores, comportamientos, clima y éxito; mientras que para otros autores, entre ellos Shein, varios de estos pilares se constituyen como elementos, según este último autor los elementos de la cultura organizacional, están compuestos por tres niveles que se intercalan entre sí: el primer nivel, se refiere a las producciones, que involucra a todos aquellos elementos que se puede captar con los sentidos; en el segundo nivel se encuentran los valores, en función de lo cual actúan de una u otra manera y por último en el tercer nivel, se encuentran las presunciones básicas, que son cuestiones indiscutibles y asimiladas por el personal, tales como: logotipos, slogan y distribución del espacio en los edificios (Guiarratana, 2008). 
Desde otro punto de vista, Lerma y Bárcena (2012), hacen referencia a Meza quien plantea que la Cultura Organizacional puede establecerse en base a factores internos o propios de la organización: comportamiento, costumbres, lenguaje, vestimenta, hábitos, tradiciones y ritos y los factores externos: país, localidad, sector, etc. Alabart (2013), plantea dos tipos de variables, las hard, compuesta por los objetivos, estrategias, estructuras, decisiones, sistemas, procesos, tecnologías, oficio, procedimientos y las variables soft, que abordan las creencias, valores, normas, actitudes, ideologías, presunciones, además de indicadores como los signos y símbolos, las tradiciones, la historia y las políticas que constituyen fuentes de información para el investigador cultural.

A través de la revisión bibliografía condensada en la tabla 6, se evidencia que, a lo que algunos autores lo denominan niveles o dimensiones de la Cultura Organizacional (Shein, 1988; Aguirre, 2004; Denison y Neale, 2000; GLOBE, 2004; Robbins y Jude, 2013), otros lo denominan como, pilares, componentes, elementos, variables o factores (Hellriegel y Slocum, 2004; Vargas, 2007; Rao y Weintraub, 2009; Lerma y Bárcena, 2012; Alabart, 2013; López, 2013).

Para Torres (2017), los elementos para alcanzar una Cultura Organizacional exitosa dependen del tipo de organización, así también como del liderazgo y visión que tengan las autoridades que se encuentren al frente de la misma.

Por esta razón se basa en el criterio de Alabart (2013) y López (2013), y propone el planteamiento de que los elementos de la Cultura Organizacional nacen de dos variables; la primera es la externa, la cual no forma parte de la organización sino de su entorno y está compuesto por la globalización, las leyes, normas y reglamentos y la plurinacionalidad; la segunda variable es la interna, es decir los elementos que están presentes en la organización, tales como: liderazgo, comportamiento organizacional, clima organizacional, valores, comunicación, motivación, trabajo en equipo y ritos creencias y tradiciones. 
Tabla 5. Conceptualizaciones de Cultura Organizacional.

\begin{tabular}{|c|c|c|}
\hline Autor & $\begin{array}{l}\text { Criterio de } \\
\text { Consideración }\end{array}$ & Descripción \\
\hline Schein (1988). & $\begin{array}{l}\text { Niveles de } \\
\text { la Cultura } \\
\text { Organizacional }\end{array}$ & $\begin{array}{l}\text { - El nivel 1: Producciones: está dado } \\
\text { por su entorno físico y social. En este } \\
\text { nivel cabe observar el espacio físico, } \\
\text { la capacidad tecnológica del grupo, su } \\
\text { lenguaje escrito y hablado y la conducta } \\
\text { expresa de sus miembros. } \\
\text { - El nivel 2: Valores, que reflejan en } \\
\text { última instancia la manera en que } \\
\text { deben relacionarse los individuos, } \\
\text { ejercer el poder y pueden ser validados } \\
\text { si se comprueba que reducen la } \\
\text { incertidumbre y la ansiedad. } \\
\text { El nivel 3: presunciones subyacentes } \\
\text { básicas, permite la solución a } \\
\text { un problema cuando se ha dado } \\
\text { repetidamente. }\end{array}$ \\
\hline $\begin{array}{l}\text { Cunningham, } \\
\text { Aldag y Swift } \\
\text { (1991) }\end{array}$ & $\begin{array}{l}\text { Conformación } \\
\text { de la Cultura } \\
\text { Organizacional }\end{array}$ & $\begin{array}{ll}\text { - } & \text { Patrones de conducta } \\
\text { - } & \text { Conceptos } \\
\text { - } & \text { Valores } \\
\text { - } & \text { Ceremonias y rituales }\end{array}$ \\
\hline $\begin{array}{l}\text { Denison y Neale, } \\
2000\end{array}$ & $\begin{array}{l}\text { Dimensiones } \\
\text { culturales } \\
\text { organizacionales }\end{array}$ & $\begin{array}{l}\text { - } \text { Implicación } \\
\text { - } \text { Empowerment - Empoderamiento } \\
\text { - } \text { Desabajo en equipo } \\
\text { - } \text { Consistencia de Capacidades } \\
\text { - Valores Centrales } \\
\text { - Acuerdo } \\
\text { - Coordinación e Integración } \\
\text { - Adaptabilidad } \\
\text { - Orientación al cambio } \\
\text { - Orientación al cliente } \\
\text { - Aprendizaje organizativo } \\
\text { - Misión } \\
\text { - } \text { Mirección y propósitos estratégicos } \\
\text { - } \quad \text { Visión y Objetivos }\end{array}$ \\
\hline Aguirre (2004). & $\begin{array}{l}\text { Niveles de } \\
\text { la Cultura } \\
\text { Organizacional }\end{array}$ & $\begin{array}{ll}\text { - } & \text { Nivel exterior (productos) } \\
\text { - } & \text { Nivel organizador (valores y } \\
\text { comunicación) } & \\
\text { - } & \text { Nivel fundante (etnohistoria y creencias) }\end{array}$ \\
\hline
\end{tabular}




\begin{tabular}{|c|c|c|}
\hline GLOBE (2004). & $\begin{array}{l}\text { Dimensiones } \\
\text { de la Cultura } \\
\text { Organizacional }\end{array}$ & $\begin{array}{ll}\text { - } & \text { Distancia del poder } \\
\text { - } & \text { Evitación de incertidumbre } \\
\text { - } & \text { Orientación Humana } \\
\text { - } & \text { Colectivismo institucional } \\
\text { - } & \text { Colectivismo grupal } \\
\text { - } & \text { Equidad de género } \\
\text { - } & \text { Orientación al futuro } \\
\text { - } & \text { Orientación en el desempeño }\end{array}$ \\
\hline $\begin{array}{l}\text { Hellriegel y } \\
\text { Slocum (2004). }\end{array}$ & $\begin{array}{l}\text { Componentes } \\
\text { de la Cultura } \\
\text { Organizacional }\end{array}$ & $\begin{array}{l}\text { - } \quad \text { Formas rutinarias de comunicarse, } \\
\text { - } \quad \text { Las normas que comparten individuos y } \\
\text { equipos de toda la organización, } \\
\text { - } \quad \text { Los valores dominantes } \\
\text { - } \quad \text { La filosofía que guía las políticas y la } \\
\text { toma de decisiones de la organización; } \\
\text { - } \quad \text { Las reglas del juego para llevarse bien en } \\
\text { la organización } \\
\text { - El sentimiento o clima que se transmite } \\
\text { en una organización }\end{array}$ \\
\hline Vargas (2007) & $\begin{array}{l}\text { Elementos } \\
\text { de la Cultura } \\
\text { Organizacional }\end{array}$ & $\begin{array}{ll}\text { - } & \text { Elementos simbólicos } \\
\text { - } & \text { Elementos estructurales } \\
\text { - } & \text { Elementos materiales } \\
\text { - } & \text { Elementos conductuales }\end{array}$ \\
\hline $\begin{array}{l}\text { Rao y Weintraub } \\
\text { (2009). }\end{array}$ & $\begin{array}{l}\text { Pilares de la Cultura } \\
\text { Organizacional }\end{array}$ & $\begin{array}{ll}- & \text { Recursos } \\
\text { - } & \text { Procesos } \\
\text { - } & \text { Valores } \\
\text { - } & \text { Comportamientos } \\
\text { - } & \text { Clima } \\
\text { - } & \text { Éxito }\end{array}$ \\
\hline $\begin{array}{l}\text { Lerma y Bárcena } \\
\text { (2012). }\end{array}$ & $\begin{array}{l}\text { Factores de } \\
\text { la Cultura } \\
\text { Organizacional }\end{array}$ & $\begin{array}{l}\text { - Factores internos } \\
\text { - Comportamiento } \\
\text { - Costumbres } \\
\text { - Lenguaje } \\
\text { - Vestimenta } \\
\text { - Hábitos } \\
\text { - Tradiciones y } \\
\text { - Ritos } \\
\text { - Factores Externos } \\
\text { - País } \\
\text { - Localidad } \\
\text { - Sector }\end{array}$ \\
\hline
\end{tabular}




\begin{tabular}{|c|c|c|}
\hline $\begin{array}{l}\text { Robbins y Jude } \\
\text { (2013). }\end{array}$ & $\begin{array}{l}\text { Dimensiones } \\
\text { de la Cultura } \\
\text { Organizacional }\end{array}$ & $\begin{array}{ll}\text { - } & \text { Innovación y toma de riesgos } \\
\text { - } & \text { Atención a los detalles } \\
\text { - } & \text { Orientación a los resultados } \\
\text { - } & \text { Orientación a la gente } \\
\text { - } & \text { Orientación a los equipos } \\
\text { - } & \text { Dinamismo } \\
\text { - } & \text { Estabilidad }\end{array}$ \\
\hline Alabart (2013). & $\begin{array}{l}\text { Variables de } \\
\text { la Cultura } \\
\text { Organizacional }\end{array}$ & $\begin{array}{l}\text { - Variables Soft } \\
\text { - Creencias, valores, normas, actitudes, } \\
\text { ideologías, presunciones, además de } \\
\text { indicadores como los signos y símbolos, } \\
\text { las tradiciones, la historia y las políticas } \\
\text { que constituyen fuentes de información } \\
\text { para el investigador cultural. } \\
\text { - Variables Hard } \\
\text { - Objetivos, estrategias, estructuras, } \\
\text { decisiones, sistemas, procesos, } \\
\text { tecnologías, oficio, procedimientos. }\end{array}$ \\
\hline López (2013). & $\begin{array}{l}\text { Funciones de la } \\
\text { cultura organizativa }\end{array}$ & $\begin{array}{l}\text { - } \text { Sistema Externo } \\
\text { - } \text { - } \text { Estrión } \\
\text { - } \text { Metas } \\
\text { - } \text { Medios } \\
\text { - Medición } \\
\text { - Corrección } \\
\text { - } \text { Sistema Interno } \\
\text { - Lenguaje } \\
\text { - Grupo } \\
\text { - Identidad } \\
\text { - Relaciones } \\
\text { - Recompensas } \\
\text { - } \text { Ideología }\end{array}$ \\
\hline Autores & $\begin{array}{l}\text { Variables de } \\
\text { la Cultura } \\
\text { Organizacional }\end{array}$ & $\begin{array}{ll}\text { - } & \text { Variables Externas } \\
\text { o } & \text { Globalización } \\
\text { o } & \text { Leyes, normas y reglamentos } \\
\text { o } & \text { Plurinacionalidad } \\
- & \text { Variables Internas } \\
\text { o } & \text { Liderazgo } \\
\text { o } & \text { Comportamiento Organizacional } \\
\text { o } & \text { Clima Organizacional } \\
\text { o } & \text { Valores } \\
\text { o } & \text { Comunicación } \\
\text { o } & \text { Motivación } \\
\text { o } & \text { Trabajo en Equipo } \\
\text { o } & \text { Ritos, Creencia y Tradiciones }\end{array}$ \\
\hline
\end{tabular}

Fuente: Torres (2017). 
Es importante indicar que esta concepción no jerarquiza a ninguna de las variables planteadas, pues se entiende el papel indispensable que juega cada una de ellas dentro del proceso de gestión, además su análisis asume un enfoque sistémico, ya que en la literatura revisada (Álvarez y Valverde, 2001; Robbins y Coulter,2005; Franklin, 2009; Chiavenato, 2009; Rodríguez, 2010; Koontz et al, 2012) se evidencia la interrelación de unas con otras, tal como se muestra en la figura 5.

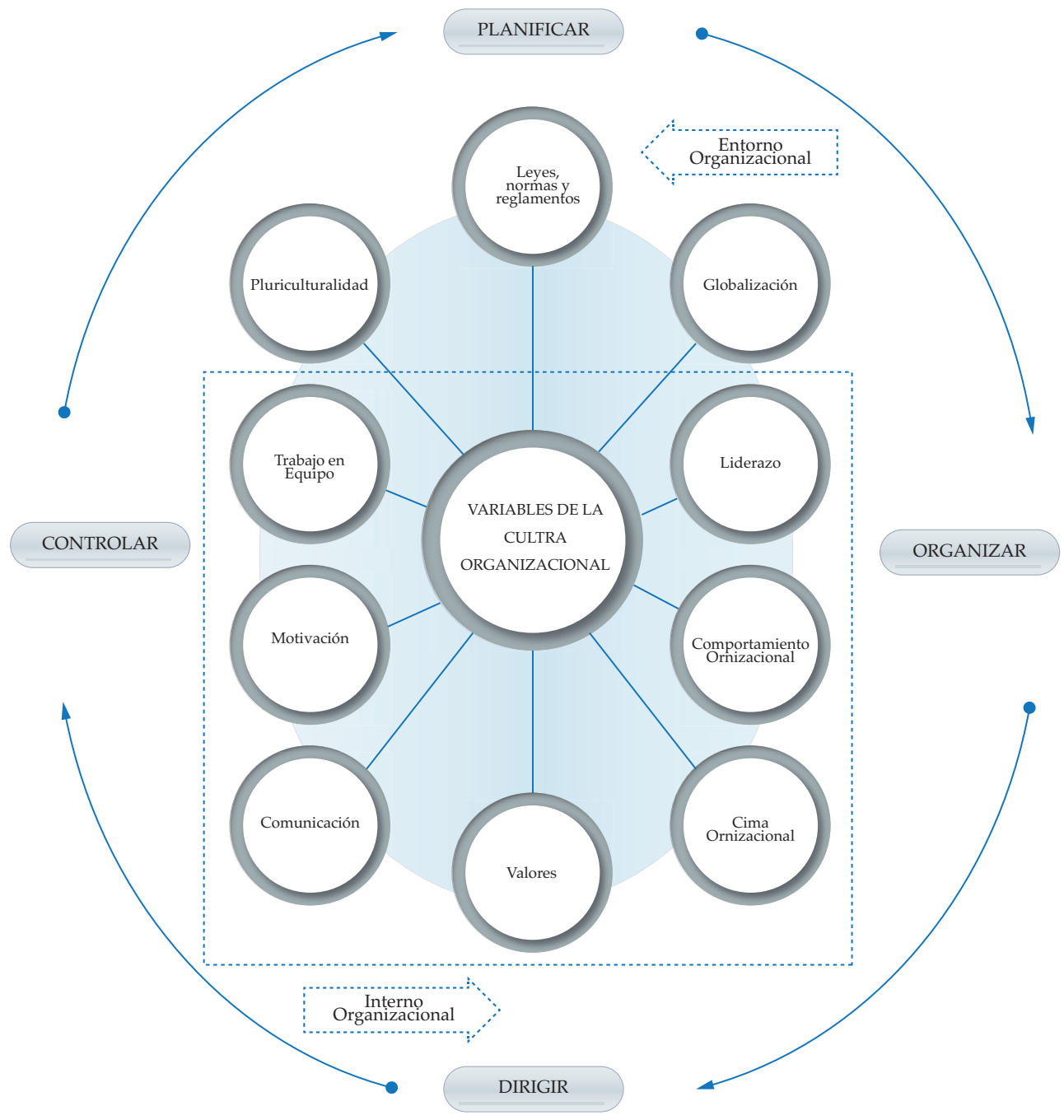

Figura 5. Variables de la Cultura Organizacional.

Fuente: Torres (2017).

En este sentido se considera que las conceptualizaciones de los elementos del proceso de gestión expuestas en el epígrafe 
anterior, sustentan la conclusión realizada por varios autores, los cuales abordan que existe una relación positiva y directa entre la Cultura Organizacional y la gestión de la organización en general; pues gracias a la cultura, una organización es capaz de atender correctamente sus procesos continuos de adaptación (externa) e integración (interna) a través de la acción pertinente y coordinada de sus miembros. Koontz, et al. (2012), Vargas (2007), Rocher (1985).

Por tal razón, en el análisis de cada una de las variables y su relación con la cultura organizacional, se considera, la analogía existente con las fases del proceso de gestión, la cual se sustenta y se complementa con una revisión bibliográfica categorizada, en base a los criterios de autores relevantes.

Entre las variables externas, se tiene a la Globalización, la cual se refiere a "la creciente gravitación de los procesos económicos, sociales y culturales de carácter mundial sobre aquellos de carácter nacional o regional" (CEPAL, 2002). En el transcurso del siglo XXI, ha producido un gran impacto en la cultura organizacional, obligando a las instituciones públicas o privadas a planificar y desarrollar constantes reingenierías en el ámbito tecnológico para ofertar bienes y servicios competitivos y de calidad con la finalidad de alcázar el éxito empresarial reflejado en altos niveles de productividad y eficiencia.

Es así como, la globalización influye principalmente en la planificación con las oportunidades y amenazas que hay que definir para el planteamiento de las estrategias y las percepciones que se generan entre los miembros de la organización deben estar direccionadas a la adaptación al cambio y a asumir las tendencias propuestas.

La segunda variable externa por describir en este trabajo de investigación son las leyes, normas y reglamentos emitidos por el Estado en general; y son consideradas como fuertes determinantes de la cultura organizacional, ya que, no dependen de la organización, 
sin embargo, se las considera en todo el proceso de gestión, que inicia con la planificación, generando percepciones y actitudes dentro de la organización.

Esta variable muestra el alcance de las funciones y actividades específicas que se debe cumplir en la organización, sin embargo, la ley no exime la responsabilidad de promover una Cultura Organizacional que priorice los valores y el compromiso de mejorar continuamente la gestión.

La tercera variable externa en análisis es la Plurinacionalidad; Hellriegel y Slocum (2004:18) la denominan como "la competencia de manejo transcultural" y se refiere "a la habilidad global de reconocer y aceptar similitudes y diferencias entre las naciones y las culturas".

Con la finalidad de comprender la importancia de esta variable, es necesario reconocer la diferencia entre plurinacional e intercultural, en efecto, la plurinacionalidad sin interculturalidad se reduciría a un agregado de nacionalidades sin proyecto común ni relaciones, mientras que la interculturalidad sin plurinacionalidad quedaría reducida a un ideal de relaciones intersubjetivas igualitarias sin transformación política e institucional que la nueva igualdad requiere (Grijalva, 2012).

En este sentido la plurinacionalidad juega un papel muy importante entre los elementos externos de la Cultura Organizacional de una institución, ya que sirve como precedente para el establecimiento de ciertas costumbres, ritos, ceremonias, etc. que se podrían llevar a cabo dentro de la organización, y que no dependen exclusivamente de ella sino del proceder de su pueblo, ciudad o país; por esta razón se aborda a la variable dentro de la planificación (Torres, 2017).

Una vez descritas las variables externas, se considera necesario describir las variables internas que se relacionan con la cultura 
organizacional, cuyas percepciones son resultado de las interacciones del interno organizacional.

El liderazgo, hoy en día es un elemento indispensable en las organizaciones a nivel mundial, pues se habla de globalización, reingenierías y la adopción e implementación de estrategias innovadoras para mejorar la gestión, es así que para Hellriegel y Slocum (2004:250), el liderazgo es "el proceso de desarrollar ideas y una visión, viviendo según los valores que apoyan esas ideas y esa visión, influyendo en otros para que las incorporen en su propia conducta y tomando decisiones difíciles sobre los recursos humanos y otros aspectos", tal definición ratifica el hecho de que los fundadores, jefes, gerentes, propietarios, etc., son los líderes que ponen en manifiesto ante sus colaboradores la cultura organizacional de la institución (Torres, 2017).

En este sentido aporta significativamente a la investigación, los poderes y estilos de liderazgo en base a las competencias básicas para la efectividad individual y gerencial de Hellriegel y Slocum (2004) y Chiavenato (2009) las mismas que están interrelacionadas y se conjugan en la práctica, estas se detallan a continuación: 1) Manejo propio: poder legítimo, poder de premiación, poder coercitivo, poder referente, poder de competencia, y poder experto. 2) Manejo de comunicación: explicativo, convencimiento, participativo y delegación. 3)Manejo de diversidad. 4) Manejo de ética. 5) Manejo transcultural: decisión, consulta individual, consulta a su equipo, facilitador, delegación. 6) Manejo de equipos y 7) Manejo del Cambio.

Según Chiavenato (2009:337), “cuando el liderazgo se basa en el poder de coerción, de recompensa o legítimo, no proviene del líder, sino del poder que le confiere su posición en la organización. El verdadero liderazgo se deriva del poder de competencia o de referencia".

Desde el punto de vista de los autores, la actuación del líder de la organización debe basarse en el cumplimiento combinado de estas 
competencias; considerando también, el manejo de la democracia sin dejar a un lado cualidades importantes como los conocimientos, carisma, imparcialidad, visión, y humildad, etc.

El liderazgo está estrechamente vinculado con la función de dirección dentro el proceso de gestión (Hellriegel y Slocum, 2004: Franklin, 2012; Chiavenato, 2009). Sin embargo, es indiscutible las percepciones causadas por el liderazgo en el proceso de gestión, el cual inicia con la planeación, donde el líder debe considerar el grado de riesgo en la ejecución de planes, así también como el ambiente que se genera en el desarrollo grupal o individual de los mismos; con respecto a la organización, se debe contemplar el grado de autonomía entre los trabajadores, así como la ejecución de labores individuales y grupales y el establecimiento adecuados de canales de comunicación; por su parte la dirección, es la función específica que contempla al liderazgo, y radica en considerar aspectos relacionados con el grado en el que el líder se interesa por aumentar la satisfacción de los empleados optando por identificar y aplicar los estilos de liderazgo más apropiados con una mentalidad constructivista inclusiva; y por último, haciendo referencia al control, se analiza los criterios de evaluación de desempeño y la periodicidad en su implementación (Robbins y Coulter, 2005; Hellriegel y Slocum, 2004: Franklin, 2012; Chiavenato, 2009).

Otra variable interna es el comportamiento organizacional, el cual genera un impacto importante en la cultura de una organización, ya que enfatiza las interacciones que la componen, en este sentido la importancia del comportamiento organizacional radica en que las organizaciones son sistemas sociales, es decir, si se desea trabajar en ellas o dirigirlas, es necesario comprender su funcionamiento mediante la estructura, la cual se define en la fase denominada organización del proceso de gestión (Robbins y Coulter, 2005).

Es así como "el comportamiento organizacional es producto de muchas cosas, por tanto, lo que se observa o diagnostica (la conducta de los empleados, los problemas y el estado actual de la organización) tiene causas múltiples" (Hellriegel y Solucm, 2004:415). 
Tomando en cuenta este enunciado, se puede determinar el éxito o fracaso de una organización en base al nivel de interacción de las personas (Chiavenato, 1999), donde juega un papel muy importante su comportamiento y que conjugados expresan resultados que en la práctica se denomina Comportamiento Organizacional y se constituye un elemento importante en la determinación de la Cultura Organizacional.

Según Alles (2007:31), el Comportamiento Organizacional "se refiere a todo lo relacionado con las personas en el ámbito de las organizaciones".

Para los autores el Comportamiento Organizacional es la manera en la que actúan y se muestran las personas dentro de una organización; definición que no difiere en ningún sentido de los autores citados. Por lo tanto, se considera que la Cultura Organizacional existente es la línea de partida para analizar el comportamiento diario de un trabajador dentro de una institución.

Para conocer el direccionamiento del comportamiento organizacional en una institución, es necesario diagnosticarla periódicamente con la finalidad de saber con certeza los problemas o fortalezas que atraviesa y de qué manera podría verse afectada su cultura organizacional, según Alles (2007), los resultados de un sistema de comportamiento organizacional o de otros intangibles, suelen medirse con tres indicadores básicos: eficiencia, eficacia y efectividad.

El Clima organizacional, es otra variable de la cultura organizacional, "cuyo concepto fue introducido por primera vez al área de psicología organizacional por Gellerman en 1960. Este concepto estaba influido por dos grandes escuelas de pensamiento" (Brunet, 1987).

La escuela de Gestalt y la escuela funcionalista. Según la escuela de Gestalt los individuos comprenden el mundo que les rodea basados en criterios percibidos e inferidos, de tal manera que se comportan 
en función de la forma en que perciben su mundo. Es así que el comportamiento de un empleado está influenciado por la percepción que él mismo tiene sobre el medio de trabajo y del entorno. Por otro lado, la escuela funcionalista formula que el pensamiento y comportamiento de un individuo dependen del ambiente que le rodea y que las diferencias individuales juegan un papel importante en la adaptación del individuo a su medio.

Goncalves (1997), menciona que, en el clima organizacional, el elemento fundamental son las percepciones que el trabajador tiene de las estructuras y procesos que ocurren en un medio laboral. Según este último autor, este enfoque radica en las percepciones que el trabajador pueda tener dentro de una organización, mas no en el resultado que puedan generar los factores organizacionales existentes. Sin embargo, estas percepciones dependen mucho de la interacción que pueda tener el trabajador con la institución y es así como el clima organizacional refleja esta interacción entre las actitudes personales y las características de la organización.

La escuela de Gestalt de Brunet y la definición de Goncalves, coinciden en el hecho de que la percepción del trabajador es un factor de gran importancia en el clima organizacional, siendo el primer paso dentro del proceso cognoscitivo, en el que los trabajadores captan las diferentes situaciones que ocurren en su entorno.

Los autores consideran que el clima organizacional, es un elemento interno de la cultura que cada organización posee, y que se establece en base a las percepciones que tienen los trabajadores de la institución, además se lo identifica en la fase de la organización del proceso de gestión. Con respecto a la variable interna "valores", los autores, Hellriegel y Slocum (2004), Robbins y Judge (2013), Chiavenato (2009), Alles (2007), consideran también que son un aspecto determinante de la Cultura Organizacional y que además son indispensables para su fomento institucional.

Según Jiménez (2010:12), “para la cultura organizacional de una empresa los valores son la base de las actitudes, motivaciones y 
expectativas de sus trabajadores. Los valores son la columna vertebral de sus comportamientos". Partiendo del análisis de las definiciones y conceptos de Cultura Organizacional, se puede observar que un elemento común y fundamental para la formación de todas ellas, lo constituye los valores.

Los valores principales son aquellos que son sostenidos profundamente y que fuertemente gobiernan el comportamiento de la cultura y, por lo tanto, son aceptados y compartidos ampliamente por más personas.

Pascal y Athos (1981), plantearon "el modelo de las 7 eses de Mckinsey como guía para el cambio basado en valores". Este sistema ofrece la posibilidad de crear consensos sobre la dirección de la organización y se concentra en acciones e iniciativas basadas en valores compartidos.

Para lograr el cambio en una organización, es necesario fundamentarse en los valores existenciales, pues son estos los que dan sentido y cohesionan el esfuerzo de lo que se quiere llegar a ser, es decir su visión, en este sentido los valores compartidos absorben la complejidad organizativa, orientan la visión estratégica y aumentan el compromiso profesional, a la vez que constituyen una herramienta que permite identificar, promover y legitimar el tipo de cambio organizacional; por tanto la variable está considerada dentro de la planeación en las fases del proceso de gestión, de las organizaciones (Briceño, 2004).

Se aborda la comunicación como otra de las variables internas de la Cultura Organizacional porque las relaciones que se establecen entre las personas que laboran en una organización, surgen gracias a este; $y$ es precisamente en estos procesos de intercambio en que se establecen compromisos, así también como se delegan y determinan funciones. 
Según Chiavenato (2009:308), la comunicación "es el flujo de información entre dos o más personas y su comprensión, o la relación entre personas por medio de ideas, hechos, pensamientos, valores y mensajes".

Para los autores, la comunicación dentro de una organización, es un conjunto de actividades y procedimientos direccionados hacia un eficiente y eficaz flujo de mensajes que se dan entre los miembros de la organización, o entre la organización y su medio.

Robbins y Judge (2013), citan a Simpson, quien menciona que la comunicación puede fluir de forma vertical o lateral. La dimensión vertical se subdivide asimismo en las direcciones ascendente y descendente.

En este sentido hay que tomar en cuenta que las constantes innovaciones y cambios en las organizaciones plantean un nuevo modelo en el que se conjuga solamente la interacción entre el emisor / receptor - receptor/emisor, esto quiere decir que la información circula en todas las direcciones y que todas las personas que laboran en la organización se convierten en transmisores y receptores ya sea en la dimensión vertical u horizontal, ascendente y descendente.

El papel del líder de la organización juega un papel importante en el proceso de comunicación interna, pues es el encargado de transmitir y delegar funciones para el cumplimiento de metas y objetivos institucionales; hoy en día la comunicación fluida dentro de la organización ya no es un tabú, pues se cuenta con herramientas indispensables e innovadoras como el internet, intranet, etc., que operativizan las labores diarias de los trabajadores demando rapidez, eficiencia y eficacia, además de que involucran una respuesta; por esta razón, la variable de la comunicación se le atribuye a la fase de dirección del proceso de gestión (Koontz et al, 2012).

Otro elemento interno de la Cultura Organizacional importante y que no todas las organizaciones lo poseen, es la motivación. Para 
Martínez (2000:34), la motivación es "un medio que moviliza, orienta y regula la actuación de un individuo, con la finalidad de satisfacer sus carencias, generadas con el fin de estimular la actuación de este y alcanzar las metas".

Para Robbins (2009:175), “se define a la motivación como los procesos que inciden en la intensidad, dirección y persistencia del esfuerzo que realiza un individuo para la consecución de un objetivo".

Según Salom, la motivación es "el resultado de la ambición y autoestima, el detonador de esta fórmula es el incentivo. Todos laboran para lograr un beneficio tangible de lo contrario existiría inestabilidad en el principio del "intercambio" (Salom, 2015).

De la aportación de estos tres autores se puede concluir que sus definiciones de motivación son muy certeras, la definición de Robbins y Martínez tienen un gran aspecto en común, "las metas" sin embargo la definición citada por Salom es más realista al plantear una formula basada en la ambición y autoestima, que hoy en día se lo aplica en la vida personal y también en las organizaciones.

Para los autores la motivación es un factor emocional indispensable en el ser humano, ya que el considerarse motivado representa la realización de actividades con empatía y sin sobreesfuerzos, una persona motivada dentro de una organización puede lograr efectos muy positivos dentro de ella, específicamente en la consecución de los objetivos propuestos.

Básicamente existen tres tipos de motivación, la motivación intrínseca que es la propensión inherente a involucrarse en los propios intereses y ejercer las propias capacidades y al hacerlo, buscar y dominar desafíos óptimos "la motivación extrínseca, que proviene de los incentivos y consecuencias en el ambiente, como alimento, dinero, alabanzas, atención, calcomanías..." (Reeve, 2010:84), y la motivación trascendente, obtenida por el beneficio o satisfacción 
que obtiene un tercero o porque este evita algo negativo para él, este tipo de motivación engloba aquellos trabajos que se realizan voluntariamente. Es habitual hablar de este tipo de motivación en el entorno empresarial debido al protagonismo que actualmente tiene la proyección en la comunidad de una imagen íntegra y solidaria de las empresas.

Estos tres tipos de motivación se distinguen de manera aislada, sino que se interrelacionan y dependen la personalidad de cada ser humano. Casi siempre los objetivos organizacionales están en oposición con los objetivos individuales de las personas. La interacción entre personas y organizaciones es un tema dinámico y complejo que puede ser visto desde diversas perspectivas. Barnard hace una distinción interesante entre eficiencia y eficacia en cuanto a los resultados de la interacción de personas y organizaciones. Según este autor, "aunque toda persona debe ser eficiente para satisfacer sus necesidades individuales a través de su participación en la organización, su participación también debe ser eficaz para alcanzar los objetivos organizacionales" (Barnard, 1971:56).

Es importante mencionar que, al hablar de eficiencia, se involucra la consecución de los objetivos individuales tales como: promoción personal, prestigio, carrera, mayor salario, seguridad personal, etc., mientras que la eficacia abarca los objetivos organizacionales, tales como: mayor productividad, reducción de costos, utilidad, crecimiento de la organización, etc.

Desde esta perspectiva, no es conveniente para las personas ser solamente eficaces, pues su paso por la organización sería momentáneo; de igual manera, tampoco es conveniente para las personas ser solamente ser eficaz, pues por cumplir con los objetivos organizacionales, pone de por medio sus intereses personales.

Lo recomendable es mantener un equilibrio entre la eficiencia y la eficacia, produciendo resultados para la organización, los cuales involucren la superación personal del trabajador. 
La interacción que debe existir entre las personas y la organización, debe ser considerada como un proceso de reciprocidad. La organización realiza ciertas cosas por el trabajador (sueldo, beneficios, capacitaciones, motivaciones, seguridad, estabilidad, etc.), mientras que el trabajador cumple a cabalidad las tareas asignadas a su persona con la finalidad de cumplir con los objetivos organizacionales. Todo ello depende de una buena gestión a través de la dirección, función del proceso de gestión que abarca a la motivación (Barnard, 1971; Álvarez y Valverde, 2001).

Continuando con el análisis de las variables internas de la Cultura Organizacional, el trabajo en equipo, genera resultados exitosos, busca el compromiso personal y la responsabilidad solidaria.

Codina (2006:78), citando a Margeriso, indica que "el éxito o el fracaso en los negocios es resultado de, si las personas pueden trabajar conjuntamente en forma eficaz en equipo". En este sentido, un equipo de trabajo es un número de personas con habilidades complementarias comprometidas con un propósito común, una serie de metas de desempeño y un método de trabajo del cual todas ellas son mutuamente responsables (Koontz y Heinz, 1998).

Las conceptualizaciones citadas, tienen en común a las personas, responsabilidades y metas; con esta consideración los autores definen al trabajo en equipo como un conjunto de personas que trabajan responsable, coordinada y comprometidamente por alcanzar un objetivo o meta.

Según Stoner (1996), existen tres tipos de equipos de trabajo, el primero es el funcional que se caracterizan por estar constituidos por un gerente y sus subordinados directos en un área funcional específica; el segundo tipo son los equipos auto dirigidos o auto administrados que son un grupo formal de empleados que trabajan sin un gerente y son responsables de un proceso especifico; y por último el equipo multidisciplinario que trata de una agrupación híbrida de personas que son expertos en distintas especialidades y 
se reúnen, transponiendo las líneas departamentales para trabajar en varias tareas organizacionales.

Se considera que el trabajo en equipo es un elemento de la Cultura Organizacional porque a través de las percepciones causadas por la interacción de los miembros de la organización, genera ventajas competitivas a la institución, considerando también, que hoy en día el trabajo individual y aislado no atribuye a una mejor gestión. Esta variable está considerada como parte de la dirección dentro del proceso de gestión (Franklin, 2009).

La última variable interna que analizar son los ritos, creencias y tradiciones, debido a distintos patrones que se forman con el tiempo dentro de las organizaciones y que determinan su cultura, por lo tanto, se los constituye como otro elemento interno de la Cultura Organizacional.

Cada Cultura Organizacional es única, pues cuenta con componentes propios, que se han construido con el paso del tiempo en base a las circunstancias vividas por cada organización, en este sentido se crean una serie de elementos conceptuales que dan paso a la implementación de un sistema vivencial que involucra ritos, creencias y tradiciones, en los cuales los valores, símbolos, mitos, etc. están arraigados a la interculturalidad territorial.

Es así que, en este sistema vivencial, los trabajadores manifiestan sus capacidades e intenciones para comunicar lo que dentro de la sociedad es aceptado día a día.

Según Contreras, Díaz y Hernández (2013), “los ritos son actividades colectivas genuinas con un alto grado de formalidad los cuales frecuentemente inician o concluyen una cierta fase de eventos. El desarrollo de ritos denota una actividad en la cual la organización (o al menos una parte de ella) intenta lograr hacerse una idea dentro de sí y su rol, así como su función en el mundo. 
En este sentido González (2003), afirma que: "casi toda técnica de gestión puede ser practicada como un rito para la empresa". Y cada uno de estos ritos se realiza mediante ceremonias que van tomando su valor en base a su formalidad, tiempo de practicárselas y la importancia que puede generar en los trabajadores de una organización.

Con respecto a las creencias, estas se consideran una parte importante de este elemento de la cultura organizacional, pues según Contreras, et al. (2013:56), "los valores, creencias, códigos éticos, códigos de moral, ideologías, significan esencialmente la misma cosa en el lenguaje de la Cultura Organizacional y son parte central de esta", además de que "las creencias son tan importantes para la Cultura Organizacional que muchos autores los definen como la cultura organizacional".

Sin embargo, es importante entender que las creencias es parte de un elemento de la Cultura Organizacional que juega un papel muy importante y específicamente tiene que ver con la esencia de lo que los trabajadores creen que es verdad o no, así también como realidades o irrealidades.

La historia en las organizaciones se fundamenta sobre las experiencias, raíces e identidad de los trabajadores, gerentes o lideres cuyo accionar fue causando un alto impacto en el camino, ya sea porque su gestión fue exitosa o porque su resultado les obliga a dejar el rastro de lecciones no aprendidas pero disponibles para quienes quieren edificar y convertir en triunfo lo que para otros significó la derrota.

Las tradiciones también forman parte de este elemento interno de la cultura organizacional; según Lozano (2014), una tradición es la encarnación institucional y cultural de un propósito impregnado de valores que otorga significado y continuidad a un colectivo, convirtiéndolo en comunidad. 
De acuerdo con el enunciado de Lozano, es importante saber que este autor no se refiere a que los valores objetivos, metas, etc., en las intuiciones no puedan ser cuestionados o modificados, pero toda tradición marca un precedente en la organización en la medida en que nos conecta con un sentido originario, único, inspirador; aquella sustancia que impregna la forma, el estilo, la actitud de enfrentarse a la realidad, al mundo, a la vida y a los problemas.

Con estas consideraciones, esta variable se aborda en la planeación dentro de las fases del proceso de gestión (Franklin, 2009).

Una vez analizadas las variables externas e internas de la Cultura Organizacional su relación con las fases del proceso de gestión es importante considerar que el control se manifiesta en la medición de la evolución de las demás fases del proceso de gestión; en este sentido, el control se relaciona con la cultura organización a través de las acciones, y evaluaciones que se planteen para mejorarla y que han sido planteadas desde la planificación, organización y dirección (Cadena, 2016; Koontz, et al. 2012).

En base a esta consideración, el control de la gestión está dada a razón de los resultados que se pueda obtener a través de la aplicación de indicadores de gestión, los cuales permiten evaluar el planteamiento de las acciones propuestas, especialmente cuando las variables a valorar son elementos intangibles de la organización (Alles, 2007).

En el Manual de Auditoría de Gestión, emitido por la CGE (2009), se aborda que los indicadores de gestión se expresan en términos de eficacia, eficiencia y efectividad.

El alcanzar una mejor gestión a través del fomento de la cultura organizacional, sin duda conlleva al logro de objetivos, y teóricamente se demuestra que está dado en la medida en que se sepa organizar un proceso de cambio, teniendo en cuenta su relación con el proceso de gestión, planificación, organización, dirección y control; todo 
esto en base a la revisión de la literatura especializada, tal como se muestra en la tabla 7.

Tabla 7. Relación de las variables de la Cultura Organizacional con las fases del proceso de gestión, según autores.

\begin{tabular}{|c|c|c|c|c|}
\hline $\begin{array}{l}\text { Fases } \\
\text { Variables }\end{array}$ & Planeación & Organización & Dirección & Control \\
\hline \multicolumn{5}{|c|}{ Variables externas } \\
\hline Globalización & $\begin{array}{l}\text { Chiavenato } \\
\text { (2009). }\end{array}$ & & & Franklin (2009). \\
\hline $\begin{array}{l}\text { Leyes, normas } \\
\text { y reglamentos }\end{array}$ & LOSEP (2015). & & & $\begin{array}{l}\text { Koontz, et al. } \\
\text { (2012); Franklin } \\
\text { (2009). }\end{array}$ \\
\hline $\begin{array}{l}\text { Plurinaciona- } \\
\text { lidad }\end{array}$ & $\begin{array}{l}\text { Hellriegel y } \\
\text { Slocum (2004). }\end{array}$ & & & Franklin (2009). \\
\hline \multicolumn{5}{|c|}{ Variables internas } \\
\hline Liderazgo & $\begin{array}{l}\text { Robbins y Coul- } \\
\text { ter (2005); }\end{array}$ & $\begin{array}{l}\text { Robbins y } \\
\text { Coulter (2005); } \\
\text { Koontz, et al. } \\
(2012) \text {. }\end{array}$ & $\begin{array}{l}\text { Robbins y } \\
\text { Coulter (2005); } \\
\text { Franklin (2009). }\end{array}$ & $\begin{array}{l}\text { Robbins y } \\
\text { Coulter (2005); } \\
\text { Franklin (2009). }\end{array}$ \\
\hline $\begin{array}{l}\text { Comportamien- } \\
\text { to Organiza- } \\
\text { cional }\end{array}$ & & $\begin{array}{l}\text { Robbins y } \\
\text { Coulter (2005); } \\
\text { Koontz, et al. } \\
(2012) ;\end{array}$ & & $\begin{array}{l}\text { Koontz, et al. } \\
\text { (2012); Franklin } \\
\text { (2009). }\end{array}$ \\
\hline $\begin{array}{l}\text { Clima Organi- } \\
\text { zacional }\end{array}$ & & $\begin{array}{l}\text { Robbins y Judge } \\
\text { (2013), }\end{array}$ & & Franklin (2009). \\
\hline Valores & $\begin{array}{l}\text { Gareth (2006); } \\
\text { Briceño (2004). }\end{array}$ & & & Franklin (2009). \\
\hline Comunicación & & $\begin{array}{l}\text { Koontz, et al. } \\
\text { (2012). }\end{array}$ & $\begin{array}{l}\text { Koontz, et al. } \\
\text { (2012); Franklin } \\
\text { (2009). }\end{array}$ & $\begin{array}{l}\text { Koontz, et al. } \\
\text { (2012); Franklin } \\
\text { (2009). }\end{array}$ \\
\hline Motivación & & & $\begin{array}{l}\text { Salom (2015); } \\
\text { Gareth (2006); } \\
\text { Franklin (2009). }\end{array}$ & $\begin{array}{l}\text { Gareth (2006); } \\
\text { Franklin (2009). }\end{array}$ \\
\hline $\begin{array}{l}\text { Trabajo en } \\
\text { equipo }\end{array}$ & & & $\begin{array}{l}\text { Robbins y Judge } \\
\text { (2013); Franklin } \\
\text { (2009). }\end{array}$ & Franklin (2009). \\
\hline $\begin{array}{l}\text { Ritos, Creen- } \\
\text { cias y Tradicio- } \\
\text { nes }\end{array}$ & $\begin{array}{l}\text { Hellriegel y } \\
\text { Slocum (2004). }\end{array}$ & & & Franklin (2009). \\
\hline
\end{tabular}

Fuente: Torres (2017).

\subsection{Tendencias sobre la Cultura Organizacional}

Un modelo, sistema, estrategia, acción $\mathrm{u}$ otra tendencia adecuadamente formulada ayuda a poner en orden $\mathrm{y}$ asignar 
eficientemente los recursos de una organización, con el fin de lograr los objetivos, así como anticipar los posibles cambios en el entorno y las decisiones estratégicas a tomar.

Las decisiones estratégicas, "son aquellas que establecen la orientación general de una empresa y su viabilidad máxima a la luz, tanto de los cambios predecibles como de los impredecibles, que, en su momento, puedan ocurrir en los ámbitos que son de su interés o competencia" (Mintzberg y Quinn, 1995:6).

Se entiende por decisiones estratégica, un proceso continuo que implica la creación de estrategias o acciones, para alcanzar las metas que alteran la base de los resultados observados.

Para diseñar una acción eficiente, se deben considerar ciertos criterios, tales como: objetivos claros y decisivos, conservar la iniciativa, concentración, flexibilidad, liderazgo coordinado y comprometido y seguridad.

Mintzberg (1999), plantea diez escuelas del procedimiento estratégico, divididas en tres grupos: prescriptivas (diseño, planificación y posicionamiento), descriptivas (empresarial, cognoscitiva, aprendizaje, poder, cultural y entorno) e integral (configurativa).

La presente investigación se identifica con la escuela cultural cuyo objetivo "se centra en el interés colectivo, y en construir una organización unificada que comparte valores, hábitos y tradiciones... en esta escuela la formación de la estrategia se convierte en dirección del conocimiento colectivo" (Díaz, et al., 2010:106).

La escuela cultural permite concebir una etapa de reconstrucción, donde las nuevas perspectivas se desarrollan colectivamente y que caminan conjuntamente con un movimiento estratégico de cambio radical. 
Para ello "se requiere de un análisis cualitativo de la organización que permitan decidir sobre las metas y estrategias a seguir y los procedimientos para modificarlas o enriquecerlas" (Díaz, et al., 2010:494).

El planteamiento de acciones de cambio para fomentar una Cultura Organizacional, "parte de la aplicación de una metodología de diagnóstico, uno de los grandes problemas de la cultura organizacional, es la creación de instrumentos que permitan a partir de los supuestos, premisas y valores de la cultura existente, en una organización, la interpretación de su entorno" (Vargas, 2007:226).

El diagnóstico es la evaluación de la Cultura Organizacional existente, herramienta previamente necesaria para la determinación de acciones coherentes, reales y actuales, para el efecto, las corrientes teóricas recomiendan utilizar las técnicas como: análisis del entorno, aplicación de técnicas cuantitativas y cualitativas, análisis de resultados y elementos a tomar en cuenta para obtener la cultura deseada (Vargas, 2007; Cruz, 2005; Alabart y Portuondo, 2004).

Una vez que se tiene el diagnóstico de la cultura existente en una organización, el siguiente paso es la identificación de las diferencias con los elementos de la cultura ideal deseada para la estructuración de las acciones a implementar.

A continuación, se analizan algunas tendencias para el cambio de la Cultura Organizacional planteada por varios autores.

Denison (1990), plantea una metodología para el cambio cultural organizacional, en la cual se debe considerar dos factores: 1) el grado en el cual el medio ambiente competitivo requiere de cambio o estabilidad, y 2) el grado de enfoque y fuerza interna y externa de la estrategia; estos dos factores involucran el desarrollo de cuatro categorías asociadas: adaptabilidad, misión, involucramiento y consistencia; considerando como herramienta fundamental a 
un cuestionario construido tras una revisión de la investigación acerca de cómo la cultura influye en la efectividad organizacional, desarrollado por este autor.

No obstante, Shein (1990), propone la estrategia de cambio cultural a través de fusiones y adquisiciones, esta estrategia es aplicada en las organizaciones donde ocurren fusiones entre dos o más instituciones, áreas, departamentos, y sostiene que el diagnóstico es la principal herramienta para no originar indigestión cultural debido a las incompatibilidades entre diferentes culturas organizacionales.

Mientras tanto, la estrategia de autodiseño, propuesta por Mohrman y Cummins (1991), sostiene que el cambio cultural se desarrolla en tres niveles; el primero consiste en establecer los fundamentos, esto quiere decir que los miembros de la organización deben adquirir " $X$ " conocimiento y sobre todo estar bien informados sobre el proceso de cambio, para luego proceder a diagnosticar a la institución y establecer las deficiencias entre la cultura actual y la deseada, evaluando y determinando los valores y estrategias corporativas positivos para la organización. Esta estrategia de autodiseño, sostiene que la base lograr un cambio cultural, inicia en el analizar la Cultura Organizacional existente, mediante el diagnóstico para llegar a la deseada.

El segundo nivel propuesto en esta estrategia involucra el diseño e innovaciones, que apoyan a los valores y estrategias organizacionales; y por últimoel tercer nivel, se refiere a laimplementación y evaluación, que abarca los ciclos de las estructuras y conductas cambiantes. En la estrategia de autodiseño, las actividades son iterativas, es decir se cree en la necesidad de retroalimentar constantemente para lograr una mejora continua.

Pearce y Osmond (1996), proponen la estrategia de puntos de apalancamiento de acceso, la cual se basa en los aspectos críticos de la cultura que con frecuencia pueden ayudar, pero algunas veces impedir la introducción y el manejo de los esfuerzos de cambio 
organizacionales, por lo tanto estos autores, plantean que el cambio cultural puede desarrollarse en tres pasos: el primero es a través del desarrollo de una metáfora que represente la cultura meta, el segundo es mediante la identificación de los puntos de apalancamiento de acceso; y el tercero es la intervención para resolver cada uno de los puntos de apalancamiento de acceso mediante el planteamiento de estrategias de cambio cultural en base a la cultura meta.

Al mismo tiempo Nemetz y Christensen (1996), plantean la estrategia para promover la diversidad multicultural en las organizaciones basada en el entrenamiento y establecimiento de sus políticas; el ámbito del entrenamiento se basa en estudios étnicos, acercamiento psicoterapéutico (Cullen, 1983), entrenamiento de sensibilidad (Smith, 1990; Spokesman Review, 1993), creación de la disonancia cognoscitiva (Leippe y Eisenstadt, 1994), conciencia cultural (Gordon, 1992) y conciencia legal. Sin embargo, Vargas (2007), promueve el cambio sistémico cultural, que se desarrolla mediante dos estrategias; la primera es el cambio sistémico que está dado por el cambio en los subsistemas, social, técnico y administrativo para llegar al cambio cultural, este ciclo empieza con las actividades de colección y análisis de los datos, es decir, con el diagnóstico de las fallas de los subsistemas y las acciones que requieren para corregirse.

La segunda estrategia está dada en que el cambio de la Cultura Organizacional puede llevar a un cambio en los subsistemas, social, técnico y administrativo. Este tipo de cambio de la Cultura Organizacional se dirige a la realización de acciones que modifiquen los artefactos, creencias, valores, supuestos, premisas básicas, etc.

Por último, Urdaneta (2014), plantea cuatro pasos a seguir como estrategia para cambiar la cultura organizacional: el primer paso es alinear la cultura a las estrategias empresariales, el segundo es comunicar claramente lo que se quiere, el tercer paso es toma de decisiones y el cuarto paso, es el apoyo y conducta de los líderes.

Shein (1990); Denison (1990); Mohrman y Cummins (1991); Pearce y Osmond (1996) y Vargas (2007), coinciden en que la estrategia 
para el cambio cultural tiene como parte medular el diagnóstico de la organización, seguido por las acciones que deben tomarse para lograr los objetivos propuestos.

A diferencia de los autores anteriormente citados, Nemetz y Christensen (1996) y Urdaneta (2014) no proponen el diagnóstico como parte de la estrategia de cambio cultural sino el establecimiento de políticas, estrategias, acciones y pasos directamente establecidos para alcanzar el cambio de la cultura organizacional en una organización.

Los autores comparten el criterio de Shein (1990); Mohrman y Cummins (1991); Pearce y Osmond (1996) y Vargas (2007): y cree firmemente en que el diagnóstico es indispensable dentro de la estrategia de cambio de la cultura organizacional, pues es importante conocer la situación actual de la institución para saber hacia dónde dirigir a la misma, sobre todo considerando que "la cultura organizacional refleja la forma en que cada organización aprende a lidiar con su entorno" (Chiavenato, 2009:126), y el entorno de cada organización es diferente, pues, cada organización es un mundo y su cultura es única, ya sea por su diversidad étnica, ideológica, cultural, etc.

$\mathrm{Al}$ abordar los elementos teóricos sobre la cultura organizacional, se inicia conceptualizando el papel de la gestión y de las fases del proceso de gestión, analizando también la evolución de las teorías administrativas que hacen relevancia a la importancia del ser humano dentro de una organización hasta llegar a la Teoría Z, planteada por Ouchi (1982), la cual considera la concepción de una Cultura Organizacional que beneficie de forma común, al trabajador y a la empresa. Con este antecedente, en base a una extensa revisión bibliográfica, se aborda a la cultura organizacional, comentando también su relación con la gestión, para dar paso al concepto propuesto por los autores sobre Cultura Organizacional Autóctona; continuando con el análisis de las variables con las que se relaciona la cultura organizacional, analizando cada una de ellas 
y su relación con las fases del proceso de gestión; para culminar con las tendencias existentes sobre esta; donde se identifica a la cultura organizacional existente como un punto de partida para llegar a la deseada; tal como se resume en el modelo conceptual planteado por los autores y detallado en la figura 6 .

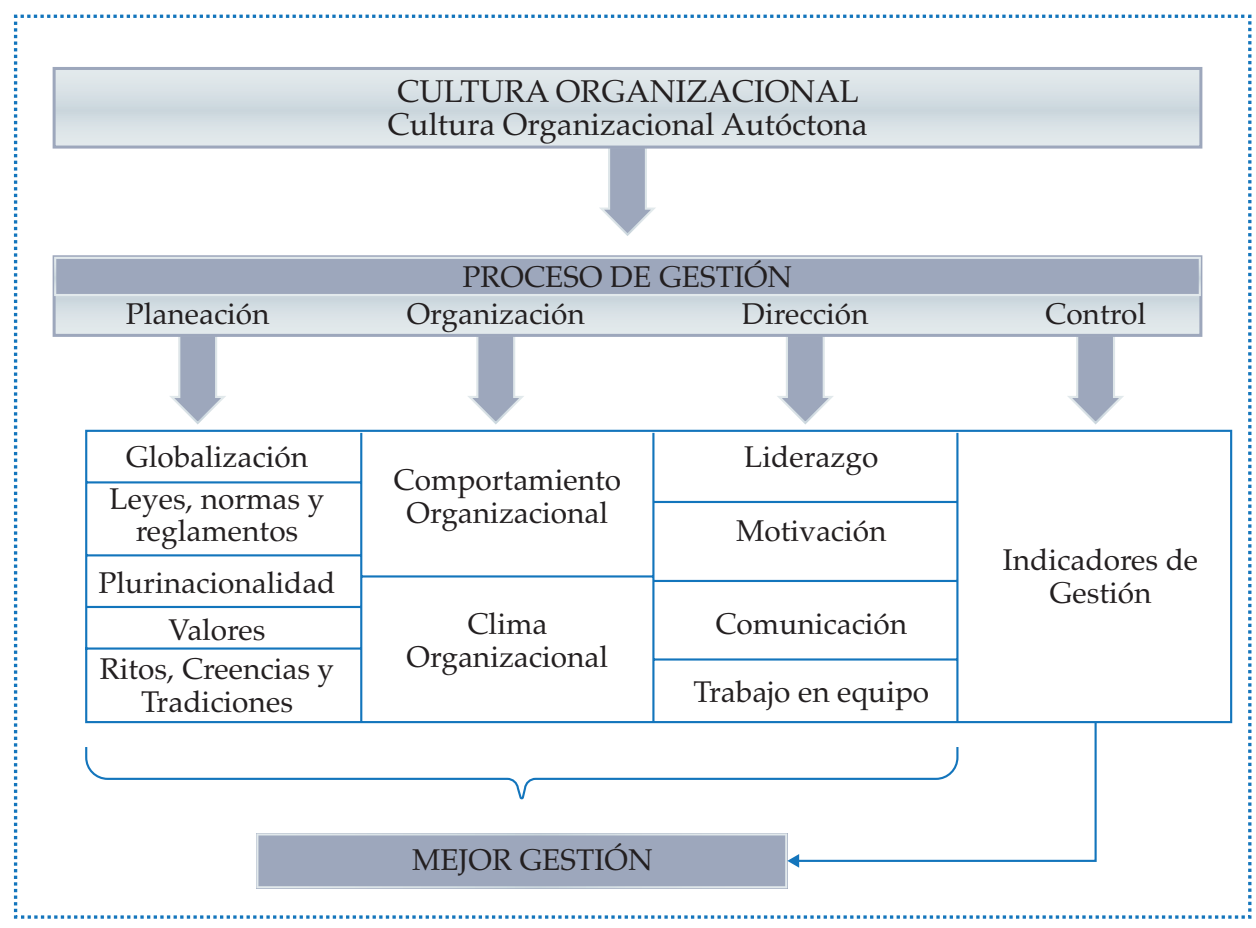

Figura 6. La Cultura Organizacional y la gestión. 


\section{CAPÍTULO IV.}

\section{DESARROLLO ECONÓMICO LOCAL}




\subsection{El Desarrollo Territorial}

El estudio de la dimensión territorial del desarrollo trasciende y alcanza más importancia después de la Segunda Guerra Mundial (II GM), lo que está condicionado entre otros factores, por la necesidad de resolver la problemática asociada a la profundización de las diferenciaciones y asimetrías existentes entre países y entre sus espacios subnacionales, en este sentido, esta investigación contribuye a la ciencia ya que su objetivo principal radica en el análisis de varias experiencias internacionales de desarrollo local; para el efecto la metodología implantada aborda una investigación analítica documental con enfoque holístico que permite considerar aspectos clásicos hasta llegar a los contemporáneos concluyendo que , se está ante un proceso en construcción, no exento de contradicciones y deformaciones, si bien existen varios esfuerzos y experiencias exitosas relacionadas con la planificación del desarrollo socioeconómico de los espacios subnacionales, las mayores distorsiones radican en la falta de coordinación intergubernamental, la desarticulación con las políticas nacionales, la inexistencia de un liderazgo territorial, la baja participación real de la ciudadanía en el proceso, lo que lleva a una separación entre los objetivos de desarrollo y la realidad del territorio, desconociendo sus potencialidades y limitaciones para alcanzar las metas propuestas.

El termino desarrollo y el contenido que este expresa fue tratado con especial énfasis después de la segunda guerra mundial, dado que es en este momento donde el accionar de la ley del desarrollo desigual, había consolidado el lugar y papel de los diferentes países y sus espacios subnacionales en la economía internacional. Según Naviero (2006), la teoría del desarrollo surgió en un contexto keynesiano, "en medio de un singular proceso de transnacionalización del capital bajo la forma de empresas transnacionales" (pág. 24).

El propósito del desarrollo, desde una perspectiva utilitarista, es la maximización de la sumatoria de las funciones individuales de bienestar, sin importar la distribución o equilibrio entre personas 
de esa suma, en tanto que la igualdad se consigue a partir de la ponderación homogénea de ganancias y pérdidas individuales de bienestar en la función objetivo.

Según Madoery (2005), al referirse al desarrollo sostiene que "es interpretado como un proceso de dinámicas centralizadas y de remoción de barreras que impedían el despliegue del potencial de las sociedades nacionales" (p. 4). Es decir, los impulsos exógenos al territorio nacional o exógeno a las regiones interiores de un Estado, eran los responsables de proveer con los recursos necesarios para el desarrollo a los territorios; entre estos se tiene a la industrialización de la estructura económica, la democratización y modernización de la sociedad.

Hay que considerar también que es una noción conceptual que siempre se ha relacionado al crecimiento económico, no obstante desde hace décadas se discute el papel del crecimiento en el desarrollo, por lo que en avances posteriores se fundamenta que el crecimiento "es un componente necesario del proceso de desarrollo, pero no lo agota, puesto que también deben producirse transformaciones estructurales, sociales y políticas, en el ascenso a la eficiencia del conjunto de variables multidimensionales que en su interrelación definen el desarrollo" (Alonso, 2006, pág. 25).

A finales de la década de 70 del siglo XX cambia la concepción del desarrollo, según Alcaniz "a partir de aquí se defiende una nueva definición de desarrollo más centrada en las personas que en el crecimiento económico, denominándose Desarrollo Humano" (Alcaniz 2008, pág. 302). El impulsor de este criterio fue Sen que define el desarrollo como un proceso de expansión de las capacidades de que disfrutan los individuos donde las capacidades simbolizan las posibilidades que tiene cada individuo para lograr altos desempeños, también las libertades fundamentales que pueden poseer, y dentro de estas menciona: la salud, la educación, los derechos políticos y humanos (Sen,1999). 
Se considera un importante logro aproximarse al concepto de desarrollo a partir del cambio de concepción, donde el bienestar del ser humano pasa a ser el objetivo fundamental, está demostrado que las grandes empresas rodeadas de pobreza no son el camino para la transformación socioeconómica necesaria, este enfoque sugiere pensar en cómo lograr este desarrollo humano donde la inclusión, las libertades y derechos se vuelven indispensables para ello.

El economista cubano O. Martinez (2000), establece un vínculo entre los aspectos económicos y sociales del desarrollo en su integralidad "que tiene como objetivo final la transformación de los seres humanos, haciéndolos más saludables, cultos, participativos y solidarios con sus semejantes... De ahí que se impulsaran las políticas sociales y económicas como elementos inseparables de un proceso que requería la marcha de ambos y su articulación recíproca" (pág. 12).

El Programa de Naciones Unidas para el Desarrollo (PNUD), utiliza un índice en sus informes sobre desarrollo humano que ha devenido en un instrumento de medición importante, a la hora de caracterizar y evaluar los niveles de desarrollo alcanzados por los diferentes países regiones y o territorios.

Al referirse al proceso de desarrollo, Boisier (2005), destaca que es un concepto en constante evolución y transformación, en la medida en que lo hace la sociedad y se enfrenta a nuevos retos o problemas.

En síntesis, en el periodo posterior a la segunda guerra mundial las concepciones en torno al desarrollo han sufrido importantes modificaciones. "La distinción entre el desarrollo y el crecimiento, primero: la comprensión de que el desarrollo constituye un complejo proceso con aristas económicas, sociales, políticas, técnicas, ambientales e institucionales, después; hasta que más recientemente surgió la precisión de que el desarrollo es un proceso en el cual al ser humano no es solo uno de sus medios sino sobre todo fin, y finalmente se tendría la incorporación del aspecto ambiental. Puede decirse que no existen referencias actuales al desarrollo que no lo designen como desarrollo sostenible" (Méndez, 2006, pág. 75). 
Gago (1993), entiende que el desarrollo "es un proceso de cambio estructural global económico, político, social, cultural y del medio ambiente, tendiente a aumentar la calidad de vida de todos los miembros integrantes de la sociedad, de forma de alcanzar una más completa satisfacción de las necesidades colectivas básicas" (pag.15).

Es importante comprender que el desarrollo no es homogéneo entre países y regiones, o incluso dentro de un mismo sector o actividad, pues a lo largo del proceso surgen diferencias en los sistemas económico, social, político, tecnológico y cultural, lo cual está condicionado por la acción de leyes económicas que explican la reproducción de las relaciones económicas imperantes: las capitalistas (Fierro, 2017).

La importancia de tratar la dimensión territorial del desarrollo se fortaleció a partir de la necesidad de resolver la problemática ocurrida después de la segunda guerra mundial con la profundización de asimetrías existentes entre los diferentes espacios subnacionales.

Las corrientes teóricas que forman parte del conjunto de fundamentaciones que abordan la problemática del desarrollo local en general, pueden ser clasificadas en dos grandes grupos: la corriente Convergente o Equilibrista y los que representan a la corriente Divergente o Desequilibrista . El centro del debate está referido a si las relaciones entre diversas economías dentro de un sistema de mercado conducen hacia la convergencia, o hacia la ampliación de las diferencias existentes en el punto de partida (Fierro, 2017).

Las concepciones de carácter convergente destacan que el desarrollo se genera de forma espontánea, en este sentido, la Teoría del Crecimiento Equilibrado sostiene que son los propios mecanismos de mercado y el libre funcionamiento de la economía los que permiten la expansión del desarrollo y la riqueza. Según sus postulados la evolución de las disparidades entre diferentes unidades espaciales 
dependía exclusivamente de la disponibilidad que estas tuvieran de recursos naturales, capital y ahorro, así como de su capacidad empresarial, dándose por supuesta la movilidad de estos factores, por lo que el equilibrio en el espacio económico era algo que se produciría de forma lógica.

Así, el capital saldría necesariamente de las zonas más desarrolladas en busca de mayores ingresos para la inversión a través de menores costos en salarios, y a la inversa, la mano de obra tendería a emigrar de las zonas de baja productividad buscando mejores salarios. Las disparidades que puedan generarse en el empleo, renta o en el costo de los factores solo reflejarían la existencia de desfases transitorios en un proceso que a mediano o largo plazo llevarían a un crecimiento equilibrado (Sthor, s/a, pag. 70).

Este tipo de desarrollo construye metas teóricamente aplicables a diferentes tiempos y lugares. Al suponer universalidad de aplicación y replicabilidad de las políticas de desarrollo, presenta una orientación hacia la uniformidad de las sociedades y la homogeneidad de los fundamentos políticos, de los procedimientos técnicos y de las prácticas metodológicas (Madoery, 2005).

Sin embargo, estos enfoques son cuestionados pues existe evidencia objetiva de que los mecanismos de mercado no eliminan las diferencias entre regiones y/o territorios, ni se manifiesta una tendencia hacia la auto estabilización automática del sistema social, es decir, el sistema no se mueve por sí mismo hacia el equilibrio, ni da lugar a efectos concurrentes en la misma dirección del cambio original impulsándolo más lejos (Diez, Gutierrez y Pazzi, 2013; Myrdal, 1957).

Por otro lado, las concepciones de carácter divergente destacan que las disparidades son causadas por las relaciones interregionales y explican que estas se reproducen e incluso se agravan en vez de corregirse. En consecuencia, las propuestas de políticas económicas que se fundamentan en la perspectiva divergente reconocen 
la necesidad de establecer diferenciaciones por regiones $\mathrm{y} / \mathrm{o}$ territorios, respondiendo a realidades objetivas diferentes en cada caso particular (Alonso y Bell, 2013).

Es la teoría keynesiana quien proporciona el soporte teórico a las políticas regionales aplicadas durante los años 50 y 60 del siglo XX, lo hizo desde una óptica más pragmática comparado con otras propuestas de políticas de carácter convergente, no obstante, los resultados efectivos quedaron en no pocos casos bastante lejos de los propósitos. Pues las diferenciaciones y asimetrías entre los espacios subnacionales se siguieron manifestando y en ocasiones profundizando.

Sehace por tantonecesario recomponer teóricamentelainterpretación de la nueva realidad y se comienza a hablar de la propuesta de desarrollo endógeno y su forma concreta de manifestación el desarrollo local (Fierro, 2017). Surge por tanto un enfoque opuesto al llamado desarrollo desde arriba el cual predominó durante tres décadas (1950 a 1980) sin que haya disminuido las desigualdades entre los niveles de vida.

El desarrollo endógeno puede entenderse como un proceso de crecimiento económico y cambio estructural, liderado por la comunidad local utilizando el potencial de desarrollo, que conduce a la mejora del nivel de vida de la población local (Hernández, et al., 2012).

El modelo de desarrollo endógeno se basa en las siguientes características: - utilización y valorización de recursos locales (capacidad empresarial, trabajadores especializados con formación y aprendizaje local, capital acumulado históricamente, conocimiento específico de los procesos de producción, tareas profesionales específicas, recursos naturales); • capacidad de controlar el proceso de acumulación; • capacidad de controlar el proceso de innovación (habilidad de internalización de los conocimientos tecnológicos y organizativos, o de introducir directamente innovación); • existencia 
de (y capacidad de desarrollar) interdependencias productivas, intersectoriales e intersectoriales a nivel local y nacional (Garofilo, 1992).

Alcaniz, considera que "el desarrollo local en el contexto actual de globalización puede suavizar los efectos perversos de un proceso dominante, realizado de forma poco democrática y sin contar para nada con la opinión de las personas y las particularidades culturales de las sociedades (Alcaniz, 2008, pág. 312).

\subsection{Experiencias sobre Desarrollo Económico Local}

El enfoque de desarrollo territorial se plantea como una solución a las limitaciones de un modelo urbano industrial, sectorial y exclusivamente económico, dependiente en lo fundamental de la burocracia nacional y multilateral; el mismo que no ha aportado con cambios significativos para mejorar la calidad de vida de la población en cada territorio.

Por ello, las experiencias internacionales investigadas de desarrollo territorial aportan a la construcción de enfoques integrales, altamente incluyentes en base a una diversidad de actores, con diferentes características determinadas por cada territorio, las cuales son dependientes en lo fundamental de la iniciativa y las capacidades de sus actores.

En la presente investigación los autores analizan las experiencias de desarrollo territorial internacionales específicamente de América Latina con la finalidad de abordar las realidades territoriales semejantes a la de Ecuador.

Desde la década de los cincuenta, la Comunidad Andina (CAN), trabaja en la elaboración de programas gubernamentales y la participación de la sociedad civil con la finalidad de combatir la pobreza y el subdesarrollo territorial; en este sentido el Acuerdo de 
Cartagena y a las Decisiones 553 y 601, establece el compromiso de los Países Miembros de la Comunidad Andina de trabajar a favor de la integración y el desarrollo de la región e incluye, entre otros temas prioritarios, el desarrollo agropecuario y agroindustrial, sin embargo es hasta el año 2006 que se propuso el Foro Andino de Desarrollo Rural para ejecutar el proyecto denominado Modelos de Desarrollo Rural con Enfoque Territorial en la Comunidad Andina (MDRT), cuyo objetivo radica en la creación de una estrategia Andina de desarrollo rural con enfoque territorial que contribuya a las políticas nacionales y a la superación de la pobreza en la subregión.

La realización de este proyecto contempla la validación de varias herramientas consideradas como ejemplos a seguir en otras intervenciones de la CAN cuyo objetivo radica en aportar a la cohesión social y económica de la subregión (Comisión Europea y CAN, 2011). Los enfoques que sustentan el proyecto se mencionan a continuación: 1. Desarrollo Rural con Enfoque Territorial: Herramienta para Enfrentar el Desafío de la Pobreza y la Exclusión; 2. Revalorización y Fortalecimiento de la Identidad Cultural; 3. Cohesión Social y Económica: Especificidades y Desafíos en Países de la CAN. Esto se concreta a través de la ejecución del procedimiento para la implementación del proyecto, el cual se muestra a continuación en la figura 7.

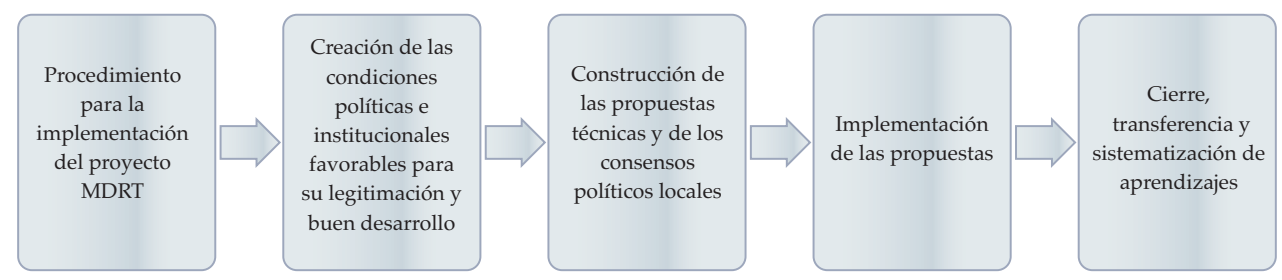

Figura 7. Procedimiento para la implementación del proyecto MDRT.

Fuente: Comunidad Andina de Naciones (CAN-2011). Experiencias de gestión y buenas prácticas en la implementación del proyecto: Modelos de Desarrollo Rural con Enfoque Territorial en países de la CAN. Lima-Perú.

A continuación, se detallan las experiencias de la aplicación del proyecto y su procedimiento en Bolivia, Colombia, Ecuador y Perú. Bolivia: La Mancomunidad Municipal de la Gran Tierra de los Lípez 
(MAMGT-Lípez), conformada por ocho municipios del suroeste del Departamento de Potosí, luego de aplicar a través de una consultoría el proyecto MDRT, a julio del año 2011 ha presentado avances referentes a la formulación de proyectos de micro riego, planes de fortalecimiento organizacionales construidos con la participación de los actores, diagnóstico de las debilidades de la mancomunidad y el financiamiento del gobierno para la réplica del proyecto en la zona de Beni.

Colombia: En Colombia, el Grupo Ad Hoc nacional seleccionó, para la validación del enfoque del Desarrollo Rural Territorial, nueve municipios del sur del Departamento del Tolima (Planadas, Ataco, Río Blanco, Chaparral, San Antonio, Rovira, Natagaima, Coyaima y Purificación), donde se trabajó sobre un cambio de mentalidades para adelantarse a una revolución agro tecnológica con una visión territorial del Desarrollo Rural; todo esto mediante la aplicación del proyecto MDRT que plantea los siguientes avances: elaboración de un mapa de actores, información de fuentes primarias y secundarias para levantar la línea base, socialización y sensibilización sobre convenios con la universidad y retroalimentación del diagnóstico territorial con los actores.

Ecuador: El cantón Nabón, ubicado en la provincia del Azuay, fue elegido como modelo a ser validado en el marco del proyecto MDRT de la CAN por los alentadores resultados logrados, entre estos se tiene: convenios con la universidad para el diseño e implementación de un sistema de información socioterritorial y la elaboración del Plan de Ordenamiento y Desarrollo Territorial Estratégico, reactivación de un comité de gestión interinstituiocional, herramienta de recolección de información, elaboración de un plan de competitividad territorial y se culminó con el registro de la marca territorial Nabón Productos Limpios.

Perú: El ámbito elegido para llevar a cabo la intervención del proyecto MDRT en el Perú está conformado por los distritos de Juli y Pomata, dos de los siete que integran la provincia de Chucuito, 
en el altiplánico departamento de Puno. Con la implementación del proyecto se obtuvieron los siguientes logros: actualización de los planes de desarrollo local, elaboración participativa de mapas de potencialidades y planes de competitividad, diseño de planes de promoción de participación ciudadana y perfil de un proyecto para la elaboración de un plan de desarrollo y ordenamiento territorial (CAN, 2011).

Otra de las experiencias internacionales destacada, ha sido realizada con el financiamiento del Banco Interamericano de Desarrollo (BID), para el proyecto denominado Experiencias Piloto de Desarrollo Rural Local en América Latina EXPIDER. Este proyecto ha sido desarrollado en tres países de América Latina: Bolivia, Ecuador y Honduras, con el objeto de evaluar el interés y la viabilidad del enfoque territorial rural en diversas zonas de América Latina y contribuir a establecer procedimientos básicos para la implementación operacional de proyectos de desarrollo territorial (Guzman, Martinez, Yruela y Moscoso, 2006).

Los componentes de los tres proyectos que tuvieron una duración de dos años fueron principalmente: 1) la creación de una Organización Local de Desarrollo (OLDER), 2) la elaboración de un Plan de Desarrollo Local (PEDER), 3) un sistema de seguimiento y evaluación, la identificación de buenas prácticas de desarrollo rural en el ámbito local. Los resultados de la implementación de los proyectos en los tres países indican que existe dificultad de dialogo entre el sector público y el sector privado debido a la falta de cultura y normas que regulen organizaciones mixtas público-privadas, dificultades en la creación de nuevas entidades para el desarrollo local, dificultad para los organismos financieros de aceptar autonomía de gestión y manejo de fondos por organizaciones locales que no tengan ni experiencia ni capacidad demostrada para tales tareas y finalmente problemas debidos al enfoque puramente productivo y no para la diversificación de los sistemas productivos y de los ingresos. 
Que implican: 1) una diferente consideración del rol (naturaleza individual o institucional) de las organizaciones campesinas en función de su representatividad, 2) la inclusión y papel de las ONG, 3) la necesidad de apoyar inversiones productivas a través de un enfoque de cadenas de valor, 4) la coordinación con los programas sociales, 5) la necesidad de evaluar cuidadosamente el rol y legitimación institucional en la creación de OLDER, 6) la necesidad de examinar alternativas a la gestión local de fondos, 7) un tiempo bastante largo para consentir la adquisición de capacidades, 8) criterios adecuados a las condiciones del público meta para financiación a individuos y a proyectos y 9) la necesidad de contemplar un proceso gradual con varias etapas dependiendo de la capacidad local y de la fortaleza institucional de cada territorio (Lucani, 2008).

Las experiencias de desarrollo territorial mencionadas, se han realizado a través de coaliciones territoriales, que son alianzas en las cuales participan actores de diferente índole, a fin de llevar a cabo e implementar iniciativas, planes y proyectos enmarcados en un objetivo estratégico y compartido de desarrollo territorial.

A continuación, se mencionan algunas experiencias individuales de desarrollo territorial:

En el Municipio de Santa María Ostuma, en La Paz, El Salvador, brinda apoyo local para el fortalecimiento de la cadena de valor de la Piña, el objetivo del proyecto es "mejorar las condiciones integrales de vida de la población en la Región de Los Nonualcos a través de la dinamización del desarrollo económico local, el desarrollo de capacidades locales y la concertación de actores públicos y privados del territorio" (Fundación para el Desarrollo Local y el Fortalecimiento Municipal e Institucional de Centroamérica y El Caribe DEMUCA, 2012, pág. 22).

Entre la problemática básica, se considera: una débil capacidad de sectores económicos para llegar al mercado; no se cuenta con un 
mercado identificado para la venta de los productos; poca atención para el desarrollo de talleres vocacionales; falta de conectividad de nuevas vías de acceso para llegar a nuevos mercados; no se cuenta con un mercado local; los sitios turísticos no reúnen las condiciones para recibir a los turistas; falta de infraestructura adecuada para la venta los productos artesanales elaborados en el municipio; falta de interés para participar en las reuniones que van en beneficio de la comunidad; poca visión en aspecto organizativo por parte de los habitantes del municipio.

La estrategia utilizada para solucionar estos problemas e impulsar el desarrollo local es la elaboración de una agenda común y por ende la generación de compromisos para apoyar y aprovechar los recursos humanos, físicos, económicos y socio institucionales, a fin de ampliar las oportunidades de negocios y de empleos en la región. Asimismo, la estrategia es un medio efectivo para identificar, jerarquizar y acordar acciones conjuntas (entre el nivel nacional y local y el sector público y privado) con el objeto de facilitar el acceso de las micro, pequeñas y medianas empresas, así como de los trabajadores independientes de la Región de Los Nonualcos, hacia una efectiva orientación de servicios financieros y técnicos de acuerdo a la demanda local (DEMUCA, 2012).

En este sentido, se mencionan algunos de los logros alcanzados: entrar a la cadena productiva con la producción de piña; moverse de producir materia prima a producir producto procesado ("upgrading" funcional); diversificación en la producción ("upgrading" de Proceso); libertad de asociación; capacitación; optimización de recursos naturales; y tratamiento de residuos, entre otros. La estrategia establece ejes y líneas estratégicas bajo un enfoque de desarrollo sostenible, determinando programas para cada uno de los ejes y responsables del seguimiento en cada uno.

Otra experiencia es la iniciativa de desarrollo económico local en la ciudad de Tandil, está ubicada en el sureste de la provincia de Buenos Aires y su problemática radica en que todavía es escaso el 
esfuerzo desplegado por las diversas instituciones en el logro de objetivos mancomunados, de acuerdo con la nueva institucionalidad, además es notorio la existencia de liderazgos dispersos, lo cual coincide con la falta de hegemonía institucional en la articulación de una estrategia común entre los sectores público y privado de la ciudad y su región; la lógica de acción de los distintos actores está aún regida mayoritariamente por sus opciones específicas, privilegiando los intereses particulares o sectoriales, para corregir lo cual es necesario incrementar la capacidad de análisis del proceso y promover una cultura integradora; se requiere, igualmente, una mayor articulación y coordinación entre las actividades de las diferentes instituciones; es notoria la escasa participación de los actores políticos en la iniciativa de desarrollo local; las instituciones educativas muestran, igualmente, cierta actitud pasiva y escaso dinamismo para relacionarse con el empresariado.

En este sentido para la iniciativa de desarrollo local contempla una visión compartida entre los diferentes actores con respecto a la necesidad de promover la iniciativa de desarrollo local, así como la articulación de las principales instituciones locales en el apoyo con un número considerable de actores involucrados y de resultados alcanzados sobre la base de un trabajo asociado orientado hacia la búsqueda de la negociación y la construcción de consensos a partir de intereses colectivo en base a una actitud receptiva a la reflexión y el aprendizaje colectivos entre los diferentes actores locales (Vazquez, 2001). 


\section{CAPÍTULO V.}

\section{PROCEDIMIENTO PARA FOMENTAR UNA CULTURA ORGANIZACIONAL AUTÓCTONA EN CHIMBORAZO}




\subsection{Caracterización de la provincia de Chimborazo}

La República del Ecuador, está situada al noreste de América del Sur, limita al norte con Colombia, al sur y este con Perú y al oeste con el Océano Pacífico, se caracteriza por ser un país pluricultural, megadiverso ${ }^{4}$ y multiétnico, donde las nacionalidades indígenas, están representadas por auto identificación étnica con el 7,0\% de la población total, los pueblos afro ecuatorianos con el 7,2\%, montubios con el 7,4\%, mestizos el 71,9\% y blancos el 6,1\%, según el Instituto Nacional de Estadísticas y Censos, INEC (2010).

Chimborazo es una de las 24 provincias del Ecuador, está ubicada en el centro del país, con una extensión jurisdiccional de 6.500,66 $\mathrm{Km}^{2}$ (Instituto Espacial Ecuatoriano IEE, 2013), políticamente se subdivide en 10 cantones y 45 parroquias rurales (INEC-2010).

Los diez cantones que conforman la provincia son: Guano, Penipe, Riobamba (cabecera cantonal), Colta, Chambo, Guamote, Pallatanga, Alausí, Cumanda y Chunchi, tal como se puede observar en la figura 8.

4 Existe diversidad cultural, gastronómica, vestimentas, tradiciones, religiones, regiones, clima, entre otros. 


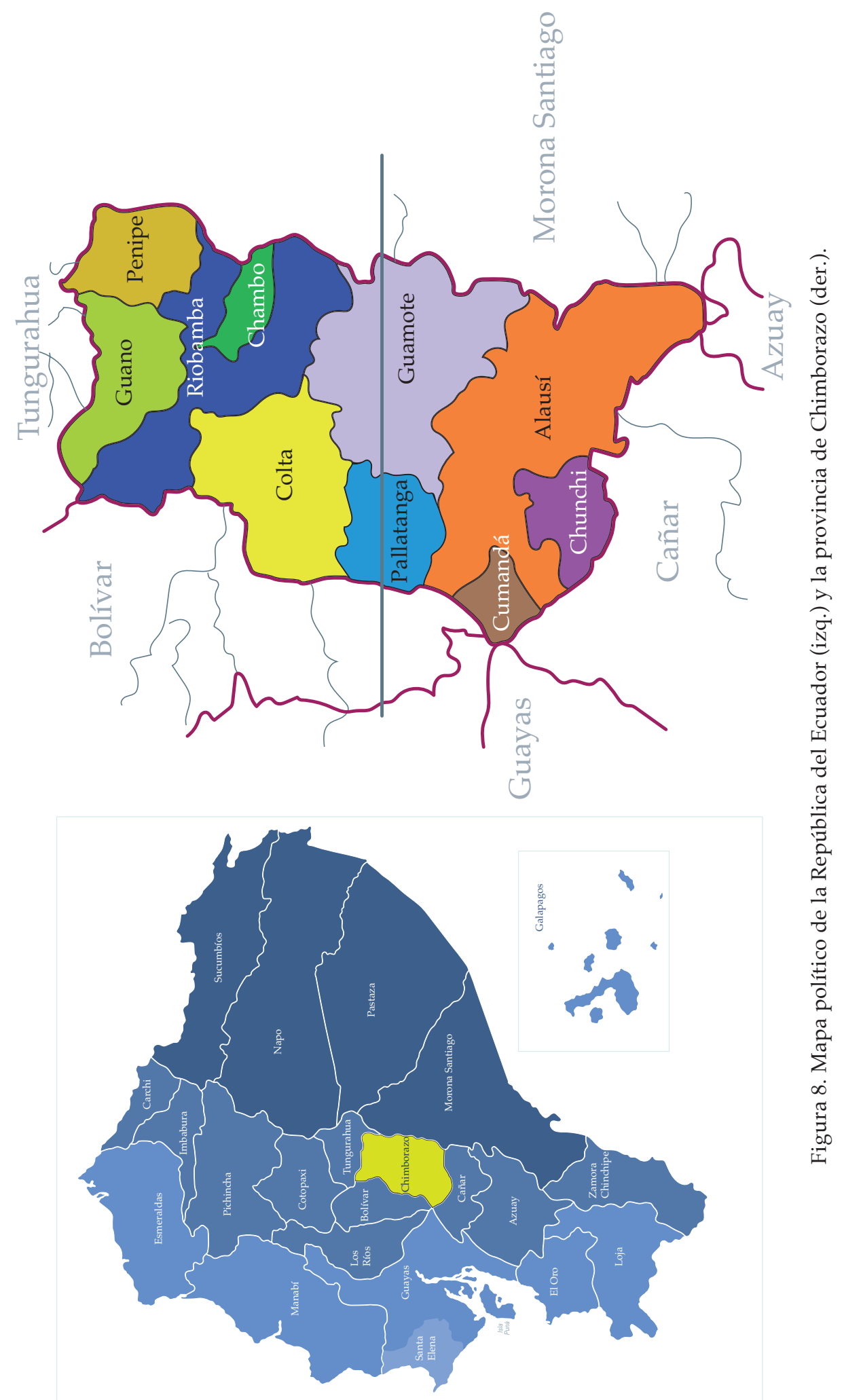


El rango altitudinal de la provincia de Chimborazo va desde los 135 m.s.n.m. a 6310 m.s.n.m. Limita al norte con la provincia de Tungurahua, al sur con la provincia de Cañar, al este, con la provincia de Morona Santiago y Cañar, y al Oeste con la provincia de Bolívar y Guayas.

Cada uno de los cantones que conforman la provincia de Chimborazo, tiene su respectiva jurisdicción a cargo del Gobierno Autónomo Descentralizado de cada territorio, pues según la Constitución de la República del Ecuador, indica que uno de los organismos que forman parte del sector público son "las entidades que integran el régimen autónomo descentralizado" ${ }^{5}$, que como su nombre lo dice, son instituciones públicas que gozan de autonomía política, administrativa y financiera.

La provincia de Chimborazo, tiene 501.584 habitantes (INEC, $2015)^{6}$, con una población económicamente activa (PEA) de 193.833 habitantes, que representan el $53,22 \%$ de la PEA provincial ${ }^{7}$. Dentro de sus actividades económicas prevalecen la agricultura, la comercialización y la artesanal. El idioma que predomina es el castellano, en el caso de los mestizos y el kichwa en las nacionalidades indígenas.

Una de las características relevantes de Chimborazo es su riqueza pluricultural y su diversidad étnica, donde el $58,41 \%$ de su población se autodetermina como mestiza, el 37,99\% indígena, el 2,18\% blanca, el $0,83 \%$ afroecuatoriana y el 0,59\% corresponde a otras etnias. Es importante mencionar que Chimborazo es la provincia con el más alto porcentaje de indígenas en el Ecuador, el cual asciende a 17,1\% (INEC, 2010).

Desde un enfoque étnico, el analfabetismo en Chimborazo es más notorio en indígenas. El mayor porcentaje se ubica en el sector rural, con el $21,13 \%$ de analfabetismo frente al 3,47\% del sector

5 Constitución de la República del Ecuador aprobada en Montecristi, 2008. Art. 225

6 Proyección INEC, 2015.

7 Plan de Desarrollo y Ordenamiento Territorial Provincial de Chimborazo, PDyOT GADPCH 2015 
urbano; inequidades adicionales que afectan al grupo étnico indígena de Chimborazo se relacionan con el grado de escolaridad de la población; pues, mientras que para la población rural el grado de escolaridad es de 5.39, para el sector urbano es de 11.73 (PDyOT GADPCH, 2015). Es por estas razones que las culturas con características de interculturalidad provenientes de los ancestros y de la pluriculturalidad nacional de un país pueden verse afectadas entorno a estas inequidades sociales.

En este sentido según Aguirre (1968), los indígenas son culturas y sociedades subyugadas que, como directa consecuencia del desarrollo colonial, han quedado situadas en una posición de subordinación respecto a la cultura y la sociedad nacionales y que esta situación de sometimiento influye considerablemente en la naturaleza y la forma de sus características culturales.

Las nacionalidades indígenas, históricamente, han sido las más explotadas, discriminadas y excluidas, derivadas de viejas prácticas coloniales de clasificación social en función del color de la piel, la lengua, la cosmovisión, las creencias religiosas, las costumbres y formas de organización. Prácticas que, "desde el poder de los conquistadores, impuso como creencia de que aquello originado en Europa está llamado a constituirse en el referente único y central de organización de la vida social, política, económica, religiosa, cultural." (Agenda Nacional para la Igualdad de Nacionalidades y Pueblos (ANINP, 2013:7); esta es una perspectiva que hizo de la diferencia una fuente de jerarquización, explotación y dominio de una pequeña élite blanco-europea por sobre las nacionalidades indígenas en el país.

La discriminación y exclusión social étnico-cultural en el Ecuador data desde sus orígenes coloniales; es decir, conlleva una deuda social respecto a la igualdad y discriminación social y cultural de las nacionalidades y pueblos. 
Frente a ese panorama histórico, Ecuador vive un proceso de transformación que incluye la demanda aún pendiente y en construcción, de refundar el Estado: de superar la matriz etnocéntrica y monocultural, para dar paso a una nueva matriz intercultural y plurinacional (ANINP, 2013, PNBV, 2013).

Esta transformación implica tiempo, es incluyente y se centra en la conservación y rescate cultural de las tradiciones y principios indígenas que aportan a la riqueza pluricultural del país y que se constituyen como patrimonio del mismo, para el efecto es necesario comprender la necesidad de que en el Ecuador exista un trabajo articulado entre el sector público, privado y educativo, para disminuir y si es posible eliminar la brecha de inequidad social existente.

En el transcurso de los últimos años, lo que se evidencia es la complejidad de un proceso relacionado a la incorporación de aspectos organizacionales y culturales en la estructura del Estado, y en las limitaciones que la institucionalidad monocultural y etnocéntrica posee, para acoger, dinamizar y fortalecer las dinámicas de autogobierno, es decir, la capacidad estatal de reconocer y respetar características y diseños institucionales que responden a otras lógicas, cosmovisiones y prácticas, tanto en la forma de planificar, ejecutar programas como de organizar y gestionar.

En este sentido, el Estado ha implementado políticas públicas y lineamientos estratégicos de inclusión para los sectores vulnerables del país, entre ellos, las nacionalidades y pueblos indígenas.

Entre las políticas implementadas se aborda el promover el respeto y reconocimiento de las nacionalidades para disminuir los estereotipos negativos fortaleciendo el derecho a una comunicación libre en los idiomas ancestrales, para potenciar el desarrollo cultural y la construcción de la plurinacionalidad; facilitando el aprendizaje de los funcionarios públicos para que conozcan el kichwa, para la prestación de servicios con eficiencia y eficacia, en las oficinas y en 
la ejecución de actividades en los territorios de las nacionalidades y pueblos.

Otra de las políticas fundamentales establecidas, es promover la incorporación de personal de pueblos y nacionalidades dentro de la planta profesional de las instituciones públicas del Gobierno Central y Gobiernos Autónomos Descentralizados, mediante la asignación de puntaje adicional en los sistemas de meritocracia (ANINP, 2013). Una de las características fundamentales de los GAD Municipales de la provincia de Chimborazo, radica en la interculturalidad existente entre sus funcionarios; fortaleza que se ve afectada por el choque de culturas entre mestizos e indígenas, lo cual debilita notablemente a su cultura organizacional, evidenciándose inequidades y desigualdades en el trato entre trabajadores.

Porello, lograr la equidad eigualdad para los pueblos y nacionalidades indígenas en Ecuador, involucra un trabajo concientizado de toda la población que tomara mucho tiempo, sin embargo, es necesario que se trabaje en ello a través de la investigación y socialización de resultados.

Es importante mencionar que los Gobiernos Autónomos Descentralizados, tienen autonomía administrativa y financiera, particular que le da la potestad a la máxima autoridad de administrar a su institución como creyere conveniente, amparándose siempre dentro del marco de la ley en lo referente al manejo de los tangibles, sin embargo, los intangibles muchas de las veces no son tomadas en cuenta, especialmente en organizaciones con características interculturales y es justamente aquí donde se evidencia una débil Cultura Organizacional sin identidad, que no contribuye a mejorar la gestión de la organización.

Por estas razones los autores consideran necesario una propuesta que involucre acciones para fomentar una Cultura Organizacional Autóctona para los GAD con características de interculturalidad 
presentes. Sin embargo, se cree en la imperante necesidad de conocer la forma de organización, costumbres, tradiciones, comportamientos de los indígenas de Chimborazo pertenecientes a la nacionalidad Puruhá y rescatar los aspectos positivos que pueden ser aplicados en una organización pública a fin de mejorar su gestión y promover el rescate intercultural y la identidad plurinacional.

Los indígenas que pertenecen a la provincia de Chimborazo, son descendientes de la nacionalidad Puruhá, que son "personas poderosas que vivian en los valles de lugares sagrados entre montañas y nevados" (Janeta, 2015:24). En la actualidad, aún se conservan costumbres, tradiciones, vestuario, formas de vivencia, comportamiento, organización, etc., de esta cultura tan poderosa, y que hoy en día forman parte de su cosmovisión indígena.

El idioma propio de los Puruhaes era el Puruhuay, fue utilizado antes de la conquista Inca y de los Españoles; actualmente en las comunidades del cantón Colta con rezagos puruhaes o propiamente puruhaes hablan el idioma kichwa en especial en la población adulta, es importante indicar que algunos son bilingües, es decir hablan kichwa y castellano, este último, específicamente en conversaciones con mestizos y blancos, sin embargo, en la juventud se identifica claramente una pérdida de identidad que avanza paulatinamente de la mano con el desarrollo, la globalización y la brecha de inequidad social existente.

Entre sus ritos y creencias se pueden resaltar la adoración a las lagunas y vertientes, consideradas como lugares de rituales míticos, de energización y purificación que se realizaban en los lugares que hoy se denominan Colta, Guamote, Riobamba, Chambo y Parte de Alausí; en lo que respecta a la comunicación, utilizaban churos, bocinas, gritos, señales, signos, símbolos, gráficos y colores; sus actividades principales eran la agricultura, ganadería, cerámica y medicina natural, las cuales, en la actualidad se han mantenido a excepción de la cerámica, la cual se practica muy poco. 
Su sistema político era una monarquía federativa ${ }^{8}$, aunque en casos graves relativos al bienestar general, todos los jefes se juntaban a deliberar en asamblea común, presidida por el curaca mayor. "Tenían un gobierno bien organizado y leyes que regulaban la sucesión de poder. La monarquía era hereditaria y sucedía siempre el hijo varón" (Freire, 2005:11). Hoy en día el sistema político y democrático, en todo el Ecuador, e involucra el derecho y la obligatoriedad de todas las etnias a elegir y ser elegidos.

Con respecto al poder, prevalecen los aspectos relacionados con la sabiduría ancestral, propios de los Puruháes, como: sensitivos, perceptivos, espirituales del talento del individuo en convivencia armónica con el cosmos de la Pachamama", es decir "el ser laborioso en el trabajo y la capacidad de relacionar, así mismo con los elementos divinos de la madre naturaleza como el Yaku, Wayra, Allpa, Nina, $\underline{\text { Inti, Killa, Kuyllur }}{ }^{10 \prime \prime}$ (Janeta, 2015).

En el aspecto social, el poder está estrechamente relacionado con el servicio a la comunidad, es decir la autoridad electa o cualquier líder social, es más poderoso cuando sirve mejor a su pueblo, utilizando la sabiduría para promover la convivencia social y la unión de la familia. En base a los legados de la cosmovisión Puruhá, sus descendientes en la actualidad se manejan en base a principios: reciprocidad, complementariedad, igualdad, armonía, enseñanza, minga, apropiación de valores, identidad cultural (Janeta, 2015, Yuquilema, 2016).

La minga es otro principio indígena que representa el trabajo en equipo, la organización, que parte desde el núcleo de la familia hacia la comunidad y los pueblos indígenas que comparten los mismos principios y valores en beneficio de la colectividad. Con respecto a la apropiación de valores, el principio de la enseñanza, juega un

8 Donde cada curaca (jefe de tribu o comunidad) gobernaba independientemente su propio pueblo.

9 Naturaleza

10 Aire, agua, tierra, fuego, sol, luna y estrellas (respectivamente) 
papel preponderante, pues son los padres y abuelos los encargados de transmitir los valores principales de la nacionalidad Puruhá, y que hoy en día norman el comportamiento en las comunidades indígenas, además de que, durante años, su aplicación en la vida diaria ha generado grandes ejemplos de organización comunitaria.

Las comunidades indígenas puruháes, practican los siguientes valores: Mana Llulla, Mana Hillu, Mana Mitza, Mana Shimilla, Mana Washa Rimak que significan: no ser mentiroso, no ser goloso, no ser egoísta, no ser solo lengua, no ser criticón, murmurón ${ }^{11}$, respectivamente (Janeta, 2015).

La identidad cultural es otro principio de la nacionalidad Puruhá y se refleja en la vestimenta, festejos, costumbres, ritos, creencias, manejo de instrumentos autóctonos, etc., que diferencian a cada nacionalidad llenando de valor y orgullo a sus representantes.

Cuando se habla de identidad, en la cultura Puruhá se entiende el respeto a la persona, familia y sobre todo al territorio de origen conocido como Llakta, así también como la valoración de la sabiduría ancestral y el conocimiento de los mayores. El empoderamiento de la identidad, debe nacer del Shunku que significa corazón (Freire, 2005; Alvarado y Pérez, 2009; Janeta, 2015; Yuquilema, 2016).

La nacionalidad de los Puruháes, contempla aún grandes riquezas que, a pesar de la conquista inca y española, no se han perdido aún, sin embargo, factores como la incidencia del capitalismo en el pensamiento Runa (humano), carcomen su vivencia social y cultual en el transcurso del tiempo.

Los principios y valores con beneficios colectivos, se van perdiendo, al igual que la juventud pierde el interés por conocer, conservar y

11 En gran parte de la literatura indígena, existen tres principios generales que se han mantenido en la actualidad y que son relacionados y aparentemente representan a la cultura indígena, AMA SHUWA. AMA LLULLA y AMA KILLA (no robar, no mentir, no ser ocioso). Sin embargo, estos principios, fueron impuestos por los colonizadores españoles para que el "indio obedezca a su patrón". 
transmitir la sabiduría Puruhá, este fenómeno es global, por esta razón, los autores de esta investigación considera que hay mucho que aprender y rescatar de los pueblos y nacionalidades indígenas: sus valores, principios, incentivos, trabajo en equipo, formas de comportamiento y de organización, liderazgo, solidaridad, responsabilidad, respeto, etc., aspectos positivos que aplicados a organizaciones donde se denota una interculturalidad dada por la presencia de indígenas y mestizos , podrían mejorar notablemente la gestión de la misma y los resultados de los objetivos que persigue. Por estas razones, se cree firmemente en la necesidad de diseñar una herramienta que explique claramente los pasos a seguir para plantear acciones para fomentar una Cultura Organizacional Autóctona en aras de una mejor gestión para los Gobiernos Autónomos Descentralizados Municipales de la provincia de Chimborazo en Ecuador.

\subsection{Procedimiento para Fomentar una Cultura Organizacional Autóctona en los GAD Municipales de la provincia de Chimborazo.}

Para el diseño del procedimiento para omentar una Cultura Organizacional Autóctona, FOCOA ${ }^{12}$, se considera los criterios derivados de las corrientes del pensamiento teórico de autores como: Shein, 1990; Denison, 1990; Mohrman y Cummins, 1991; Nemetz y Christensen, 1996; Pearce y Osmond, 1996; Vargas, 2007; Alles, 2007; Chiavenato, 2009; Franklin, 2009; Robbins y Judge, 2013; Urdaneta 2014 y Matamala 2015, en el sentido de que, es posible fomentar una Cultura Organizacional que propicie un cambio en beneficio de la institución y de los funcionarios públicos, mejorando su gestión.

Es así que, la existencia del problema científico en esta investigación, crea la necesidad de realizar una propuesta, que radica en el diseño del procedimiento FOCOA, el cual, se constituye en la novedad científica en esta tesis, donde los autores, pretende evidenciar la solución al

12 Denominación de los autores de la investigación, en base al objetivo que se persigue: Fomentar una Cultura Organizacional Autóctona. 
problema científico expuesto, tomando como punto de partida la Cultura Organizacional existente para aplicar el procedimiento y como resultado fomentar una Cultura Organizacional Autóctona que mejore la gestión, siendo esta, la cultura organizacional deseada.

Por otro lado, se aborda como eje transversal a la interculturalidad, ya que el procedimiento se diseña para los Gobiernos Autónomos Descentralizados Municipales de la provincia de Chimborazo, caracterizados por la diversidad étnica existente entre sus funcionarios públicos, es decir la presencia de personas mestizas e indígenas; estos últimos, descendientes de la Nacionalidad Puruhá, cuyos valores, principios y formas de organización y comportamientos se pretende rescatar, fomentando una Cultura Organizacional Autóctona que mejore la gestión institucional.

Como se evidencia en la figura 9, el procedimiento FOCOA se desarrolla en base a cinco etapas y sus pasos, mediante la aplicación de técnicas y herramientas. 


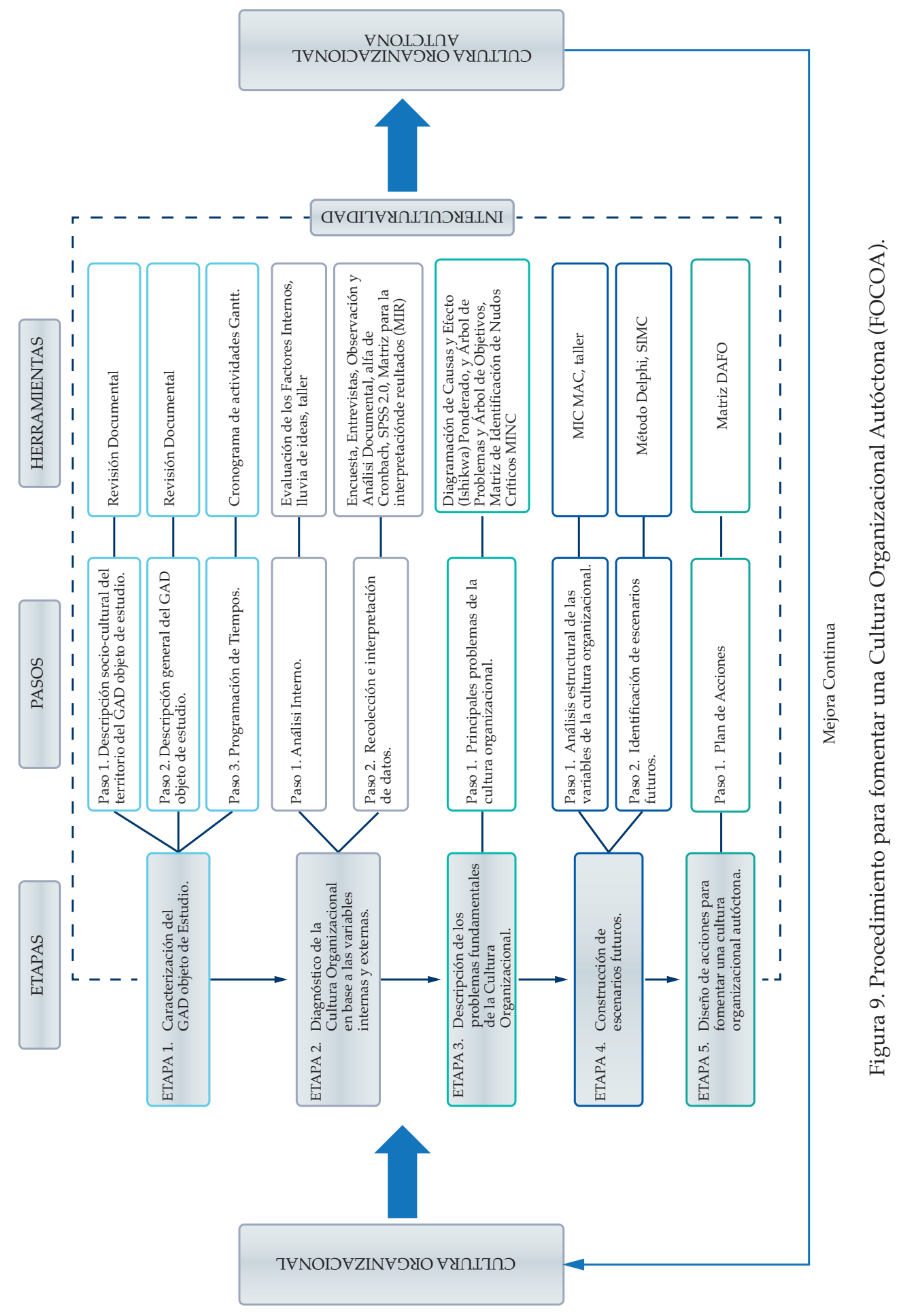


Para el efecto, se plantea considerar en cada una de sus etapas, la diversidad étnica o interculturalidad entre los funcionarios públicos; desde la caracterización del territorio, y la del propio GAD Municipal, para luego efectuar el diagnóstico en base a las variables externas e internas de la cultura organizacional, el cual permite identificar los principales problemas de la cultura organizacional, con la finalidad de diseñar acciones que permitan fomentar una Cultura Organizacional Autóctona en aras de una mejor gestión.

Este procedimiento, asume el enfoque sistémico, que según Bueno, et al. (1991), Koontz, et al. (2012), contempla al objeto de estudio como un todo unitario en efectiva relación con el entorno.

Se utiliza el paradigma mixto ya que se emplean técnicas cuantitativas y cualitativas con un enfoque holístico para el análisis de datos (Hernández, 2010).

FOCOA es un procedimiento con un enfoque intercultural, que se sugiere aplicar a las autoridades de los Gobiernos Autónomos Descentralizados Municipales de Chimborazo, cada cuatro años, ya que este es el periodo en que por elección popular se mantienen estas dignidades en su cargo. Además, se debe considerar como premisas fundamentales para su ejecución, el compromiso de la alta dirección y de los funcionarios públicos de la organización, pues se recomienda que el procedimiento FOCOA sea realizado por un equipo interdisciplinario conformado por un coordinador y por funcionarios de las áreas de talento humano, planificación y calidad, delegados por el alcalde.

Es importante también, mencionar que el procedimiento FOCOA se basa en el principio de mejora continua, pues se cree firmemente en la posibilidad de alcanzar científicamente un perfeccionamiento que proyecte y beneficie a la organización, según Harrington (1997), mejorar continuamente un proceso o procedimiento significa cambiarlo para hacerlo más efectivo, eficiente y adaptable. 
¿Qué cambiar? y ¿Cómo cambiar?, depende de la voluntad de las autoridades de la organización. Según Chiavenato (2009); esta filosofía favorece el trabajo en equipo y la participación e inclusión de los funcionarios públicos y tiene como objetivo, el perfeccionamiento continuo y sistemático de la organización y de las personas involucradas a fin de satisfacer al ciudadano.

\subsection{Caso de estudio: Gobierno Autónomo Descentralizado Municipal del cantón Colta.}

El procedimiento FOCOA puede ser aplicado en todos los Gobiernos Autónomos Descentralizados Municipales de la provincia de Chimborazo que cuenten con características interculturales entre sus funcionarios, provenientes de las nacionalidades Puruháes, reconocidos por sus valores, principios y formas de comportamiento. Por su parte, el procedimiento se aplica al GAD Municipal del cantón Colta, el cual ha sido identificado por los autores como objeto de estudio en esta investigación.

Etapa 1. Caracterización del Gobierno Autónomo Descentralizado Municipal del cantón Colta

Paso 1. Descripción socio-cultural del cantón Colta de la provincia de Chimborazo

Colta proviene de la lengua kichwa "Kulta" que significa "pato". Se cree también que dada la conquista Inca, el vocablo Colta puede descender de Perú, que actualmente es uno de los diez distritos que conforman la provincia de Páucar del Sara Sara, ubicada al sur del departamento de Ayacucho, creado en el año 1767, señalándose su ubicación en la ladera del cerro conocido como "Collota", vocablo que proviene la lengua indígena, que quiere decir piedra redonda que sirve para moler, complemento del mortero; también significa un barranco entre dos laderas o pendientes. ${ }^{13} \mathrm{El}$ asentamiento que

13 Gobierno Autónomo Descentralizado Municipal del cantón Colta (2013). Plan de Desarrollo y Ordenamiento Territorial 2014-2030. 
hoy constituye el cantón Colta fue 500 años antes el pre-hispánico Liribamba centro estratégico del Imperio Puruhá. ${ }^{14}$

El cantón Colta se encuentra ubicado en la parte Noroccidental de la provincia de Chimborazo, a $20 \mathrm{Km}$. de la ciudad de Riobamba y a $206 \mathrm{Km}$. de Quito la capital de la República del Ecuador. Está limitada al norte por el cantón Riobamba, con sus parroquias San Juan y Licán, al sur con los cantones Pallatanga y Guamote, al este con el cantón Riobamba con sus parroquias Cacha, Punín Flores y la parroquia Cebadas del cantón Guamote, al oeste con el cantón Guaranda ${ }^{15}$ tal como se evidencia en la figura 10.

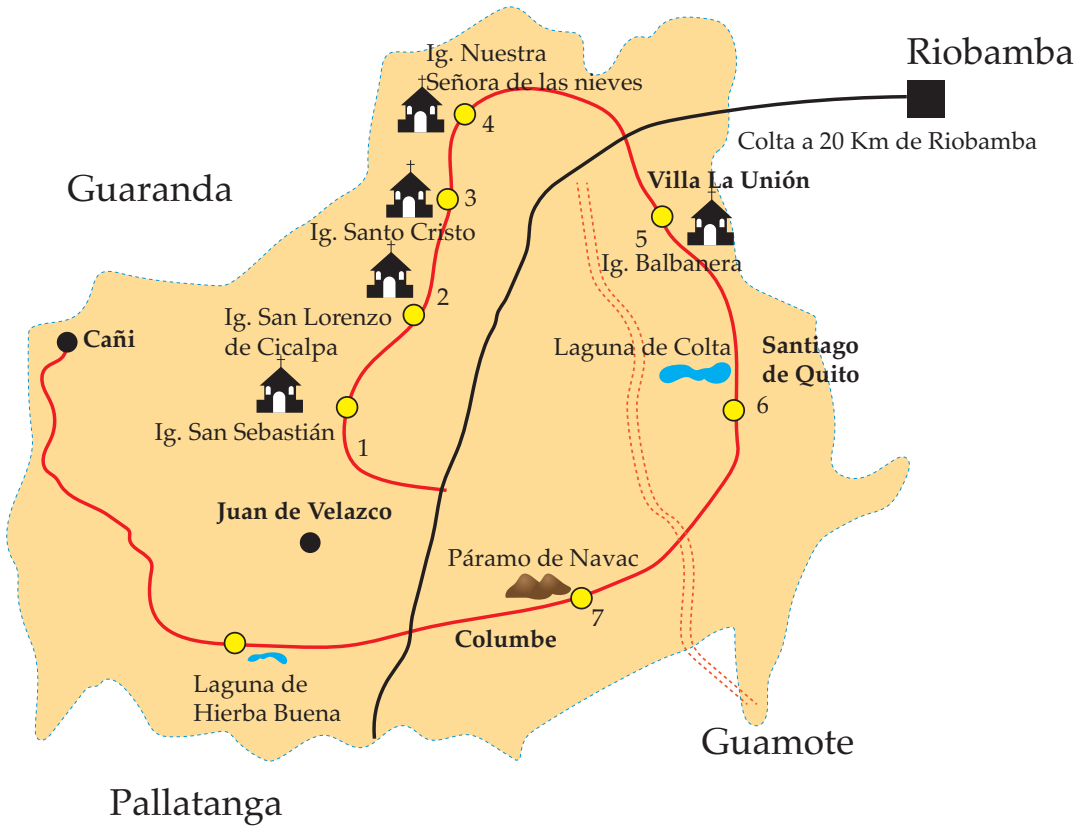

Figura 10. Mapa del cantón Colta.

Fuente: Recuperado de http:/ / coltatour.galeon.com/principal.html.

14 Ministerio de Defensa Nacional, Instituto Espacial Ecuatoriano, Secretaría Nacional de Planificación y Desarrollo, Ministerio de Agricultura, Ganadería, Acuacultura y Pesca. 2013. "Memoria Técnica del cantón Colta". Proyecto: Generación de Geoinformación para la gestión del territorio a nivel nacional escala 1: 25000. Ecuador

15 ESTRELLA, Alonso.2011. “Colta capital de la nación Puruhá". Oficina de Información Turística de Colta. Ecuador 
Colta se constituye como cantón de la provincia de Chimborazo el 27 de febrero de 1884, promulgado en el registro oficial el 2 de agosto del mismo año; tiene una extensión territorial de 83.382,19 (Ha) y un rango altitudinal de 2600 - 4300 msnm. (PDyOT cantón Colta, 2014).

El idioma predominante es el kichwa especialmente entre las mujeres, gran parte de los jóvenes y adultos son bilingües y hablan también el Castellano.

Tiene una población de 44.971 habitantes (INEC, 2010), de los cuales 2.313 pertenece a la zona urbana y 42.658 a la zona rural; con respecto al género, el 48,12\% de su población son hombres y el $51,88 \%$ son mujeres. En el cantón Colta, el $87 \%$ de sus habitantes se autodetermina como indígenas, el $12 \%$ mestizos y el 1\% corresponde a otras razas o etnias (blancos, afrodecendientes, otros. ${ }^{16}$.

Los indígenas del cantón Colta son descendientes de la Nacionalidad Puruhá y se caracterizan por conservar valores y principios que norman su forma de vida en la familia y la comunidad con respecto al trabajo colectivo y su convivencia día a día; tratando de cumplir y respetar la palabra dada, que es la base para su comportamiento; entre los principios se tiene: reciprocidad, complementariedad, igualdad, armonía, enseñanza, minga, apropiación de valores y respeto a la identidad cultural (Janeta, 2015, Yuquilema, 2016); entre los valores se destacan: Mana Llulla, Mana Hillu, Mana Mitza, Mana Shimilla, Mana Washa Rimak que significan: no ser mentiroso, no ser goloso, no ser egoísta, no ser solo lengua, no ser criticón, murmurón ${ }^{17}$, respectivamente (Janeta, 2015).

16 El término mestizo fue aplicado por el Imperio español en el siglo XVI, para denominar a una de las "castas" o "cruzas" que integraban la estratificación social de tipo racista impuesta en sus colonias en América. Ecuador es un país pluricultural y multiétnico. En el Censo de Población y Vivienda de 2010 hubo un proceso de auto-identificación1 de acuerdo a las costumbres y tradiciones de los ciudadanos, los resultados del censo determinaron que los ciudadanos del Ecuador se auto identifican de la siguiente manera: (71,9\%) Mestizos, (7,2\%) Afroamerinos, (7,1\%) Indígenas, (7\%) Montubios, $(6,1 \%)$ Blancos y $(0,3 \%)$ Otros. El término mestizo en Ecuador hace referencia a la unión de la raza blanca con la indígena.

17 En gran parte de la literatura indígena, existen tres principios generales que se han mantenido en la actualidad y que son relacionados y representan a la cultura Puruhá 
La población económicamente activa (PEA) del cantón Colta, asciende a 22005, de los cuales, en la rama económica de agricultura, ganadería concentra al 77,00\% de la población, seguido del comercio al por mayor y al por menor 8,08\%; Enseñanza 3,72\%, Construcción $3.41 \%$ y otras actividades de servicios comunitarios, sociales y personales el 7,79\% (PDyOT cantón Colta, 2014).

La tasa de asistencia de Educación Superior es de 14,98, además la tasa analfabetismo es de 52,61, constituyéndose este uno de los grandes problemas que evitan que se dinamice la economía de la localidad, ya que hay muy pocos profesionales dentro del cantón y algunos de estos migran a la ciudad; ocasionando que las organizaciones se vean en la necesidad de contratar personal de otras localidades, etnias, culturas, tradiciones, etc.

Colta se caracteriza por su vestimenta, tradiciones y riqueza patrimonial cultural, pues en el cantón se encuentra la primera iglesia católica del Ecuador con 479 años de su fundación.

Paso 2. Descripción general del Gobierno Autónomo Descentralizado Municipal del cantón Colta.

El Ecuador es un estado constitucional de derechos, social, democrático, soberano, independiente, intercultural, plurinacional y laico, cuyo deber primordial es planificar el desarrollo nacional, promover el desarrollo sustentable, redistribuir la riqueza, etc. para acceder al buen vivir. ${ }^{18}$

Dentro de esta planificación, se encuentra, la asignación de competencias exclusivas para el Gobierno Central y para los Gobiernos Autónomos Descentralizados (GAD) del país, en este

indígena, AMA SHUWA. AMA LLULLA y AMA KILLA (no robar, no mentir, no ser ocioso). Sin embargo, estos principios, fueron escogidos por los colonizadores españoles para que el "indio obedezca a su patrón".

18 Asamblea Nacional Constituyente (2008). Constitución de la República del Ecuador. Art. 1, Art. 2, 
sentido cada circunscripción territorial tiene un GAD para la promoción del desarrollo y la garantía del buen vivir, a través del ejercicio de sus competencias. Está integrado por ciudadanos electos democráticamente quienes ejercen su representación política (COOTAD, 2012).

Los Gobiernos Autónomos Descentralizados son instituciones públicas que gozan "de autonomía política, administrativa y financiera, y están regidos por los principios de solidaridad, subsidiariedad, equidad, interterritorial, integración y participación ciudadana" (Constitución de la República del Ecuador, Art. 238).

El objeto caso de estudio de la presente investigación es el Gobierno Autónomo Descentralizado Municipal del cantón Colta.

El Gobierno Autónomo Descentralizado Municipal del cantón Colta, es una organización con "personería jurídica de derecho público, con autonomía política, administrativa y financiera" ${ }^{19}$, cuya ejecución de competencias le atribuyen en beneficio del cantón Colta de la provincia de Chimborazo del Ecuador, toda vez que una de sus funciones principales es promover el desarrollo sustentable de su circunscripción territorial cantonal, para garantizar la realización del buen vivir a través de la implementación de políticas públicas cantonales, en el marco de sus competencias constitucionales y legales.

El GAD Municipal del cantón Colta, fue creado mediante Decreto Legislativo el 27 de febrero de 1.884; a continuación se mencionan las principales leyes que lo regulan y que están relacionadas con el tema de investigación: Constitución de la República del Ecuador (2008), Código Orgánico de Organización Territorial, Autonomía y Descentralización (COOTAD), ley Orgánica de Servicio Público (LOSEP) y su Reglamento, Código de Trabajo, Plan Nacional del Buen Vivir, Normas de Control Interno para las entidades,

19 Ministerio de Coordinación de la Política y Gobiernos Autónomos Descentralizados. “Art. 53 y Art. 54 literal a) Código Orgánico de Organización Territorial, Autonomía y Descentralización". Primera Edición. Quito - Ecuador. 2011. 
organismos del sector público, y personas jurídicas de derecho privado que dispongan de recursos públicos, expedidas por la Contraloría General del Estado y Ordenanzas Municipales

La Misión del GAD Municipal del cantón de Colta es "trabajar en el ámbito de las competencias exclusivas y concurrentes, incrementado la eficiencia de la gestión institucional, a través del mejoramiento continuo de sus procesos; logrando calidad, transparencia y calidez de los servicios municipales, con talento humano competente, alcanzando la equidad e inclusión social de la población del cantón Colta" y su Visión radica en que "el Gobierno Autónomo Descentralizado Municipal del cantón Colta es en el año 2020 un referente a nivel regional y nacional, con eficacia, eficiencia y efectividad en la gestión institucional, que ha invertido en el desarrollo social, cultural y económico, ha reducido los índices de las necesidades básicas insatisfechas, su población está orgulloso de su cultura y su hábitat, en busca del Sumak Kawsay" (PDyOT cantón Colta, 2014).

El GAD Municipal del cantón Colta, cuenta con 186 funcionarios públicos de los cuales, 103 se auto determinan como indígenas, y 83 como mestizos; con respecto a la situación laboral 78 son funcionarios que pertenecen al código de trabajo con nombramiento, 30 administrativos tienen nombramiento, ${ }^{20} 10$ son cargos directivos y pueden ser removidos cuando la máxima autoridad lo creyere conveniente, y 56 funcionarios tienen contrato ocasional y son elegidos en base a los requerimientos institucionales.

Las autoridades del GAD, considera que si se aspira cambiar la Cultura Organizacional de los servidores públicos municipales para que adopten nuevos principios, valores y comportamientos, el medio para conseguirlo es rediseñando y cambiando su estructura organizacional (PDyOT cantón Colta, 2014); sin embargo, dentro de este marco no se toma en cuenta el adecuado manejo de las variables que se relacionan con la Cultura Organizacional tales como leyes,

20 Estabilidad laboral 
globalización, plurinacionalidad, liderazgo, comportamiento organizacional, clima organizacional, valores, motivación, comunicación, trabajo en equipo y ritos, creencias y tradiciones.

En conformidad al Art. 227 de la Constitución de la República del Ecuador "La administración pública constituye un servicio a la colectividad que se rige por los principios de eficacia, eficiencia, calidad, jerarquía, desconcentración, descentralización, coordinación, participación, planificación, transparencia y evaluación" ${ }^{21}$, el GAD Municipal del cantón de Colta continuamente ha realizado actividades de capacitación y motivación dirigidas a sus funcionarios públicos con la finalidad de dar cumplimiento a lo estipulado en el artículo citado; sin embargo no ha logrado mejorar su gestión, pues los procesos no se cumplen a cabalidad, además los conflictos entre el personal son continuos, y sobre todo el personal no se adapta a los frecuentes cambios y los valores culturales compartidos por los funcionarios públicos se definen por presunciones básicas y la persistencia del pensamiento individual de los servidores. Además de que existen factores que pueden afectar al cumplimiento de la misión y visión del GAD Municipal del cantón Colta como: la desigualdad étnica que existe en el país ${ }^{22}$, el analfabetismo, la discriminación, etc.

Por las razones expuestas se considera que el cambio institucional radica en el fomento de una Cultura Organizacional Autóctona en el GAD Municipal del cantón Colta, donde se rescaten los valores y principios que prevalecen en las nacionalidades puruháes, impulsando un sentido de pertenencia para mejorar la gestión en la institución propiciando el desempeño y satisfacción laboral con una orientación firme al cumplimiento de los objetivos y metas institucionales.

21 Constitución de la República del Ecuador aprobada en Montecristi, 2008.

22 Según la Secretaría Nacional de Planificación, SENPLADES, la situación de discriminación de las comunidades, nacionalidades y pueblos indígenas, afroecuatorianos y montubios se identifica aún en la sociedad ecuatoriana. El debate sobre la construcción del Estado plurinacional e intercultural y sus implicaciones, se encuentra en desarrollo tanto al interior de la Función Ejecutiva, como en las organizaciones de pueblos y nacionalidades y en la sociedad en general. No han existido, por lo tanto, avances significativos en una transformación de la institucionalidad plurinacional e intercultural que se expresen en progresos institucionales o normativos específicos. (SENPLADES, 2013) 
Paso 3. Programación de tiempos

Para el desarrollo de este paso, previa delegación del alcalde de la institución, se coordina con el director administrativo con la finalidad de definir los periodos en los que se desarrollan cada una de las etapas del procedimiento FOCOA en la organización, para el efecto se utilizó el cronograma de Gantt (Bernal, 2010), el cual se ha cumplido con exactitud con la finalidad de evitar retrasos en la investigación y culmina con la entrega y socialización de un ejemplar para ser aplicado en el GAD Municipal del cantón Colta.

Etapa 2. Diagnóstico de la Cultura Organizacional en base a las variables internas y externas.

Paso 1. Análisis interno

Para el desarrollo de este paso se realiza un taller para evaluar los factores internos organizacionales (debilidades y fortalezas) implementado la técnica de lluvia de ideas con la participación de sesenta funcionarios públicos de nivel jerárquico operativo con la finalidad de propiciar un ambiente de confianza y recabar la mayor información posible, que posibilite la construcción de los cuestionarios, utilizando también los criterios de los autores de la bibliografía revisada. Al término del taller, se concluye lo siguiente: Resultado de Debilidades y Fortalezas

Debilidades

1. Mal clima laboral

2. Falta de colaboración entre compañeros, no se trabaja en equipo.

3. Reuniones laborales y trabajo fuera de horario laboral sin compensación económica.

4. Discriminación racial.

5. Falta de capacitación.

6. Mala atención a la ciudadanía y demora en los trámites.

7. Edificio y oficinas en mal estado. 
8. Mala comunicación entre compañeros.

9. No hay ningún tipo de motivación para los funcionarios públicos.

10. No se cumplen las leyes, por desconocimiento, falta de gestión $\mathrm{o}$ ineficiencia.

11. Llamados de atención en público en gabinetes.

12. División entre personal de nombramiento y contrato.

13. Contratación de funcionarios que no pertenecen a Colta.

14. No se toma en cuenta a los funcionarios para tomar decisiones.

Fortalezas

1. Existe puntualidad.

2. Liderazgo con experiencia y participación.

3. Técnicos para dar atención a toda la ciudadanía.

4. Adquisición de paquetes informáticos, maquinaria y tecnología.

5. Cuenta con técnicos profesionales.

6. Realización de gabinetes cada quince días con las autoridades y funcionarios públicos.

7. El GAD tiene una misión y visión institucional.

8. El GAD cuenta con un Plan de Desarrollo y Ordenamiento Territorial actualizado.

Paso 2. Recolección e interpretación de datos

La población y muestra con las que se trabajó en esta investigación, a criterio de los autores, involucra dos casos tal como se refleja en tabla 8 .

Tabla 8. Población y Muestra.

\begin{tabular}{|l|l|l|}
\hline Descripción & $\begin{array}{l}\text { Caso 1. Funcionarios } \\
\text { del GAD }\end{array}$ & $\begin{array}{l}\text { Caso 2. Población económicamente } \\
\text { activa (PEA) de Colta }\end{array}$ \\
\hline Población & 186 & 22.005 \\
\hline Muestra & 125 & 378 \\
\hline
\end{tabular}


En este sentido se procede a aplicar las encuestas en base al cuestionario modelo sin ninguna modificación, a 125 funcionarios públicos del GAD Municipal del cantón Colta, y a 378 ciudadanos del cantón, estimados dentro de la PEA; para el efecto se considera los resultados del análisis de factores internos organizacionales realizado en el paso anterior y los criterios expuestos por 45 autores con respecto a las variables externas e internas de la Cultura Organizacional con las que se trabaja en esta investigación.

El programa estadístico en ordenador utilizado, fue el Statistical Package for the Social Sciences (paquete estadístico para las ciencias sociales) SPSS 22.0, en el cual se ingresaron los datos recolectados para ser explorados, analizados y visualizados descriptivamente por variable.

La fiabilidad del cuestionario utilizado (anexo 1) para la recolección de datos de los funcionarios del GAD, está representada en un 0.887 de acuerdo al Alfa de Cronbach, mientras que la fiabilidad del cuestionario aplicado a la ciudadanía está representada por 0.78 , estos resultados demuestran buena consistencia ya que se encuentra dentro del rango de aceptación dado entre 0.70 y 0.9 (Castañeda, Cabrera, Navarro y Vries, 2010, Saravia, 2015).

Luego delasencuestas, se realizanlasentrevistas estructuradas (anexo 2) a: cinco concejales, siete directores y tres jefes departamentales, así también como una entrevista abierta al alcalde del GAD.

Otra técnica aplicada fue la observación semiestructurada, para el efecto los autores utilizan una guía para el levantamiento de información (anexo 3), en base a cada una de las variables externas e internas de la Cultura Organizacional. Además, coteja la información implementado también la técnica de análisis documental.

Los resultados generales de dicha triangulación, se reflejan a continuación: 
1. No se considera las opiniones de los funcionarios en la toma de decisiones.

2. Las condiciones de la infraestructura son deficientes e insuficientes para el total de funcionarios de la municipalidad.

3. Se conoce parcialmente sobre el cumplimiento de las leyes y reglamentos que norman a los GAD.

4. Se cuenta con las herramientas y paquetes actuales pero muchos funcionarios no saben cómo manejarlos.

5. Existen problemas de atención a la ciudadanía porque varios funcionarios, especialmente los mestizos no dominan el idioma kichwa, y tampoco conocen los hábitos y costumbres indígenas puruháes.

6. La comunicación es vertical descendente y ascendente diariamente a excepción de las reuniones quincenales donde la comunicación es horizontal y participativa.

7. Liderazgo autocrático.

8. No existe equidad entre funcionarios de nombramiento y contrato, por temas relacionados, con sueldos, estabilidad laboral, participación en las reuniones laborales fuera de horario de trabajo.

9. Las capacitaciones en el GAD son esporádicas y en temas generales.

10. La rotación del personal está dada en base al desempeño y evaluaciones periódicas. Otra determinante son las disposiciones expresas en la ley sobre la renovación de un contrato máximo por dos periodos de un año, caso contrario se deberá iniciar con el proceso de nombramiento que involucra la aprobación de partidas por parte de varias instituciones del Gobierno Central.

11. No se ha gestionado nombramientos dentro de los dos últimos años.

12. Existe un mal clima laboral.

13. Se denota la ausencia de valores como respeto, solidaridad, responsabilidad, etc., entre los funcionarios de la institución. 
14. Los incentivos están dados por reconocimientos verbales en honor al trabajo desempeñado, mientras que las sanciones son verbales y se basan en la evaluación.

15. La mayoría de los funcionarios del GAD no se sienten totalmente a gusto en sus puestos de trabajo.

16. Varios de los funcionarios laboran en días de descanso o fuera de horario laboral, sin un reconocimiento económico por las horas extras.

17. No existe cooperación entre el personal de nombramiento ni el de contrato.

18. Se promueve el rescate de la identidad cultural a nivel cantonal, pero no a nivel institucional.

19. Existe percepciones de racismo entre los funcionarios públicos mestizos e indígenas.

Etapa 3. Descripción de los problemas fundamentales de la Cultura Organizacional

Paso 1. Principales problemas de la Cultura Organizacional.

Partiendo de los resultados obtenidos en la triangulación realizada en la Matriz de Interpretación de Resultados (MIR) (anexo 4) y mediante la realización de un taller con los Directores departamentales, se procede a elaborar el diagrama de Ishikawa ponderado (anexo 5), identificándose como efecto el problema central de la investigación que radica en que el GAD Municipal del cantón Colta no cuenta con una Cultura Organizacional Aautóctona, para luego determinar las causas en relación al efecto, abordando cada una de las variables externas e internas de la Cultura Organizacional.

Con respecto a la ponderación, se utiliza la metodología de Cuesta (2010), donde las causas fundamentales o espinas primarias, son ponderadas con el objetivo de conocer el orden de importancia de las causas en el efecto, indicando el orden de prioridad respecto a las soluciones y su nivel de influencia en el cambio pretendido, además 
de que a través de un procedimiento sistémico, se indica el orden de importancia de las causales y definir los problemas fundamentales de la Cultura Organizacional en un nivel de concordancia entre los Directores departamentales del 85,71\%.

En base a la MIR, y al diagrama de Ishikawa ponderado, los autores proceden a desarrollar el árbol de problemas para desarrollar el árbol de objetivos, con la finalidad de transformar los problemas en soluciones positivas para la organización e identificar los nudos críticos y objetivar los problemas fundamentales de la cultura organizacional en el GAD Municipal del catón Colta.

En este sentido los principales problemas identificados son:

Variables externas

Globalización

- Difícil adaptación al cambio

Leyes, normas y reglamentos

- Incumplimiento de las leyes

- Sanciones emitidas por las instituciones de control

Plurinacionalidad

- Pérdida de identidad cultural

Variables internas

Liderazgo

- Liderazgo autocrático y experto con participación de funcionarios, pero sin toma de decisiones conjuntas.

- Falta de delegación.

Comportamiento organizacional

- $\quad$ No se cumplen con los planes de capacitación en competencias generales y específicas. 
- Choque de culturas entre indígenas y mestizos.

Clima organizacional

- Infraestructura en malas condiciones

- Gran contratación de funcionarios mestizos que no pertenecen al cantón Colta.

- La tecnología es obsoleta

Valores

- Ausencia de valores que identifiquen a los servidores

- Carencia de un código de ética

Comunicación

- Deficiente comunicación interna, sin libertad de expresión

\section{Motivación}

- Sanciones verbales en público.

- Poca claridad en las escalas de remuneraciones.

- Horas extras laboradas, sin reconocimiento económico.

Trabajo en equipo

- $\quad$ No se promueve el trabajo en equipo

- Deficiente coordinación y colaboración entre funcionarios públicos

Ritos, creencias y tradiciones

- Desconocimiento del Idioma y hábitos culturales por parte de los funcionarios públicos que no pertenecen al cantón Colta.

Etapa 4. Construcción de escenarios futuros

Paso 1. Análisis estructural de las variables de la cultura organizacional 
Los autores consideran necesario, realizar un análisis de las variables externas e internas de la cultura organizacional, para determinar a través del MIC - MAC la influencia y dependencia entre las variables de la investigación, lo que permite una gestión prospectiva más completa de identificación de escenarios.

En este sentido, se desarrolla el taller con cuatro directores departamentales del GAD Municipal del cantón Colta, quienes mediante un consenso construyen la matriz de análisis estructural (MAE), para evaluar la influencia y dependencia entre las variables de la cultura organizacional.

En el sistema MIC MAC se ingresan los datos y se procede a elaborar el gráfico directo (anexo 6), a través del cual se concluye que las variables más influyentes son: globalización, leyes, plurinacionalidad, liderazgo, comportamiento organizacional, clima organizacional, valores, comunicación, motivación y trabajo en equipo; mientras que los ritos, creencias y tradiciones se consideran como variables resultantes en la cultura organizacional.

Se ha elaborado también el plano directo, a través del cual se refleja los siguientes resultados sobre la influencia y dependencia entre las variables de la investigación.

- La globalización, leyes y plurinacionalidad, consideradas como variables externas, al encontrarse en el primer cuadrante del plano de influencias, se consideran como variables entrantes, cuya característica radica en que son muy influyentes y poco dependientes, ya que condicionan la dinámica de las variables internas.

- El liderazgo, trabajo en equipo, comportamiento organizacional, clima organizacional, comunicación, valores y motivación, son siete de las ocho variables internas y se encuentran en el segundo cuadrante, el cual refleja las variables repetidoras, ya 
que son al mismo tiempo muy influyentes y muy dependientes, son inestables por naturaleza ya que cualquier acción sobre ellas tendrá, simultáneamente, repercusiones sobre las otras variables y un efecto sobre ellas, modificando así considerablemente la dinámica global del sistema (Godet y Durance, 2011).

- Por su parte la variable interna de ritos, creencias y tradiciones, se encuentra en el tercer cuadrante, donde se contemplan a las variables resultantes que son poco influyentes y muy dependientes; su desarrollo se evidencia por impactos que provienen de las otras variables.

Partiendo de estos resultados, juntamente con los directores departamentales, se procede a establecer cinco hipótesis para posteriormente validarlas con los expertos.

Paso 2. Identificación de escenarios futuros.

El desarrollo de este paso inicia con la selección de expertos, mediante el método Delphi y el Sistema de Matrices de Impactos Cruzados SMIC, los cuales conjuntamente permiten establecer los escenarios futuros. Se han seleccionado a once expertos para trabajar con la presente investigación utilizando la metodología de Hurtado (2012). Considerando los resultados obtenidos en la etapa 3, y en el paso 1 , de la etapa 4 , se procede a identificar los escenarios futuros (anexo 7) para la cultura organizacional del Gobierno Autónomo Descentralizado Municipal del cantón Colta.

En este sentido, en una primera ronda, se valida con los expertos, las cinco hipótesis planteadas con sus porcentajes de ocurrencia respectivos las cuales se detallan a continuación:

H1. Se trabaja en base a un liderazgo participativo, democrático e incluyente que motiva e incentiva a los funcionarios del GAD en un $94,09 \%$. 
H2. Se logra el trabajo en minga en un 93,07\% respetando la cosmovisión indígena ancestral de Ama Quilla, Ama Shua, Ama Llulla (no mentir, no robar, no ser ocioso).

H3. Se logra una imbricación entre la Universidad, el GAD Municipal y la población del cantón Colta para realizar programas y planes de capacitación para promover el desarrollo de competencias y conocimientos requeridos por la organización local en un $94,09 \%$.

H4. Se realiza Capacitación con las Instituciones de Regulación y Control de los GAD, en lo referente al cumplimiento de la normativa vigente y cambios administrativos en un $90 \%$.

H5. Se implementan acciones para rescatar la identidad y la cultura en el GAD Municipal del cantón Colta un 94,09\%.

En una segunda ronda, se consulta a los expertos la probabilidad de ocurrencia de las hipótesis dadas en base a tres matrices identificándose los siguientes escenarios:

Escenario I: 01. $(\mathrm{P}=0,56)$ : Al considerar el Histograma de probabilidades de escenarios, se desecha esta opción en vista de que cumple con totas las hipótesis, pero no se encuentra dentro del rango establecido por el software SPSS, presentando una débil coherencia de 0,56; razón por la que se abordan los tres siguientes escenarios.

Escenario II: 32. $(P=0,09)$ : Se considera como un escenario pesimista ya que no se cumplen con ninguna de las hipótesis establecidas, concluyendo que no existiría el apoyo por parte de la dirección para motivar e incentivar a los funcionarios públicos del GAD Municipal del cantón Colta; además no se promovería el trabajo en minga y el rescate de los valores y principios de la cosmovisión indígena, trabajando por la recuperación de la identidad y cultura del cantón dentro de la Institución; entendiéndose también que la capacitación 
sería una utopía. Este escenario permite alertar a la investigadora sobre la necesidad de establecer acciones claras y precisas que puedan contradecir la posibilidad presentada.

Escenario III: 05. ( $P=0,06)$ : Este escenario se considera como tendencial y es el más optimista considerando que se cumplan los eventos futuros previstos por los expertos para fomentar una Cultura Organizacional Autóctona en aras de una mejor gestión en el GAD Municipal del cantón Colta a través de las acciones a establecer.

En este escenario se presenta la probabilidad de que se cumplan las hipótesis 1, 2,4 y 5 excluyendo a la 3 que aborda la imbricación entre la Universidad, el GAD y la población del cantón Colta para realizar programas y planes de capacitación para promover del desarrollo de competencias y conocimientos requeridos por la organización local; de esta manera se anularía la posibilidad de impulsar y promover a los ciudadanos de la localidad a formarse para brindar sus servicios profesionales en el cantón, posibilidad que puede afectar a largo plazo a la cultura organizacional del GAD, sobre todo considerando las características interculturales del mismo.

Escenario VI: 03. $(P=0,05)$ : Este escenario también es considerado como tendencial y a criterio de la investigadora es el más probable en su realización, pues cumple con las hipótesis, 1, 2, 3 y 5, excluyendo a la hipótesis 4 sobre la capacitación con las instituciones de regulación y control de los GAD, lo que provocaría a corto y largo plazo un desconocimiento en la aplicación de leyes y reglamentos relacionados con el cumplimiento de los objetivos del GAD, sin embargo, se prevé la probabilidad de que a través de un liderazgo participativo, democrático e incluyente, se trabaje por una imbricación entre la Universidad, GAD y la población del cantón para formar personal capacitado en las competencias que requiere la organización rescatando siempre el trabajo en equipo, considerado cómo minga desde la cosmovisión indígena y los principios y valores ancestrales que aportan al rescate de la identidad y cultura de los pueblos y del GAD Municipal del cantón Colta. 
La posibilidad de que se lleven a cabo estos escenarios dependerá de una premisa muy importante que condiciona su cumplimiento y es el compromiso de las autoridades del GAD. Además, es importante indicar que de acuerdo al escenario escogido (03), la hipótesis 4, es negativa; sin embargo, los autores consideran necesario diseñar acciones para causar el efecto de reversión y evitar que la falta de capacitación con las Instituciones de regulación y control de los GAD, cause ineficiencia por desconocimiento en los procesos provocando un mal clima y comportamientos que afecten a su cultura organizacional.

Etapa 5. Diseño de acciones para fomentar una cultura organizacional autóctona.

Paso 1. Diseño de acciones

Partiendo de los resultados identificados como escenarios futuros y los problemas principales de la cultura organizacional, se procede a elaborar la matriz DAFO con la finalidad de determinar las opciones de acciones viables para la investigación, todo esto en base al desarrollo de la tercera ronda con los expertos, concluyendo que de acuerdo a los resultados combinados en la matriz DAFO, la cultura organizacional del GAD, se encuentra dentro del cuadrante III, que representa una posición adaptativa con un impacto del $43.45 \%$ sobre los demás cuadrantes, eliminando o reduciendo al máximo las debilidades para aprovechar las oportunidades; además esta posición coincide con el criterio de los autores con respecto a la realidad de la cultura organizacional en el GAD Municipal del cantón Colta. Además, se concibe que se debe procurar la definición de las acciones más adecuadas aprovechando al máximo las potencialidades, minimizando los riesgos, enfrentado los desafíos, y procurando neutralizar las limitaciones. 



\section{CAPÍTULO VI. ACCIONES PARA EL FOMENTO DE UNA CULTURA ORGANIZACIONAL AUTÓCTONA EN LOS GAD DE LA PROVINCIA DE CHIMBORAZO}




\subsection{Acciones para fomentar un Cultura Organizacional Autóctona}

A continuación, se mencionan las acciones propuestas para Fomentar una Cultura Organizacional Autóctona en los GAD de la provincia de Chimborazo.

- Acciones externas

- Globalización

Macroacción: Determinar un proceso de adaptación al cambio organizacional (Quirant y Ortega 2011).

Objetivo: Lograr una adaptación de la organización hacia las diferentes transformaciones externas.

Acciones:

A1. Análisis externo organizacional (oportunidades y amenazas).

A2. Sensibilización con los funcionarios públicos.

A3. Realizar convenios entre la universidad y el GAD, para desarrollar capacitaciones sobre el proceso de cambio organizacional (a. dejar ir el pasado; b. transición, proceso psicológico con la finalidad de entender la nueva situación; c. inicio de nueva etapa).

- $\quad$ Leyes, Normas y Reglamentos

Macroacción: Realizar alianzas estratégicas entre las entidades de Regulación y Control de los GAD y el GAD Municipal del cantón Colta.

Objetivo: Evitar las sanciones emitidas por las Instituciones de Regulación y Control por incumplimiento de leyes y reglamentos. 
Acciones:

A4. Realizar convenios para capacitación entre las Instituciones de Regulación y Control y el GAD Municipal del cantón Colta.

- Plurinacionalidad

Macroacción: Impulsar las políticas públicas establecidas en la Agenda Nacional para la Igualdad de Nacionalidades y Pueblos Indígenas.

Objetivo: Contribuir a la eliminación de la brecha de inequidad social existente entre los pueblos y nacionalidades indígenas.

Acciones:

A5. Realizar alianzas estratégicas con el Ministerio Coordinador de Patrimonio Nacional y Cultural MCPNC, para promover y sensibilizar a los funcionarios públicos del GAD sobre el Plan Plurinacional para eliminar la Discriminación Racial y la Exclusión Étnica y Cultural (MCPNC, 2009)

A6. Realizar alianzas estratégicas con la Secretaría Nacional de Planificación y Desarrollo SENPLADES, para promover y sensibilizar a los funcionarios públicos sobre las políticas y lineamientos correspondientes al eje 7 de la ANINP (2013): La plurinacionalidad y la interculturalidad.

- Acciones Internas

- Liderazgo

Macroacción: Desarrollar un liderazgo, participativo, democrático e incluyente que motiva e incentiva a los funcionarios del GAD.

Objetivo: Orientar motivadamente el pensamiento y las acciones de cada uno de los servidores públicos hacia el logro eficaz y eficiente de la misión, visión y objetivos de la organización, con participación, democracia e inclusión. 
Acciones:

A7. Sensibilizar a los funcionarios públicos para lograr un pensamiento colectivo motivante en aras del cumplimiento de la misión, visión y objetivos organizacionales.

A8. Implementar el manejo en base a competencias Hellriegel y Slocum (2004) y Chiavenato (2009): Manejo propio, manejo de comunicación, manejo de diversidad, manejo de ética, manejo transcultural, manejo de equipos y manejo de cambio.

A9. Manejar la democracia sin dejar a un lado cualidades importantes como los conocimientos, carisma, imparcialidad, visión, y humildad.

A10. Promover la interculturalidad y el rescate de los valores y principios ancestrales provenientes de las nacionalidades Puruhaes entre sus funcionarios públicos.

A11. Realizar convenios entre la universidad y el GAD para capacitar a los líderes dentro de la organización.

- Comportamiento organizacional

Macroacción: Fomentar un sentido de pertenencia y compromiso con la organización en los funcionarios públicos del GAD Municipal del cantón Colta, considerando la interculturalidad presente.

Objetivo: Impulsar un comportamiento basado en la interacción de sus funcionarios, en el que promueva el sentido de pertenencia y compromiso para con la organización considerando sus características interculturales.

Acciones:

A12. Elaborar un plan de capacitación en competencias generales y especificas acorde a las necesidades reales de la organización. Verificar su cumplimiento. 
A13. Realizar convenios entre la universidad y el GAD para ejecutar los planes de capacitación en competencias generales y específicas.

A14. Planificar y ejecutar actividades de integración, que motiven en incentiven a los funcionarios públicos del GAD.

- Clima Organizacional

Macroacción: Crear un ambiente de compromiso y satisfacción generado por el bienestar de los funcionarios públicos dentro de la organización.

Objetivo: Contar con un equipo de funcionarios públicos más productivos y comprometidos con la organización y población.

Acciones:

A15. Mejorar las condiciones y adecuaciones físicas de la organización.

A16. Contratar preferentemente a personas provenientes del cantón Colta que cumplan con los requisitos establecidos.

A17. Desarrollar convenios entre la universidad, el GAD y la población del cantón Colta para promover el desarrollo de competencias acorde a las necesidades de la organización.

A18. Mejorar la capacidad tecnológica de la organización.

Valores

Macroacción: Fomentar valores organizacionales efectivos que favorezcan al funcionario público y a la organización.

Objetivo: Establecer los valores y principios más relevantes y necesarios para el GAD, con un enfoque intercultural. 
Acciones:

A19. Elaborar y socialización de un código de ética en el que se recaten los valores y principios de un funcionario público, especialmente de la cosmovisión Indígena descendiente de las nacionalidades Puruháes: reciprocidad, complementariedad, igualdad, armonía, enseñanza, minga, apropiación de valores, identidad cultural.

- Comunicación

Macroacción: Crear una cultura comunicativa en la organización e informar a los funcionarios públicos de su existencia.

Objetivo: Desarrollar las actividades laborales en una misma dirección, hacia la consecución de la misión, visión y objetivos organizacionales.

Acciones:

A20. Establecer un trato igualitario entre funcionarios públicos.

A21. Lograr una comunicación Ascendente y Descendente Asertiva generando respeto y confianza.

A22. Socializar y difundir la misión, visión y objetivos organizacionales para tener un conocimiento absoluto por parte de los funcionarios públicos.

- Motivación

Macroacción: Establecer un sistema de motivación que propicie un mejor desempeño entre los funcionarios públicos del GAD.

Objetivo: Cumplir los objetivos organizacionales logrando una satisfacción laboral entre los funcionarios públicos del GAD. 
Acciones:

A23. Socializar las Leyes Normas y Reglamentos que regulan, controlan y orientan a la organización.

A24. Definir de forma clara las funciones en cada puesto de trabajo y su remuneración

A25. Otorgar compensaciones: reconocimientos verbales en público, certificados de reconocimiento y pago de horas extras, atención médica, seguridad ocupacional, permisos para estudios (acorde a la ley).

- Trabajo en equipo

Macroacción: Definir a la minga como eje fundamental para el desarrollo de las actividades laborales de los funcionarios públicos del GAD.

Objetivo: Cumplir eficaz y eficientemente con los objetivos organizacionales a través de un trabajo en equipo sólido que incluye entre sus características los principios ancestrales de la cosmovisión indígena de las nacionalidades Puruháes.

Acciones:

A26. Socializar e implementar en todas las actividades laborales con los funcionarios públicos el trabajo en minga, rescatando los valores ancestrales de Ama Shuwa, no robar; Ama Killa, no ser ocioso; Ama Llulla, no mentir; Mana Mitza, no ser egoísta; Mana Washa rimak, no ser criticón; Mana shimilla, no ser solo lengua.

- Ritos, Creencias y Tradiciones

Macroacción: Promover el rescate de la identidad y cultura ancestral de los pueblos y nacionalidades Puruháes. 
Objetivo: Rescatar los hábitos y costumbres ancestrales de los pueblos y nacionalidades Puruhaes logrando un sentido de pertenencia entre los funcionarios públicos del GAD.

Acciones:

A27. Incluir como requisito la contratación de los funcionarios públicos del GAD que hablen el idioma kichwa, sea acorde al porcentaje existente de la población indígena del territorio que habla este idioma.

A28. Realizar convenios entre la universidad y el GAD para capacitar a sus funcionarios públicos sobre la realidad e importancia socio - cultural del cantón Colta y como transmitirla.

Se recomienda a las autoridades del GAD, aplicar este procedimiento cada cuatro años, realizando de una forma planificada y organizada cada una de las acciones establecidas, las cuales tiene sus problemas y objetivos planteados, así como los responsables, cronograma y la coordinación para su ejecución.

\subsection{Evaluación y control de la gestión}

Es importante mencionar también, que la implementación de las acciones diseñadas para fomentar una Cultura Organizacional Autóctona, conllevan a mejorar la gestión, razón por la que se las considera como una inversión, mas no como un costo. En este sentido, el presupuesto anual asciende a $\$ 19.000,00$, los cuales corresponden al 0,24\% del presupuesto anual de la Municipalidad, valor que debe ser planificado en base a lo contemplado por las leyes ecuatorianas, razón por lo que se considera que esta propuesta constituye un aporte valioso para la organización.

Con respecto a la medición del cumplimiento de las acciones, los autores consideran que estas deben ser evaluadas mediante los 
indicadores de gestión, como eficacia y eficiencia, tal como se detalla en la tabla 9.

Tabla 9. Indicadores de gestión.

\begin{tabular}{|c|c|c|c|}
\hline Acciones & Nombre del Indicador & $\begin{array}{l}\text { Tipo de } \\
\text { Indicador }\end{array}$ & Fórmula del Indicador \\
\hline $\begin{array}{l}\text { A.1. } \\
\text { A. } 2 . \\
\text { A. } 3\end{array}$ & $\begin{array}{l}\text { Satisfacción del } \\
\text { funcionario público con } \\
\text { respecto a la adaptación } \\
\text { al cambio. }\end{array}$ & Eficacia & $\begin{array}{ll}\left(\mathrm{N}^{\circ} \text { de }\right. & \text { funcionarios } \\
\text { satisfechos } / \mathrm{N}^{\circ} \text { total de } \\
\text { funcionarios encuestados }) \\
* 100\end{array}$ \\
\hline A.4. & $\begin{array}{l}\text { Sanciones emitidas } \\
\text { por las instituciones de } \\
\text { control. }\end{array}$ & Eficacia & $\begin{array}{l}\left(\mathrm{N}^{\circ} \text { sanciones emitidas }\right. \\
\text { Año actual / } \mathrm{N}^{\circ} \text { sanciones } \\
\text { emitidas año anterior })^{*} 100\end{array}$ \\
\hline $\begin{array}{l}\text { A. } 5 . \\
\text { A. } 6 .\end{array}$ & $\begin{array}{l}\text { Sensibilización } \\
\text { funcionario público: } \\
\text { interculturalidad en la } \\
\text { organización. }\end{array}$ & Eficacia & $\begin{array}{l}\left(\mathrm{N}^{\circ} \text { de funcionarios }\right. \\
\text { satisfechos capacitados / } \\
\mathrm{N}^{\circ} \text { total de funcionarios } \\
\text { capacitados encuestados) * } \\
100\end{array}$ \\
\hline $\begin{array}{l}\text { A.7. } \\
\text { A.8. } \\
\text { A.9. } \\
\text { A.10. } \\
\text { A.11. }\end{array}$ & $\begin{array}{l}\text { Satisfacción del } \\
\text { funcionario público con } \\
\text { respecto a la gestión de la } \\
\text { máxima autoridad. } \\
\text { Cumplimiento de metas }\end{array}$ & Eficacia & $\begin{array}{l}\left(\mathrm{N}^{\circ} \text { de funcionarios }\right. \\
\text { satisfechos / } \mathrm{N}^{\circ} \text { total de } \\
\text { funcionarios encuestados) } \\
\text { * } 100 \\
\left(\mathrm{~N}^{\circ} \text { de objetivos y metas }\right. \\
\text { cumplidas / } \mathrm{N}^{\circ} \text { de objetivos } \\
\text { y metas planificadas) }\end{array}$ \\
\hline $\begin{array}{l}\text { A.12. } \\
\text { A.13. }\end{array}$ & $\begin{array}{l}\text { Capacitaciones en comp. } \\
\text { generales } \\
\text { Capacitaciones en Comp. } \\
\text { específicas }\end{array}$ & Eficacia & $\begin{array}{l}\mathrm{N}^{\circ} \text { de funcionarios } \\
\text { satisfechos-capacitados } \\
\text { (comp. genr. o espc.) } \\
\mathrm{N}^{\circ} \text { total de funcionarios } \\
\text { capacitados encuestados) * } \\
100\end{array}$ \\
\hline & Capacitaciones & Eficiencia & $\begin{array}{l}\text { (gasto real capacitaciones } \\
\text { comp. Gen. y Esp. / } \\
\text { valor presupuestado } \\
\text { capacitaciones comp. gen. } \\
\text { y esp.) }{ }^{*} 100\end{array}$ \\
\hline $\begin{array}{l}\text { A.15. } \\
\text { A.16. } \\
\text { A.17 }\end{array}$ & $\begin{array}{l}\text { Satisfacción del } \\
\text { funcionario público con } \\
\text { respecto al clima laboral }\end{array}$ & Eficacia & $\begin{array}{l}\left(\mathrm{N}^{\circ} \text { de funcionarios }\right. \\
\text { satisfechos / } \mathrm{N}^{\circ} \text { total de } \\
\text { funcionarios } \\
{ }^{*} 100\end{array}$ \\
\hline
\end{tabular}




\begin{tabular}{|c|c|c|c|}
\hline A.19. & $\begin{array}{l}\text { Socialización del Código } \\
\text { de Ética }\end{array}$ & Eficacia & $\begin{array}{l}\left(\mathrm{N}^{\circ} \text { de funcionarios }\right. \\
\text { satisfechos capacitados / } \\
\mathrm{N}^{\circ} \text { total de funcionarios } \\
\text { capacitados encuestados) * } \\
100\end{array}$ \\
\hline $\begin{array}{l}\text { A. } 20 . \\
\text { A. } 22 \text {. }\end{array}$ & $\begin{array}{l}\text { Satisfacción del } \\
\text { funcionario público con } \\
\text { respecto a la gestión de } \\
\text { sus superiores }\end{array}$ & Eficacia & $\begin{array}{l}\left(\mathrm{N}^{\circ} \text { de funcionarios }\right. \\
\text { satisfechos / } \mathrm{N}^{\circ} \text { total de } \\
\text { funcionarios encuestados }) \\
{ }^{*} 100\end{array}$ \\
\hline $\begin{array}{l}\text { A. } 23 \\
\text { A. } 24 \\
\text { A. } 25\end{array}$ & $\begin{array}{l}\text { Satisfacción del } \\
\text { funcionario público con } \\
\text { respecto a remuneración, } \\
\text { beneficios, funciones. }\end{array}$ & Eficacia & $\begin{array}{ll}\left(\mathrm{N}^{\circ} \text { de }\right. & \text { funcionarios } \\
\text { satisfechos / } & \mathrm{N}^{\circ} \text { Total de } \\
\text { funcionarios } & \text { encuestados }) \\
* 100 & \end{array}$ \\
\hline A.26. & Minga & Eficacia & $\begin{array}{l}\left(\mathrm{N}^{\circ} \text { metas y objetivos }\right. \\
\text { alcanzados en equipo / } \\
\mathrm{N}^{\circ} \text { de metas y objetivos } \\
\text { planificados en equipo) * } \\
100\end{array}$ \\
\hline $\begin{array}{l}\text { A. } 27 . \\
\text { A. } 28\end{array}$ & $\begin{array}{l}\text { Sentido de pertenencia } \\
\text { institucional }\end{array}$ & Eficacia & $\begin{array}{l}\left(\mathrm{N}^{\circ} \text { funcionarios }\right. \\
\text { capacitados en el idioma } \\
\text { kichwa / } \mathrm{N}^{\circ} \text { planificado de } \\
\text { funcionarios a capacitar en } \\
\text { el idioma kichwa) }\end{array}$ \\
\hline
\end{tabular}

Fuente: Elaboración propia.

\subsection{Validación del procedimiento}

Para la validación del procedimiento para fomentar una Cultura Organizacional Autóctona FOCOA, se considera pertinente medir el grado de satisfacción de los usuarios a través una consulta a los alcaldes de los GAD municipales de los diez cantones de la provincia de Chimborazo, para el efecto se ha implementado la técnica IADOV, considerando los criterios teóricos de Campistrous y Rizo (2006).

La Técnica se desarrolla partiendo de una encuesta, la cual se estructura en base a cinco preguntas: tres cerradas y dos abiertas, tal como se muestra a continuación:

Validación del procedimiento para fomentar una Cultura Organizacional Autóctona FOCOA en los GAD Municipales de la provincia de Chimborazo 
Investigador:

GAD Municipal del cantón:

Nombre del alcalde:

Objetivo de la investigación: Diseñar un procedimiento que permita proponer acciones para fomentar una Cultura Organizacional Autóctona en aras de una mejor gestión en los Gobiernos Autónomos Descentralizados Municipales de la provincia de Chimborazo.

Introducción: Su colaboración es muy importante para esta investigación, ya que se considera que la validación del procedimiento FOCOA debe ser realizada por los alcaldes de los GAD de la provincia de Chimborazo con la finalidad de medir la viabilidad del mismo desde un punto de vista real, para el efecto se aplica a continuación el siguiente cuestionario:

¡Gracias por su colaboración!

1. ¿Está satisfecho con el procedimiento propuesto?

- Sí

No

— No sé

2. ¿Qué es lo que más le gustó del procedimiento propuesto?

3. ¿Qué es lo que le disgustó del procedimiento propuesto? 
4. ¿Le gusta la forma en que se realizó el procedimiento?

_ Me gusta mucho

_ Me gusta más de lo que me disgusta

_ Me es indiferente

_ Me disgusta más de lo que me gusta

_ No me gusta nada

_ No puedo decir

5. Si pudiera elegir libremente la vía para fomentar una Cultura Organizacional Autóctona en su GAD Municipal, ¿elegiría un procedimiento con características similares al presentado?

- Sí

- No

— No sé

Los criterios de valoración, están dados a través de la relación existente entre las tres preguntas cerradas, los mismos que se evidencian el cuadro lógico IADOV.

El número resultante de la interrelación de las tres preguntas indica la posición de cada usuario en base a la siguiente escala de satisfacción:

1. Clara satisfacción

2. Más satisfecho que insatisfecho

3. No definida

4. Más insatisfecho que satisfecho

5. Clara insatisfacción

6. Contradictoria

En la tabla 10, se observa los resultados obtenidos con respecto a la satisfacción individual de los usuarios consultados, ante lo cual se puede evidenciar una clara satisfacción, reflejada en un 
90\% de correspondencia con las respuestas dadas con respecto al procedimiento FOCOA.

Tabla 10. Resultados de satisfacción individual.

\begin{tabular}{|l|c|c|}
\hline Criterio & Cantidad & Porcentaje \\
\hline 1. Clara satisfacción & 9 & $90 \%$ \\
\hline 2. Más satisfecho que insatisfecho & 1 & $10 \%$ \\
\hline 3. No definida & & \\
\hline 4. Más insatisfecho que satisfecho & & \\
\hline 5. Clara insatisfacción & & \\
\hline 6. Contradictoria & & \\
\hline Total & & $100 \%$ \\
\hline
\end{tabular}

Fuente: Elaboración a partir de los resultados obtenidos en la aplicación de los cuestionarios.

Partiendo de la información obtenida, se procede a calcular el índice de satisfacción grupal (ISG), cuyo valor es de 0,95 , lo que demuestra la aceptación general hacia el procedimiento FOCOA, tal como se muestra en la figura 11.

Insatisfacción

Satisfacción

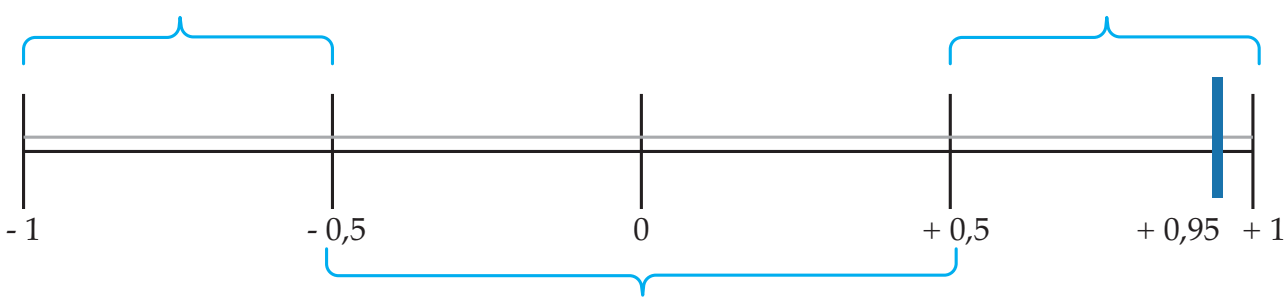

Contradicción o identificación

Figura 11. Índice de satisfacción grupal (ISG) de los usuarios.

Aplicando la técnica IADOV, se concluye que los usuarios de la investigación validan el procedimiento para fomentar una Cultura Organizacional Autóctona FOCOA.

En tal razón, la validación del procedimiento para fomentar una Cultura Organizacional Autóctona en los GAD Municipales de la provincia de Chimborazo, inicia con la identificación del objeto de estudio entre los diez GAD Municipales de la provincia; evidenciándose mediante una calificación ponderada al GAD Municipal del cantón Colta como la Institución donde se validará el 
procedimiento propuesto mediante el desarrollo de cada una de las etapas, pasos y herramientas propuestas; planteando veinte y ocho acciones para fomentar una Cultura Organizacional Autóctona en la organización y culminando con la validación del procedimiento propuesto denominado FOCOA, a cargo de los usuarios externos de la investigación es decir los diez alcaldes de la provincia de Chimborazo, los mismos que indican su satisfacción ante la propuesta en un procedimiento que permita diseñar acciones para fomentar una Cultura Organizacional Autóctona en aras de una mejor gestión. 


\section{CONCLUSIONES GENERALES}

La cultura Organizacional es una variable administrativa intangible que influye en el Desarrollo Organizacional de una empresa o institución, en este sentido, se considera que, al fomentarla, esta contribuye notablemente a mejorar la gestión y el rendimiento de la misma, es decir permite alcanzar el éxito.

La fundamentación teórica que se aborda en esta obra parte de dos estudios importantes, el primero comprende los resultados del proyecto de investigación titulado "Lineamientos para fomentar una Cultura Organizacional Exitosa" ejecutado en la Universidad Nacional de Chimborazo (Unach); en el que se identifican factores y variables necesarias para promover el éxito organizacional a través del impacto directo en su cultura.

Porsu parteel segundoestudioestimalos resultadosdelainvestigación denominada a "Fomento de una Cultura Organizacional Autóctona en aras de una mejor gestión para los Gobiernos Autónomos Descentralizados Municipales de la provincia de Chimborazo" la cual presenta resultados novedoso que concluyen en que el incidir en la Cultura Organizacional a través de acciones que rescaten las características interculturales y plurinacionales de los pueblos con tradiciones propias, es posible mejorar la gestión pública de los Gobiernos Locales en cada territorio, ya que estas instituciones son las encargadas de promover el desarrollo económico en los pueblos; por tanto es una responsabilidad social de los actores locales el asumir posturas administrativas que integren a la organización que trabaja en pro de la ciudadanía.

$\mathrm{Al}$ interrelacionar las variables Cultura Organizacional y desarrollo local, se concibe la interpretación sistémica de variables que benefician a la organización y a la población que depende de ella, esto quiere decir que, si se trabaja en mejorar la motivación, liderazgo, comunicación, trabajo en equipo, etc., de los funcionarios públicos de un Gobierno Autónomo Descentralizado que promueve 
el rescate de su cultura, el impacto será directo en la población que es atendida por este actor local. En tal virtud, las acciones que se realicen, garantizan una mejor atención promoviendo el desarrollo económico de la ciudadanía.

Hoy en día, es posible evaluar variables Intangibles que permitan potenciar variables Tangibles, por ello el Fomento de una Cultura Organizacional exitosa, se constituye un fenómeno que permite alcanzar el éxito en las organizaciones, muchas veces los administradores, se centran solamente en evaluar aspectos cuantificables como la ejecución presupuestaria, el cumplimiento de metas y resultados, etc., sin en embargo el factor que permite incrementar el nivel de dichos indicadores es el empoderamiento del funcionario hacia la organizacional y eso se logra trabajando o incidiendo directamente en la cultura organizacional.

Por su parte uno de los objetivos fundamentales de los Gobierno Autónomos Descentralizados es promover el desarrollo local de los territorios, estos involucra la participación activa de los funcionarios públicos que para desempeñar eficiente y eficazmente sus labores deben tener sentido de pertenencia y pertinencia hacia su institución, además de las competencias generales y especificas en cada puesto de trabajo con la finalidad de direccionar y apoyar a la ciudadanía con proyectos que potencien su economía.

Para alcanzar el éxito organizacional es imperante fomentar una Cultura Organizacional propia o autóctona de acuerdo a cada una de las realidades y necesidades locales que incentive a los funcionarios públicos a entregar con aptitud y actitud sus conocimientos en beneficio de la población a la que dirigen su trabajo y de la que se espera que contribuyan con iniciativas productivas que impulsen el desarrollo económico local. 


\section{REFERENCIAS BIBLIOGRÁFICAS}

1. Aguirre, A. (2004). La cultura de las organizaciones. Editorial Ariel. Madrid, España.

2. Alvesson, M. y Sveningsson, S. (2015). Changing organizational culture: Cultural change work in progress. New York: Routledge.

3. Alabart, Y. y Portuondo A. (2004). Propuesta Metodológica para el diagnóstico de la Cultura Organizacional. Tesis Doctoral. Universidad la Habana. La Habana - Cuba.

4. Albizu G. (2000) La Gestión de los Recursos Humanos: Retos y Tendencias en una Función de Cambio. Revista Alta Dirección No. 216.63p.

5. Alcaniz, M. (2008). El desarrollo local en el contexto de la globalización. Scielo. Convergencia Vol. 15 (47). Pág. 285-315. España. http:/ / www.scielo.org.mx/scielo.php?pid=S140514352008000200011\&script=sci_arttext\# nota. Consultado: 10-12-2015.

6. Alonso, A. (2006). Desarrollo territorial y desarrollo endógeno. Economía y Desarrollo, Año XXXVI. Vol.139 (1). Pág.113-124. Habana, Cuba.

7. Alonso, A. (2013). El desarrollo territorial a escala local. Visión Crítica y Referencias sobre Cuba. Tesis Doctoral. Facultad de Economía. Universidad de La Habana. La Habana, Cuba.

8. Alonso, A. y Bell, R. (2013). Desarrollo Territorial a escala local. Primera Edición. Editorial Universidad de la Habana. La Habana, Cuba.

9. Alles, M. (2007). Comportamiento Organizacional. Como lograr un cambio cultural a través de la Gestión por competencias. Primera Edición. Granica S.A. Buenos Aire Argentina.

10. Alles, M. (2013). Comportamiento Organizacional: cómolograr un cambio cultural a través de Gestión por Competencias. Buenos Aires: Ediciones Granica. 
11. Amaru, A. (2009). Fundamentos de la Administración, Teoría General y proceso administrativo México. Primera Edición. Pearson Educación de México.

12. Aportela, I. et, al. (2008), La Segunda Generación de la Gestión del Conocimiento: un nuevo enfoque de la gestión del conocimiento. Ciencias de la Información (19-30).

13. Arnoletto, E. y Díaz, A. (2009). Un aporte a la Gestión Pública, Hacia nuevos enfoques en la gestión organizacional, de la administración pública. Córdova - Argentina.

14. Asamblea Nacional. (2010). Ley Orgánica del Servicio Público. Segundo Suplemento del Registro Oficial No 4 .

15. Askenazy, P. y Amable, B. (2014). Introduction à l'économie de la connaissance. Contribution pour le rapport UNESCO Construire des sociétés du savoir. Extraído el 20 de febrero de 2009 desde: http:/ / www.jourdan.ens.fr/ amable/ unesco \%20final.pdf

16. Barnard, Ch. (1971). As iutvcoe: do executivo. Atlas. Sao Paulo - Brasil.

17. Barbero, J.M. (2010). Notas para hacer memoria de la investigación cultural en Latinoamérica. En N. Richard (Ed.) En Torno a los Estudios Culturales. Localidades, Trayectorias y Disputas (pp.33- 141). Santiago de Chile: Editorial ARCISCLACSO.

18. Becker, G. (1983). “El capital Humano” Alianza Universidad de Textos, Alianza Editorial, S.A. Madrid.

19. Boisier, S. (2005). ¿Hay espacio para el desarrollo local en la globalización?. Revista de la CEPAL. Vol.86. Pág. 47-62. Santiago de Chile, Chile.

20. Briceño, C. (2004). Valores organizacionales y gerenciales en empresas. Primera Edición. CICAG. Recuperado de: http: / / publicaciones.urbe.edu / index.php/cicag/article / viewArticle/570/1411. Consulta: 14-05-2016.

21. Brunet, L. (1987). El clima de trabajo en las organizaciones: Definición, Diagnóstico y Consecuencias. Editorial Trillas. México. 
22. Bueno, C. (1997). Organización de Empresas: estructura, procesos y modelos. Ediciones Pirámide. Madrid. España.

23. Bueno, C. (1997). Organización de Empresas: estructura, procesos y modelos. Ediciones Pirámide. Madrid. España.

24. Cesca, C. et al. (2012). Indicadores de Gestión y Medición de Desempeño. Guayana. Trabajo de Especialización en Gerencia de Mantenimiento. Universidad Nacional Experimental Politécnica Antonio José de Sucre.

25. CEPAL (2012). Población, territorio y desarrollo sustentable. Ecuador: Cepal, Naciones Unidas.

26. Chaparro, F. (2015) Conocimiento, Innovación y Construcción de Sociedad: Una Agenda para la Colombia del Siglo XXI. Santafé de Bogotá, Agosto 15. http:/ / colombia-siglo21.net/ index.html

27. Chiavenato, I. (1999). Administración de los Recursos Humanos. Quinta Edición. Editorial Mc Graw Hill. Argentina.

28. Chiavenato, I. (2009). Comportamiento Organizacional-La dinámica del éxito en las organizaciones. Segunda Edición. McGraw-Hill. México.

29. Chiavenato, I. (2009). Gestión del Talento Humano. Tercera edición. McGraw-Hill. México.

30. Comunidad Andina de Naciones (2011). Experiencias de gestión y buenas prácticas en la implementación del proyecto: Modelos de Desarrollo Rural con Enfoque Territorial en países de la CAN. Recuperado de: http:/ / www.comunidadandina. org / cescan / Documentos / SISTEMATIZACION\%20 PROYECTO\%20MDRT.pdf. Consultado: 15-04-2016. Lima, Perú.

31. Contraloría General del Estado (2009). Manual de Auditoría de Gestión. Recuperado de: enhttp: / / www.contraloria.gob. ec/documentos/normatividad/ManAudFin.pdf, Consulta: 12-09-2015.

32. Contreras, C. Díaz, B. y Hernández, E. (2013). Multiculturalidad: Su análisis y perspectivas a la luz de sus actores, clima y cultura organizacional prevalecientes en un mundo globalizado. 
33. Corominas, J. (1995). Breve Diccionario etimológico de la Lengua Castellana Madrid. Segunda Edición. Editorial Gredos. Madrid - España.

34. Coulter, R. (2010). Administración. Décima Edición, Editorial Pearson. México.

35. Cox, T. (1991). The multicultural organization. Academy of management Executive, 5 (2).

36. Delgado, S. (2008). Recursos Humanos, Administración y Finanzas (Madrid: Editorial Paraninfo, Pag.23

37. Denison, D. (1990). Corporate culture and organisational effectiveness. John Wiley and Sons. New York.

38. Denison, D. y Neale, W. (2000). Denison Organizational Culture Survey. Ann Arbor: Denison Consulting.

39. Dessler, G. (1993). Organización y AdminisTración.México: Editorial PrenTce-Hall.

40. Diaz, I. (2009). La organización como sistema abierto: Subsistemas, dimensiones y ambiente. Consultado en: http: / / manuelgross.bligoo.com/20140910-la-organizacion-comosistema-abierto-subsistemas-dimensiones-y-ambiente\# . WQ3xE9I19YI. Fecha de consulta: 22-01-2017.

41. Díaz, I. et al. (2010). Estrategia Organizacional. Primera Edición. Editorial Félix Varela. La Habana-Cuba.

42. Didrikson, A. (2006). Universidad, sociedad del conocimiento y nueva Economía. Extraído el 28 de abril de 2009 desde: http: / / www.riseu.unam.mx/documentos / acervo_ documental/txtid0016.pdf Axel Didriksson.

43. Diez, J. et al. (2013) ¿De arriba hacia abajo o de abajo hacia arriba?. Revista Científica Complutense. Vol. 4 (2). Pág. 199235. Madrid, España.

44. Drucker, P. (1954). The Practice of Management. Harper \& Brothers. New York.

45. Druker, P. (1969) The Age of Discontinuity. New York: Harper \& Row. 1969.

46. Fayol, H. (1949). General and Industrial Management. Pitman \& Sons. Londres. 
47. Fierro, P. (2017). Metodología para contribuir al fomento de la base productiva agropecuaria como aporte al desarrollo local en los cantones pequeños de Chimborazo - caso: cantón Chunchi. Tesis Doctoral. Universidad de La Habana, Cuba.

48. Fombrun, C. (2008). Gestión de Intangibles. Unidad de Conocimiento. Fundación para la motivación de los Recursos Humanos. Barcelona - España.

49. Franklin, E. (2009). Organización de Empresas. Tercera Edición. McGraw-Hill. Interamericana Editores S.A. México.

50. Fundación para el Desarrollo Local y el Fortalecimiento Municipal e Institucional de Centroamérica y El Caribe DEMUCA. (2012). Estudios de Casos Prácticos en Desarrollo Económico Local. Apoyo local el fortalecimiento de la cadena de valor de la piña en el municipio de Santa María Ostuma, La Paz, El Salvador. Recuperado de: http: / / www.conectadel. org / wp-content / uploads / downloads / 2013 / 03/17casosa ntamariaostumaelsalvador-120502104140-phpapp02.pdf. Consultado: 14-01-2017.

51. Gago, A. (1993). Planificación y Desarrollo Regional. Curso Latinoamericano de Desertificación. Mendoza, Argentina.

52. García, C. (2005). Ponencia: En torno al concepto marxista de Capital Humano. La Habana: Escuela Superior del PCC

53. Garofoli G. (1992), Endogenous Devolopment and Southerne Europe, Avebury, Aldershot (UK). Pág. 1-13.

54. Garzón, C. (2011). Análisis de los conceptos de administración, gestión y gerencia en enfermería, desde la producción científica de enfermería, en américa latina, Tesis de Maestría, Universidad Nacional de Colombia, Bogotá, Colombia. Recuperado de: http:/ /www.bdigital.unal.edu.co/6678/1/ claramariagarzonrodriguez.2011.pdf. Consulta: 28-07-2014.

55. Goncalves, A. (1999). Dimensiones del Clima Organizacional. Sociedad Latinoamericana para la Calidad

56. Gonzales, Z. (2003). Los Ritos y rituales en la cultura corporativa de Wal Mart Supercenter: estudio de caso para la medición de la cultura corporativa a través de los ritos 
y rituales observados en Wal Mart Supercenter. N$^{\circ} 2346$. Madrid - España.

57. Guiarratana, M. (2008). La Cultura Organizacional. Revista Electrónica Gerencia y Negocios en Hispanoamérica. Recuperado de: http://www.degerencia.com/artículo/la cultura_organizacional_mg. Consulta: 21-11-2015.

58. Guillén, M. (2018). Gestión del conocimiento para el diseño de estrategias que lleven al aprendizaje significativo en grupos heterogéneos. Trabajo de obtención de grado, Maestría en Educación y Gestión del Conocimiento. Tlaquepaque, Jalisco: ITESO. Recuperado de: http: / / hdl.handle.net/11117/ 5402

59. Guzmán, M. et al. (2006). Nuevos enfoques del desarrollo rural en América Latina. Reflexiones a partir de la aplicación y evaluación del proyecto EXPIDER en Ecuador y Bolivia. Instituto de Estudios Sociales Avanzados de Andalucía (IESA -CSIC) y Empresa Pública Desarrollo Agrícola y Pesquero.

60. Hellriegel, D; Slocum, J. (2004). Comportamiento Organizacional. Décima Edición. Thomson. México.

61. Heredia, R. (1985). Project Management. Dirección Integrada de Proyecto DIP. Segunda Edición. Alianza Editorial. Madrid - España.

62. Hernández, A., et, al. (2012). Un nuevo Modelo de desarrollo local. IDEAZ S.L. Quinta Edición. Zafra - España.

63. Herzberg, F. (1959). The Motivation to Work, John Wiley, Nueva York.

64. Hirst, Paul (2000): “La economía del conocimiento: ¿realidad o fábula?", Este país tendencias y opiniones.

65. Hogan, S. J., y Coote, L. V. (2014). Organizational culture, innovation, and performance: A test of Schein's model. Journal of Business Research, 67(8), 1609-1621.

66. Instituto Nacional de Estadísticas y Censos, INEC. (2010).

67. Jiménez, J. (2010). El valor de los valores en las organizaciones. Tercera Edición. Ediciones de Cograf Comunicaciones. Caracas-Venezuela. 
68. Koonts, H. et al. (2012). Administración una perspectiva global y empresarial. Décimo cuarta edición. McGraw-Hill. Interamericana Editores S.A. México.

69. Koontz, H. y O’donell, C. (1985). Administración. McGrawHill.

70. Lazcano, C. y Font, E. (2006) Capital Humano, en busca de un contexto. e- ailcugio@infomed.sld.cu.

71. Lerma, A. y Bárcena, S. (2012). Planeación Estratégica por áreas funcionales. Alfaomega Grupo Editor S.A. Primera Edición. México.

72. López, M. (2013). La cultura organizativa como herramienta de gestión interna y de adaptación al entorno. Un estudio de casos múltiple en empresas murcianas. Tesis de Doctorado. Universidad de Murcia. Murcia-España.

73. Lozano, J. (2014). Expook, Comunicación de sustentabilidad y RSE. La importancia de la Tradición. Recuperado de: http: / / www.expoknews.com/la-importancia-de-la-tradicion/. Consulta: 10-10-2015.

74. Lucani, P. (2008). Programas y Proyectos. Enfoques de desarrollo territorial en proyectos de inversión. Estudios de caso. Programa de Cooperación FAO/Banco Mundial. Recuperado de: http://www.fao.org/3/a-k3622s.pdf. Consultado: 17-09-2016.

75. Ludwig, B. (1989). General System Theory: foundations, development, applications. New York: Brasilier, Inc.

76. Macías, L. (2017). El comportamiento orientado a los grupos de interés desde el enfoque de la responsabilidad social corporativa y su efecto en el desempeño empresarial. Tesis Doctoral. Universidad de Vigo. España.

77. Madoery, O. (2005). La "primera generación" de políticas locales de desarrollo en Argentina: Contexto, características y desafíos. Recuperado de: http://municipios.unq.edu. ar/modules / mislibros / archivos / Madoery_locales.pdf. Consultado: 23-11-2015.

78. Mancera, Gloria. (2013). Cultura Organizacional en Entidades 
del Gobierno. Recuperado de: http://gloriamancerasi. blogspot.com / 2013/10/cultura-organizacional-enentidades-del.html. Consulta: 14-03-2014.

79. Martínez, C. (2011). Teoría de la argumentación y enfoque sistémico de la organización. Consultado en https:// www. gestiopolis.com/teoria-de-la-argumentación-y-enfoquesistémico-de-la-organización/. Fecha de consulta: 12-122016.

80. Martinez, J. (2000). Investigación sobre desarrollo humano y equidad en Cuba 1999. La Habana, Caguayo S.A.

81. Marx, C. (1973). El Capital, tomo 1, p. 130-158.

82. Maslow, A. (1954). Motivation and Personality, Harperand Co. Nueva York.

83. Matamala, R. (2015). Entrevista sobre cultura organizacional. Recuperado de: http://www.occsolutions.org/blog/ entrevistaeladndeunaorganizacion. Consulta: 12-12-15.

84. McClelland, D. (1969). Motivating Economic Achievement, Free Press, Nueva York.

85. Mendez, D, Lloret, C. (2006). Globalizacion: interrogantes y dimensiones. EUMED. Espana.

86. Mintzberg, H. y Quinn, J. (1995). El proceso estratégico. Segunda Edición. Prentice Hall Hispano Americana S.A. México.

87. Mohrman, S. y Cummings, G. (1991). Selfdesigning Organizations. Learning how to create performance. Reading. Mass. Adisson-Wesley Publishing.

88. Mohrman, S. y Cummings, G. (1991). Selfdesigning Organizations. Learning how to create performance. Reading. Mass. Adisson-Wesley Publishing.

89. Morgan, G. (1998). Imágenes de la organización. México: Alfa Omega.

90. Navarro, I. (2005). Capital Humano: Su Definición y Alcances en el Desarrollo Local y Regional. Education Policy Analysis Archives/Archivos Analíticos de Políticas Educativas, vol. 13, 2005, pp. 1-36 Arizona State University Arizona, 
Estados Unidos Recuperado de: https: / / www.redalyc.org / pdf / 2750/275020513035.pdf

91. Naviero, O. (2006). Estrategias de desarrollo territorial en América Latina: entre la imitación y la innovación social. Artículo publicado en Vergara, P. y Alburquerque, F. (coord): Desarrollo económico territorial. Chile.

92. Nogueira, D. (2002). Fundamento para el control de la gestión Empresarial. Tesis Doctoral. ISPJAE. La Habana - Cuba.

93. Ochoa, M. et al. (2007), “Innovación, tecnología y gestión tecnológica”. Acimed, Vol. 16(4). Recuperado de: http:/ / bus. sld.cu/revistas / aci/vol16_4_07/aci081007.html. Consulta: 02-06-15.

94. Odriozola, S. (2013). Una propuesta alternativa al concepto del llamado capital humano Textos \& Contextos (Porto Alegre), v. 12, n. 2, p. $265-280$.

95. Overal, L. (2013). Cultura Organizacional de la Universidad Nacional del Este. Tesis Doctoral. Univesidad e Jaén, Facultad de Humanidades y Ciencias de la Educación. España.

96. Pascale, R., Athos, A. (1981). The Art of Japanese Management. Penguin Books. Londres.

97. Pérez, O. (2000) Apuntes sobre la Globalización y Crítica de la economía política economía y desarrollo no. 2 / vol. 127 / jul.-dic.

98. Perez, Y. et.al. (2009) Agregación de valor a los servicios de información para la gestión del conocimiento en la creación de servicios y productos informáticos. Ciencias de la Información (15-26).

99. Pettigreew, M. (1979). On studyng Organizational Cultures, Administrative Science Quarterly, N²4 December.

100. Programa de las Naciones Unidas para el Desarrollo PNUD (2010). La verdadera riqueza de las Naciones: Caminos al Desarrollo Humano. Informe sobre Desarrollo Humano 2010. Edición por el Vigésimo Aniversario. Communications Development Incorporated. Nueva York. Estados Unidos.

101. Reeve J. (2010). Motivación y Emoción. Quinta Edición. México. 
102. Rementeria, A. (2008). Concepto de gestión. Editorial Universidad Bolivariana. Santiago de Chile

103. Robbins, S. y Coulter, M. (1996). Administración. Quinta Edición. Prentice Hall. México.

104. Robbins, S. y Coulter, M. (2005). Administración. Octava Edición. Pearson Educación. México.

105. Robbins, S. y Jude, T. (2013). Comportamiento Organizacional. Décimo quinta edición. Pearson. México.

106. Rocher, G. (1977). Introducción a la Sociología General. Herder - Barcelona.

107. Rodríguez, C. (2010). Procedimiento para estudiar las necesidades informativas de los directivos en la EHTC "Hermanos Gómez". Aplicación de AMIGA. Universidad de Camagüey. Centro de Estudios Multidisciplinarios para el turismo. Camagüey - Cuba.

108. Salom, G. (2015). Motivación. Revista electrónica Forum. Recuperado de: http://www.revistainterforum.com/ espanol/artículos/public_negocios.html. Consulta: 25-071016.

109. Sanabria, M. (2007). De los conceptos de administración, gobierno, gerencia, gestión y management: algunos elementos de corte epistemológico y aportes para una mayor comprensión. Univ. Empresa, Vol. 6(13), p. 155-194.

110. Schein, E. (1988). La cultura empresarial y el liderazgo. Una visión dinámica. Plaza \& Janes Editores. P.

111. Schultz, T. (1983) La inversión en capital humano, educación y sociedad, volumen 8.

112. Sen, A. (1999). Desarrollo y Libertad. Material Didáctico. Editorial Planeta. Buenos Aires, Argentina.

113. Smircich, L. (1983). Concepts of culture and organizational analysis. Administrative Science Quarterly, N 28, p. 339-358. doi:10.2307/2392246.

114. Sthör, W. (s/a). Desarrollo desde abajo: el paradigma de desarrollo de abajo hacia arriba, y de la periferia hacia adentro. Naciones Unidas, CEPAL, ILPES. Chile. 
115. Stoner, J. (1996). Administración. Sexta Edición. Prentice Hall. México.

116. Torres, N. (2017). "Fomento de una Cultura Organizacional Autóctona en aras de una mejor Gestión para los Gobiernos Autónomos Descentralizados Municipales de la provincia de Chimborazo". La Habana - Cuba. Universidad de La Habana, Tesis Doctoral.

117. Torres, N. et al. (2018). La conceptualización de organización desde un enfoque sistémico. SATHIRI: Sembrador, [S.l.], v. 13, n. 1, p. 147 - 159, jul. 2018. ISSN 1390-6925. Disponible en: $<$ http:/ / revistasdigitales.upec.edu.ec/index.php/sathiri / article/view/508>. Fecha de acceso: 14 sep. 2018.

118. Urdaneta, H. (2014). Como cambiar la Cultura Organizacional. Huconsulting.net. Recuperado de: http://huconsulting. net/ wp-content / uploads / 2014 / 10 / COMO-CAMBIAR-LACULTURA-ORGANIZACIONAL.pdf. Consulta. 12-05-2016.

119. Vargas J. (2007). La Culturocracia organizacional en México. Recuperado de: www.eumed.net/libros/2007b/ 301. 2007. Consulta: 20-09-2013.

120. Vázquez, A. (2001). La política de desarrollo económico local en: Aghón, Gabriel et al. Desarrollo económico local y descentralización en América Latina: un análisis comparativo. Santiago de Chile, Chile.

121. Wang, C. H., Chen, K. Y., y Chen, S. C. (2012). Total quality management, market orientation and hotel performance: The moderating effects of external environmental factors. International Journal of Hospitality Management, 31(1), 119129.

122. William Ouchi. (1982). Teoría Z. Cómo pueden las empresas hacer frente al desafío Japones. Barcelona: EDICIONES ORBIS, S.A.

123. Yuquilema, E. (2016). Cultura y Sabiduría Puruhá. Primera Edición. Riobamba- Ecuador. 


\section{ANEXO 1.}

Encuesta para el diagnóstico de la Cultura Organizacional

Aplicada a los funcionarios públicos del Gobierno Autónomo Descentralizado Municipal del cantón Colta

OBJETIVO: El objetivo de esta encuesta es obtener información que permita diagnosticar a la Cultura Organizacional y sus elementos dentro el GAD Municipal del cantón Colta. Servirá como un medio para establecer estrategias que mejoren la Cultura Organizacional. Agradecemos su participación en esta investigación. Para su conocimiento, todas las respuestas se tratarán confidencialmente.

INSTRUCIONES: Por favor lea detenidamente y conteste con sinceridad cada pregunta de la encuesta; marque con una $\mathrm{X}$ el casillero que corresponda a su respuesta.

¡Gracias por su colaboración!

GENERO: F........... M...........

SITUACIÓN LABORAL:

Nombramiento...

Contrato

Otra

\section{AUTODETERMINACION:}

Indígena Mestizo

Blanco

Otra

EDAD:

Escala de Calificación: 1 (Siempre), 2 (Frecuentemente), 3(A veces), 4 (Rara vez) y 5 (Nunca) 


\begin{tabular}{|c|c|c|c|c|c|c|}
\hline Preguntas & 1 & 2 & 3 & 4 & 5 & $\begin{array}{l}\text { ¿por qué? / } \\
\text { observaciones }\end{array}$ \\
\hline \multicolumn{7}{|l|}{ GENERALIDADES } \\
\hline $\begin{array}{l}\text { 1. ¿Conoce la Misión y Visión } \\
\text { del GAD Municipal del cantón } \\
\text { Colta? }\end{array}$ & & & & & & \\
\hline \multicolumn{7}{|l|}{$\begin{array}{l}\text { 2. ¿Participa Ud. en el proceso de } \\
\text { planificación del GAD? }\end{array}$} \\
\hline $\begin{array}{l}\text { 3. ¿Considera que la infraestructura } \\
\text { (Edificios, oficinas, instalaciones) } \\
\text { del GAD es adecuada para } \\
\text { desempeñar sus labores? }\end{array}$ & & & & & & ¿Qué falta?: \\
\hline $\begin{array}{l}\text { 4. ¿Los materiales y equipos con los } \\
\text { que cuenta son suficientes para } \\
\text { realizar un buen trabajo? }\end{array}$ & & & & & & ¿Qué falta? \\
\hline \multicolumn{7}{|l|}{ LEYES } \\
\hline \multicolumn{7}{|l|}{$\begin{array}{l}\text { 5. ¿El GAD Municipal, socializa las } \\
\text { leyes, reglamentos y ordenanzas } \\
\text { con los ciudadanos? }\end{array}$} \\
\hline \multicolumn{7}{|l|}{ GLOBALIZACIÓN } \\
\hline $\begin{array}{l}\text { 6. ¿Emplea herramientas } \\
\text { tecnológicas y procedimientos } \\
\text { nuevos en la realización de su } \\
\text { trabajo? }\end{array}$ & & & & & & $\begin{array}{l}\text { ¿Qué herra- } \\
\text { mientas? }\end{array}$ \\
\hline \multicolumn{7}{|l|}{ PLURICULTURALIDAD } \\
\hline \multicolumn{7}{|l|}{$\begin{array}{l}\text { 7. ¿Considera que el idioma es una } \\
\text { de las barreras para trabajar en } \\
\text { las comunidades? }\end{array}$} \\
\hline \multicolumn{7}{|l|}{$\begin{array}{l}\text { 8. ¿Considera que los funcionarios } \\
\text { del GAD deben ser bilingües? }\end{array}$} \\
\hline \multicolumn{7}{|l|}{ LIDERAZGO } \\
\hline \multicolumn{7}{|l|}{$\begin{array}{l}\text { 9. ¿Tiene Ud. acceso a la máxima } \\
\text { autoridad del municipio si lo } \\
\text { requiere? }\end{array}$} \\
\hline \multicolumn{7}{|l|}{$\begin{array}{l}\text { 10. ¿Su jefe mantiene un trato } \\
\text { afable? }\end{array}$} \\
\hline \multicolumn{7}{|l|}{$\begin{array}{l}\text { 11. ¿Considera Ud. que existe } \\
\text { equidad entre los funcionarios } \\
\text { públicos del GAD? }\end{array}$} \\
\hline $\begin{array}{l}\text { 12. Los servidores públicos del GAD } \\
\text { participan con su opinión en la } \\
\text { toma de decisiones }\end{array}$ & & & & & & ¿Por qué? \\
\hline $\begin{array}{l}\text { 13. ¿En el GAD, se capacita a sus } \\
\text { servidores públicos? }\end{array}$ & & & & & & \\
\hline
\end{tabular}




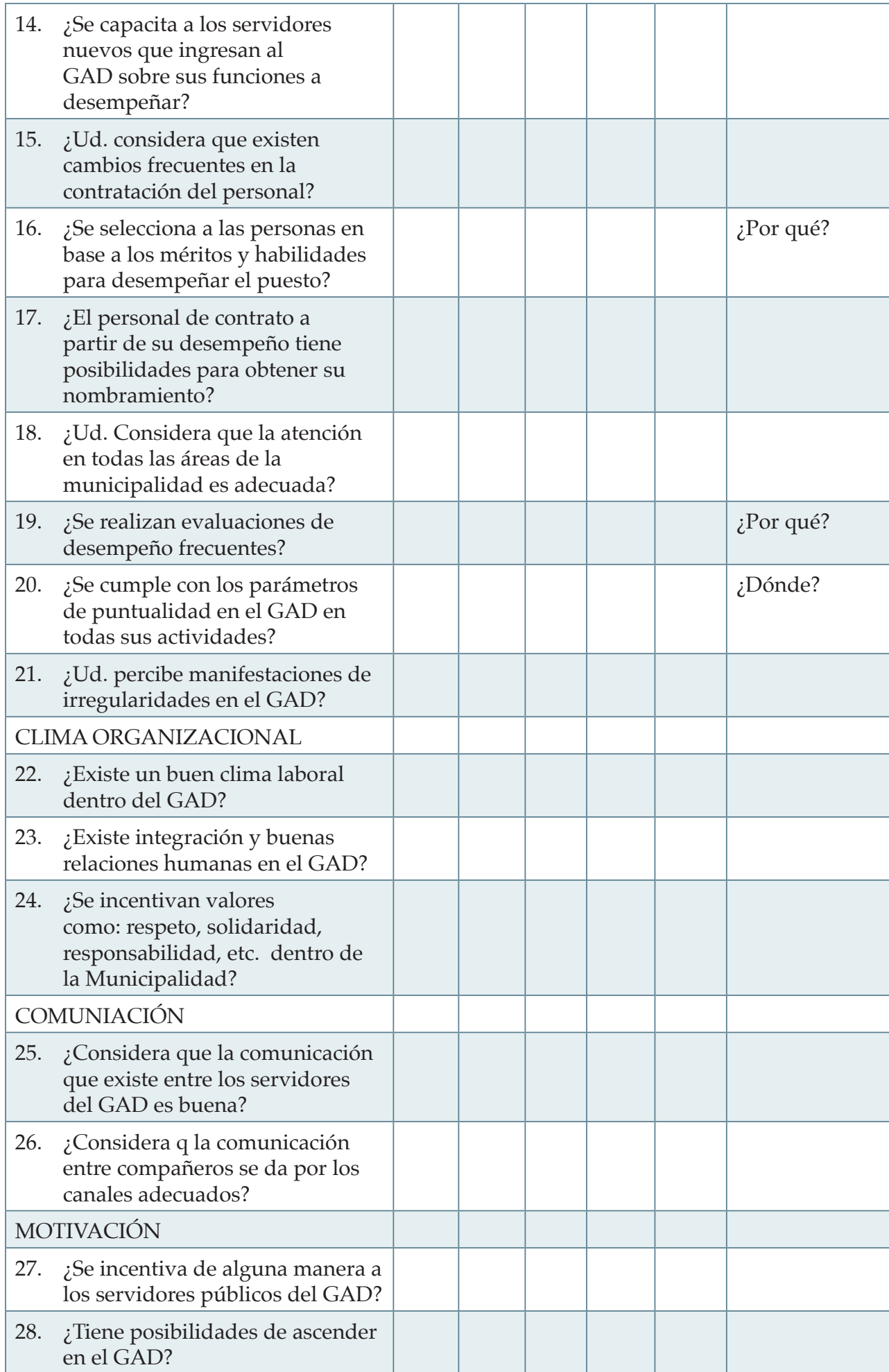




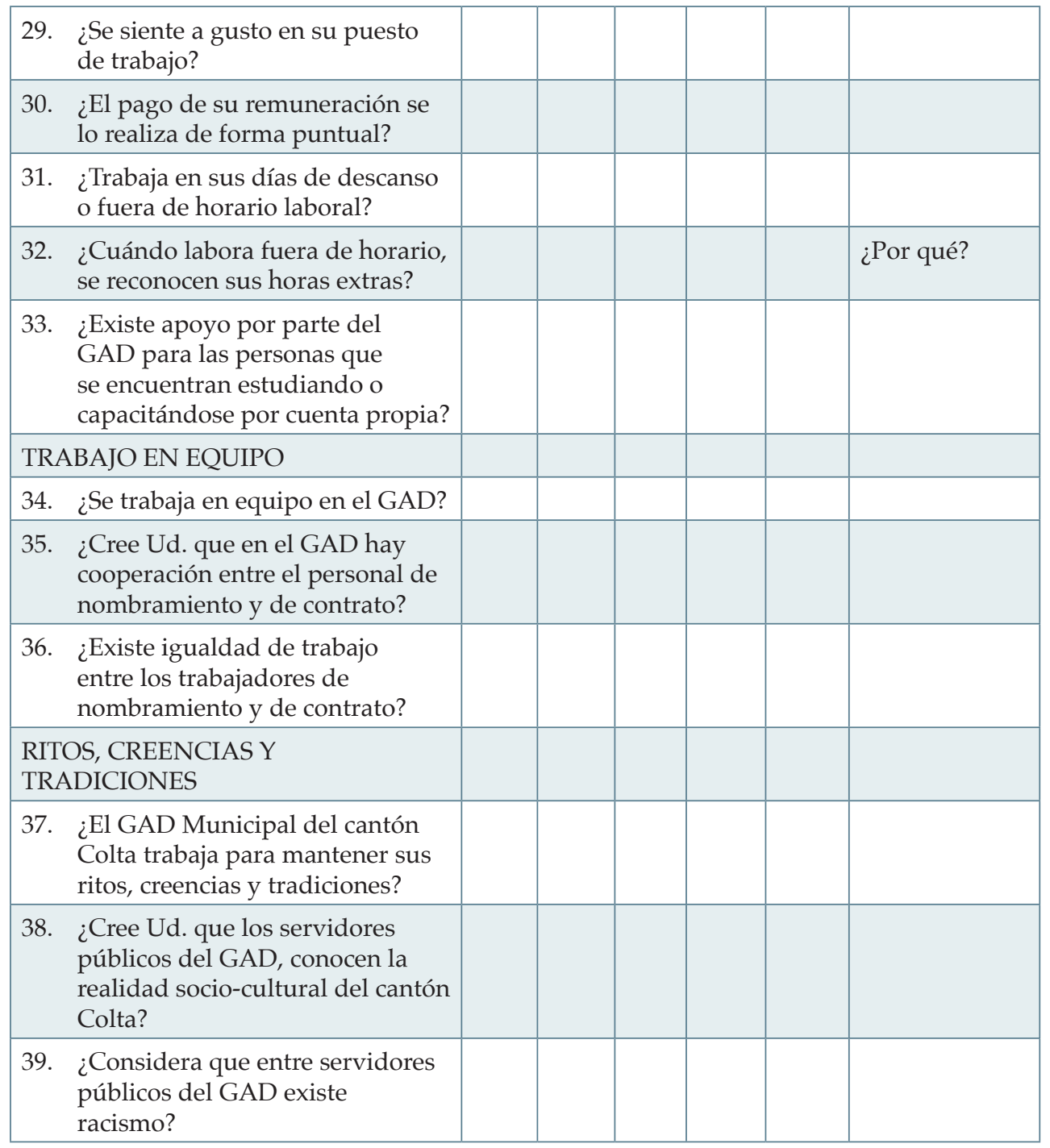

Fuente: Torres, 2017.

Encuesta para el diagnóstico de la Cultura Organizacional aplicada a la población económicamente activa del cantón Colta

OBJETIVO: El objetivo de esta encuesta es obtener información que permita diagnosticar a la Cultura Organizacional del GAD Municipal del cantón Colta. Agradecemos su participación en esta investigación. Para su conocimiento, todas las respuestas serán confidenciales. 
INSTRUCCIONES: Por favor lea detenidamente y conteste con sinceridad cada pregunta de la encuesta; marque con una $\mathrm{X}$ el casillero que corresponda a su respuesta basándose en la siguiente escala: Escala de Calificación: 1 (Siempre), 2 (Frecuentemente), 3(A veces), 4 (Rara vez) y 5 (Nunca), si cree necesario explique el porqué. ¡Gracias por su colaboración!

GENERO: F........... M..........

\section{¿DE QUE RAZA SE AUTODETERMINA?:}

Indígena...... Mestizo........ Blanco........ Otra......

\section{EDAD:}

\begin{tabular}{|c|c|c|c|c|c|c|}
\hline Preguntas & 1 & 2 & 3 & 4 & 5 & ¿Por qué? \\
\hline $\begin{array}{l}\text { 1.- ¿Ud. realiza trámites en el GAD } \\
\text { Municipal del cantón Colta? }\end{array}$ & & & & & & \\
\hline $\begin{array}{l}\text { 2.- ¿Considera que el GAD cumple } \\
\text { con las leyes que norman sus } \\
\text { procedimientos y gestión? }\end{array}$ & & & & & & \\
\hline $\begin{array}{l}\text { 3.- ¿Considera que el GAD cuenta } \\
\text { con instalaciones, sistemas } \\
\text { operativos y tecnología adecuada } \\
\text { para prestar sus servicios a la } \\
\text { ciudadanía? }\end{array}$ & & & & & & \\
\hline $\begin{array}{l}\text { 4.- ¿Ud. ve reflejada la cultura del } \\
\text { cantón en el GAD? }\end{array}$ & & & & & & \\
\hline $\begin{array}{l}\text { 5.- ¿La atención que recibe por parte } \\
\text { de las autoridades del GAD es } \\
\text { aceptable? }\end{array}$ & & & & & & \\
\hline $\begin{array}{l}\text { 6.- ¿La atención que recibe por parte } \\
\text { de los funcionarios públicos es } \\
\text { aceptable? }\end{array}$ & & & & & & \\
\hline $\begin{array}{l}\text { 7.- ¿Percibe un buen ambiente de } \\
\text { trabajo entre los funcionarios } \\
\text { públicos del GAD? }\end{array}$ & & & & & & \\
\hline $\begin{array}{l}\text { 8.- ¿El tiempo de demora en la } \\
\text { atención a sus trámites es } \\
\text { aceptable? }\end{array}$ & & & & & & \\
\hline $\begin{array}{l}\text { 9.- ¿El GAD promueve la } \\
\text { participación ciudadana en sus } \\
\text { procesos? }\end{array}$ & & & & & & \\
\hline
\end{tabular}




\begin{tabular}{|c|l|l|l|l|l|l|}
\hline $\begin{array}{c}\text { 10.- ¿Cree que los ciudadanos del } \\
\text { cantón Colta, tienen facilidades } \\
\text { para ingresar a la Universidad? }\end{array}$ & & & & & & \\
\hline $\begin{array}{c}\text { 11.- ¿El GAD Municipal incentiva a } \\
\text { su población para Ingresar a la } \\
\text { Universidad? }\end{array}$ & & & & & & \\
\hline
\end{tabular}

Fuente: Torres, 2017. 
ANEXO 2.

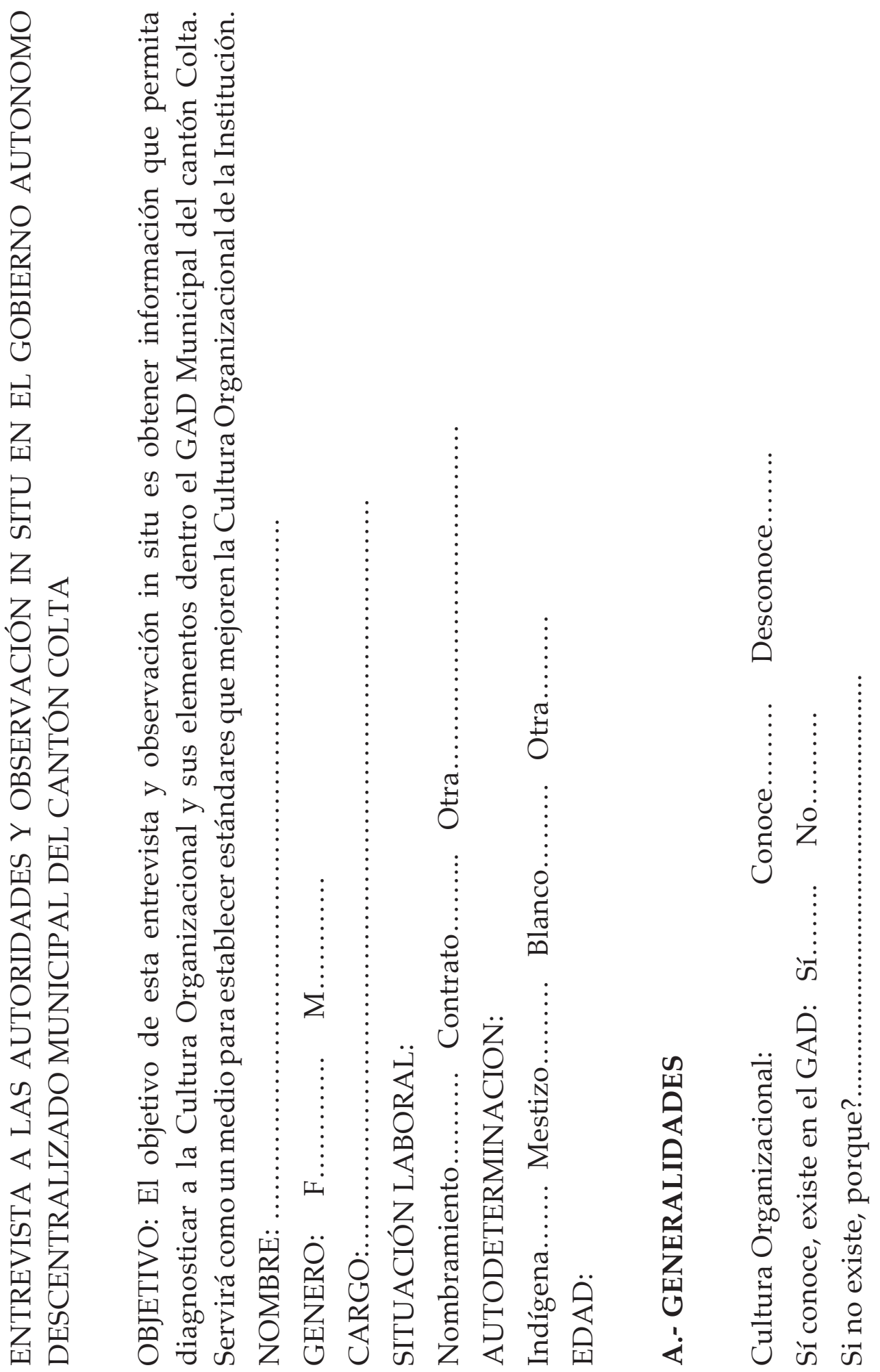




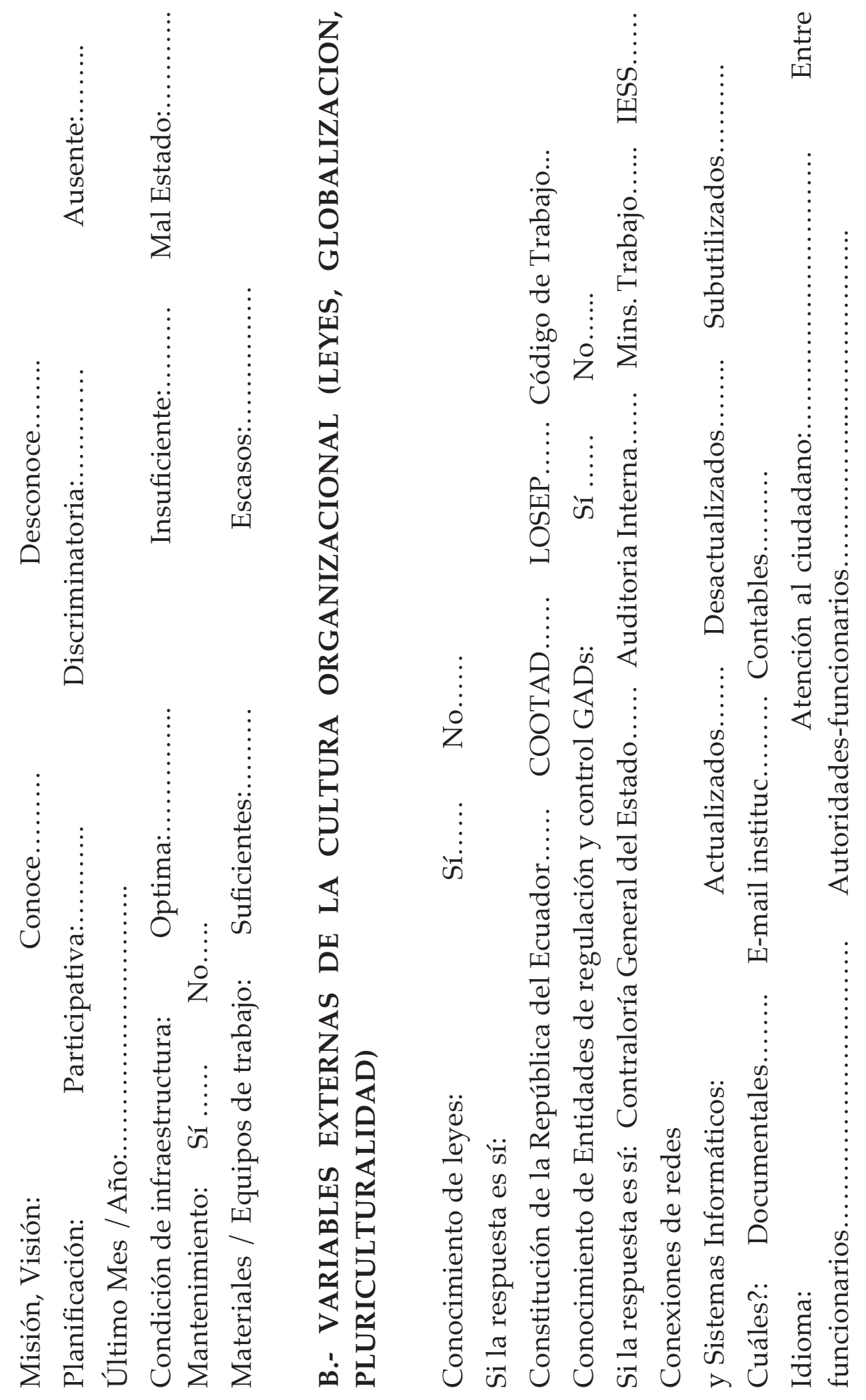




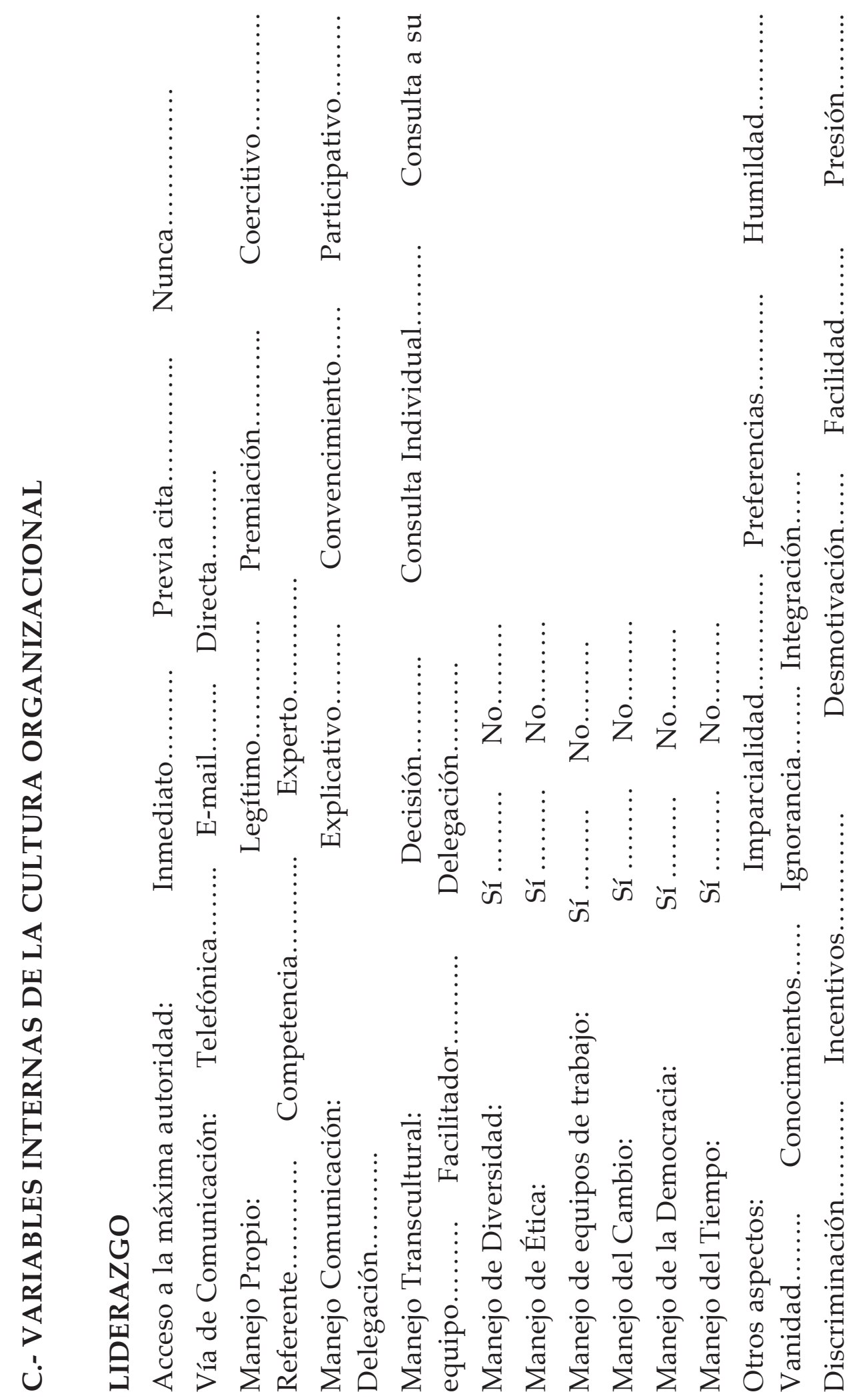




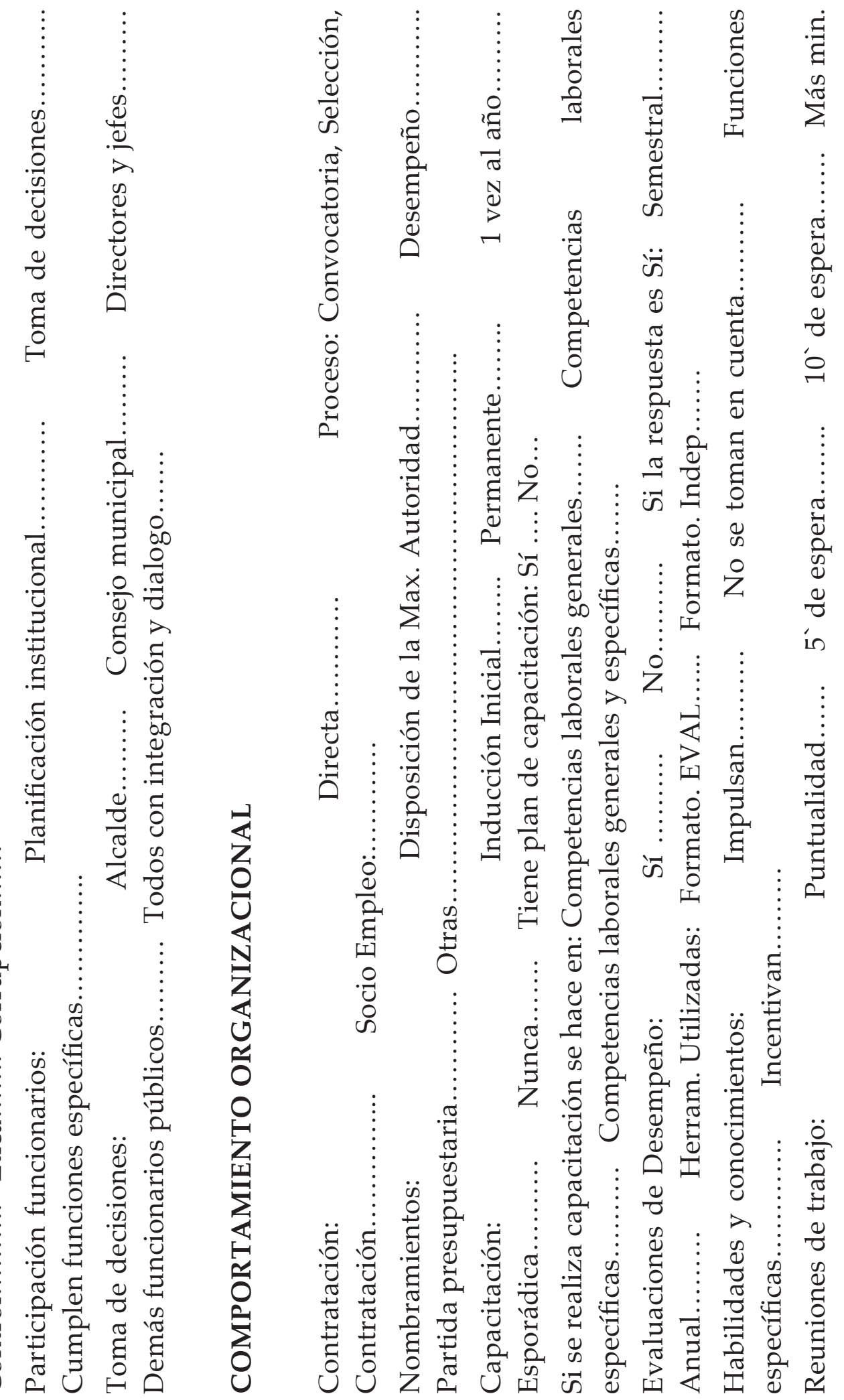


高

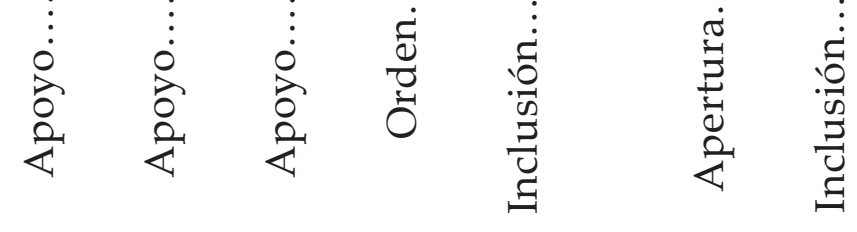

คั

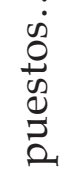

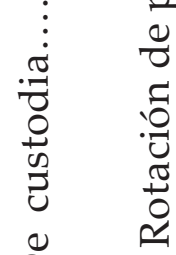

คั

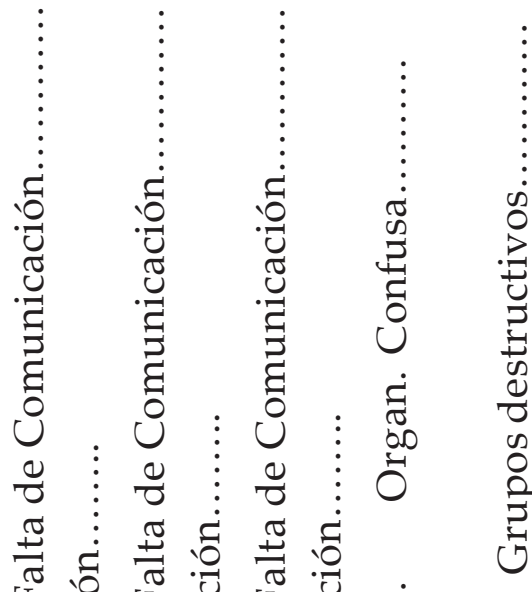

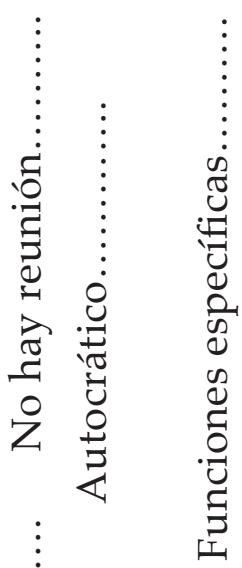

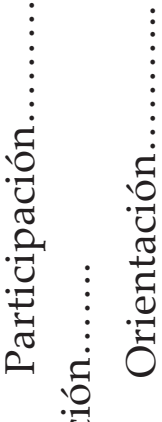

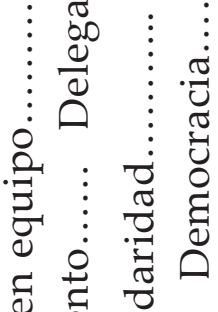

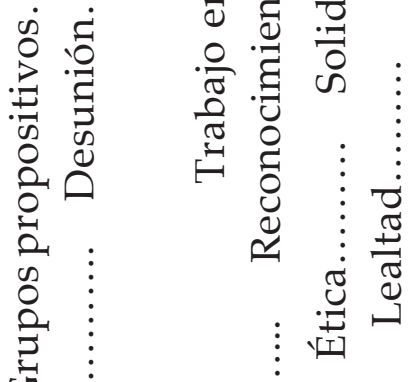

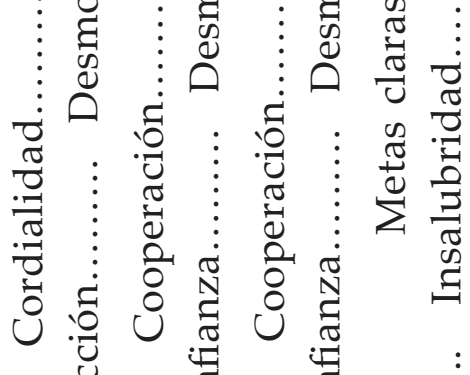

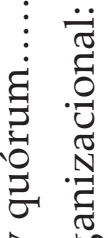

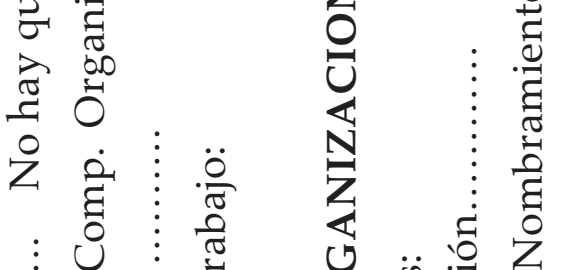

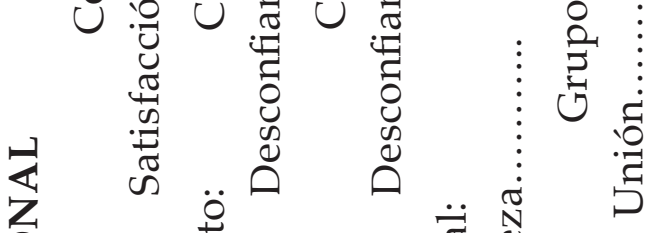

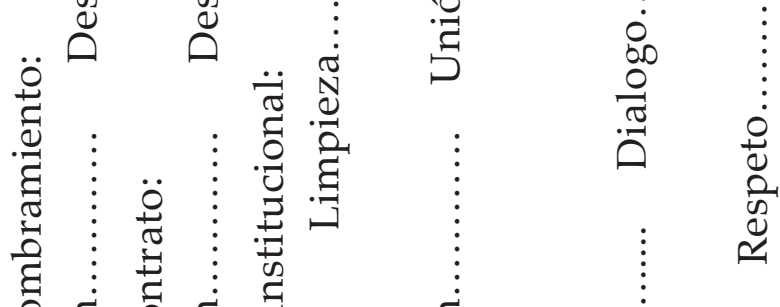

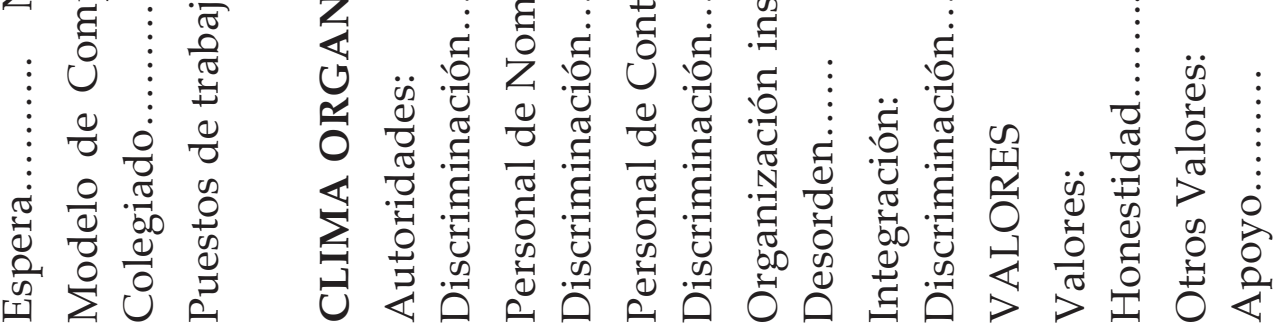

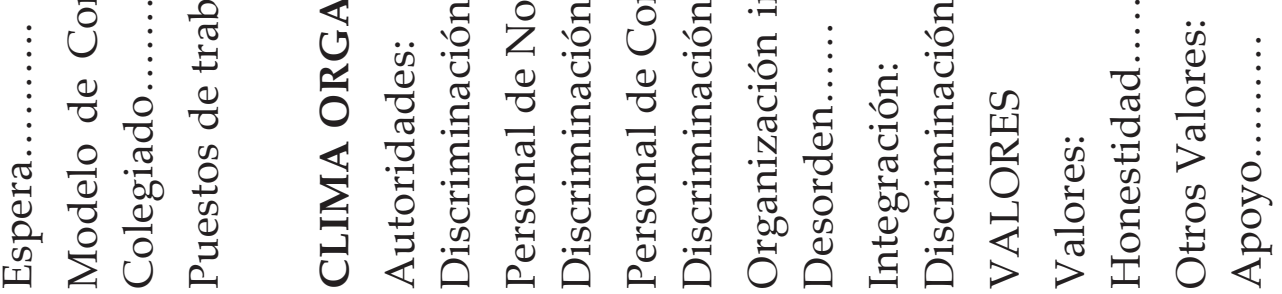




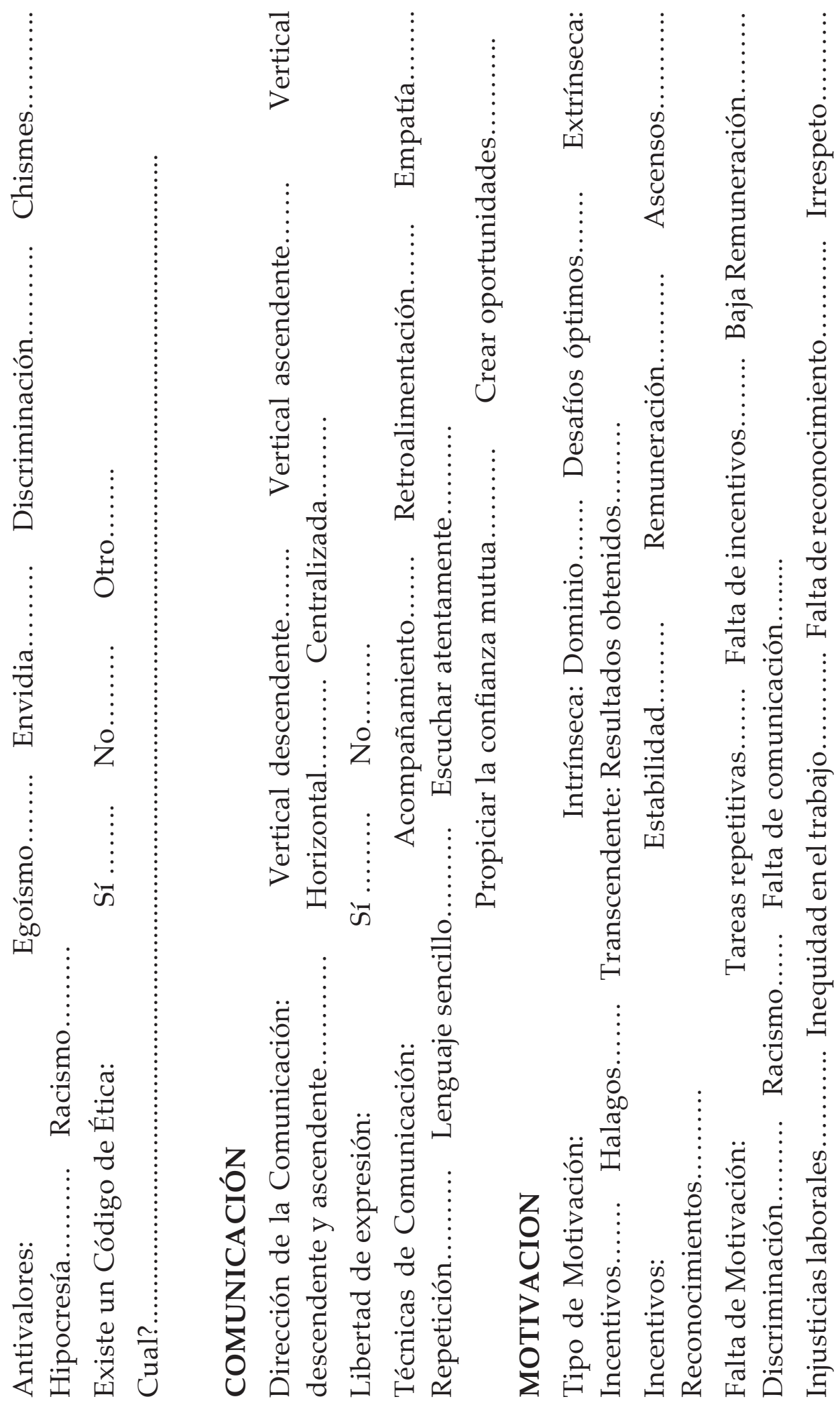




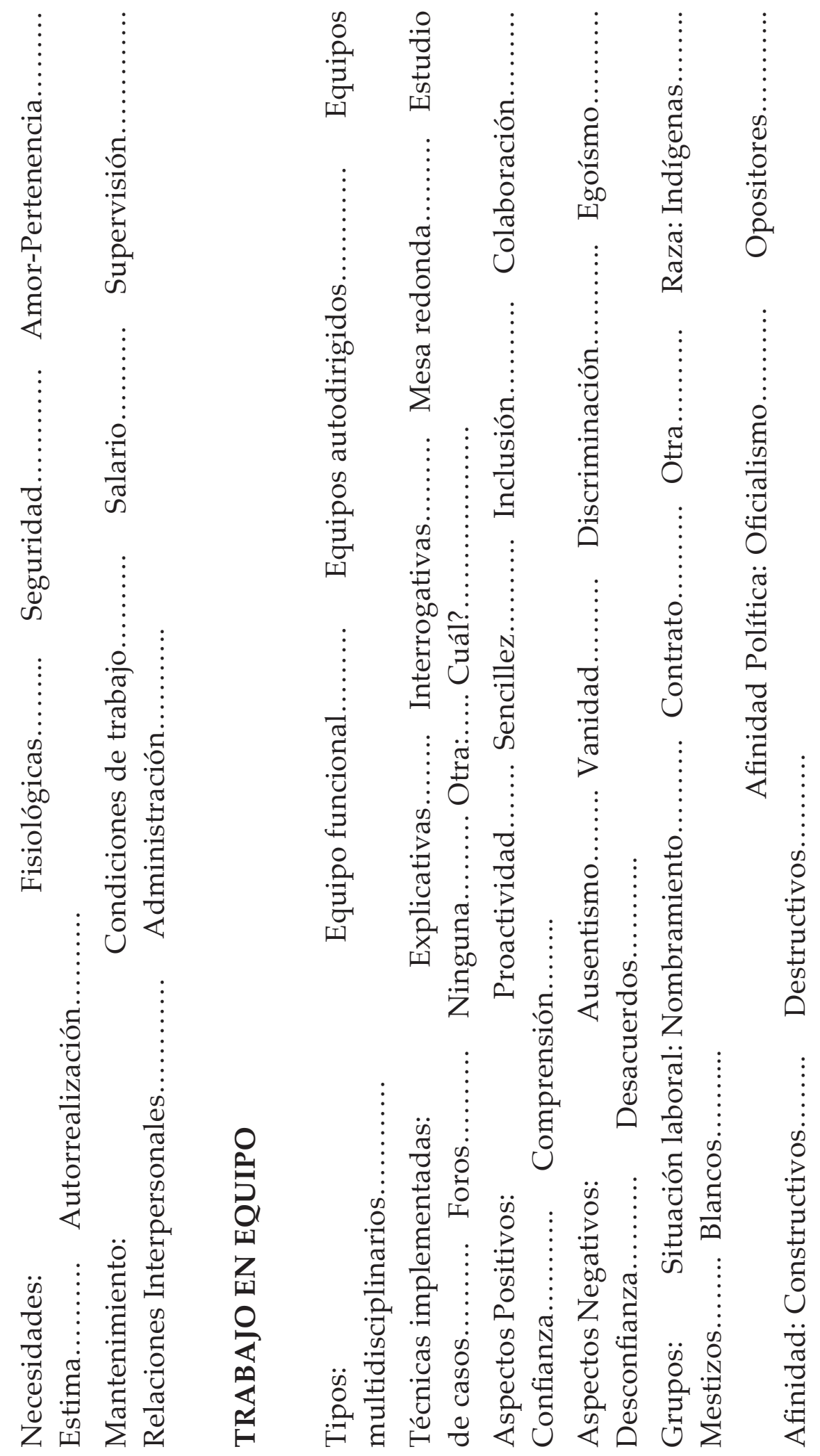




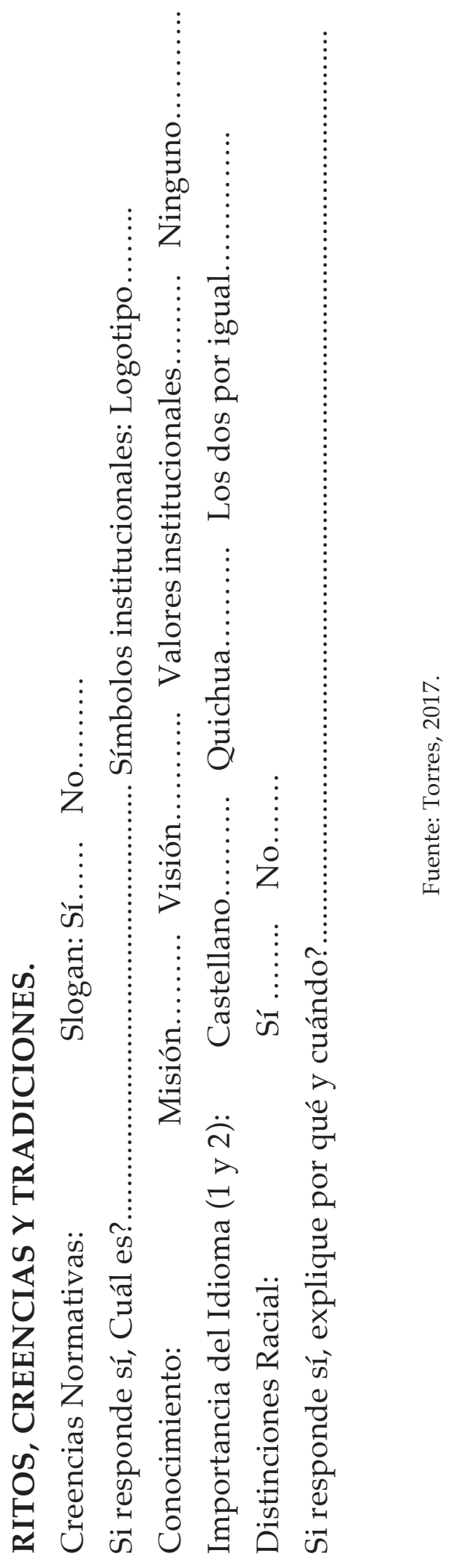




\section{ANEXO 3.}

Guía de Observación Semiestructurada

Fecha:

Departamento/ Área:

\begin{tabular}{|c|c|c|}
\hline \multicolumn{2}{|c|}{ Variables Externas } & Pluriculturalidad \\
\hline Leyes & Globalización & Clima Organizacional \\
\hline Liderazgo & $\begin{array}{c}\text { Comportamiento } \\
\text { Organizacional }\end{array}$ & \\
\hline Valores & Comunicación & \\
\hline Trabajo en equipo & Motivación \\
& Creencias y tradiciones & \\
\hline
\end{tabular}

Fuente: Torres, 2017.

\section{ANEXO 4.}

Matriz De Interpretación De Datos (MIR)

Interpretación de resultados cuantitativos vs. observación in situ y entrevistas

\begin{tabular}{|l|l|l|l|}
\hline Preguntas & Resultados encuestas & $\begin{array}{c}\text { Observación y } \\
\text { revisión } \\
\text { documental }\end{array}$ & Entrevistas \\
\hline & & & \\
\hline & & & \\
\hline & & & \\
\hline & & & \\
\hline & & & \\
\hline & & & \\
\hline & & & \\
\hline
\end{tabular}

Fuente: Torres, 2017. 


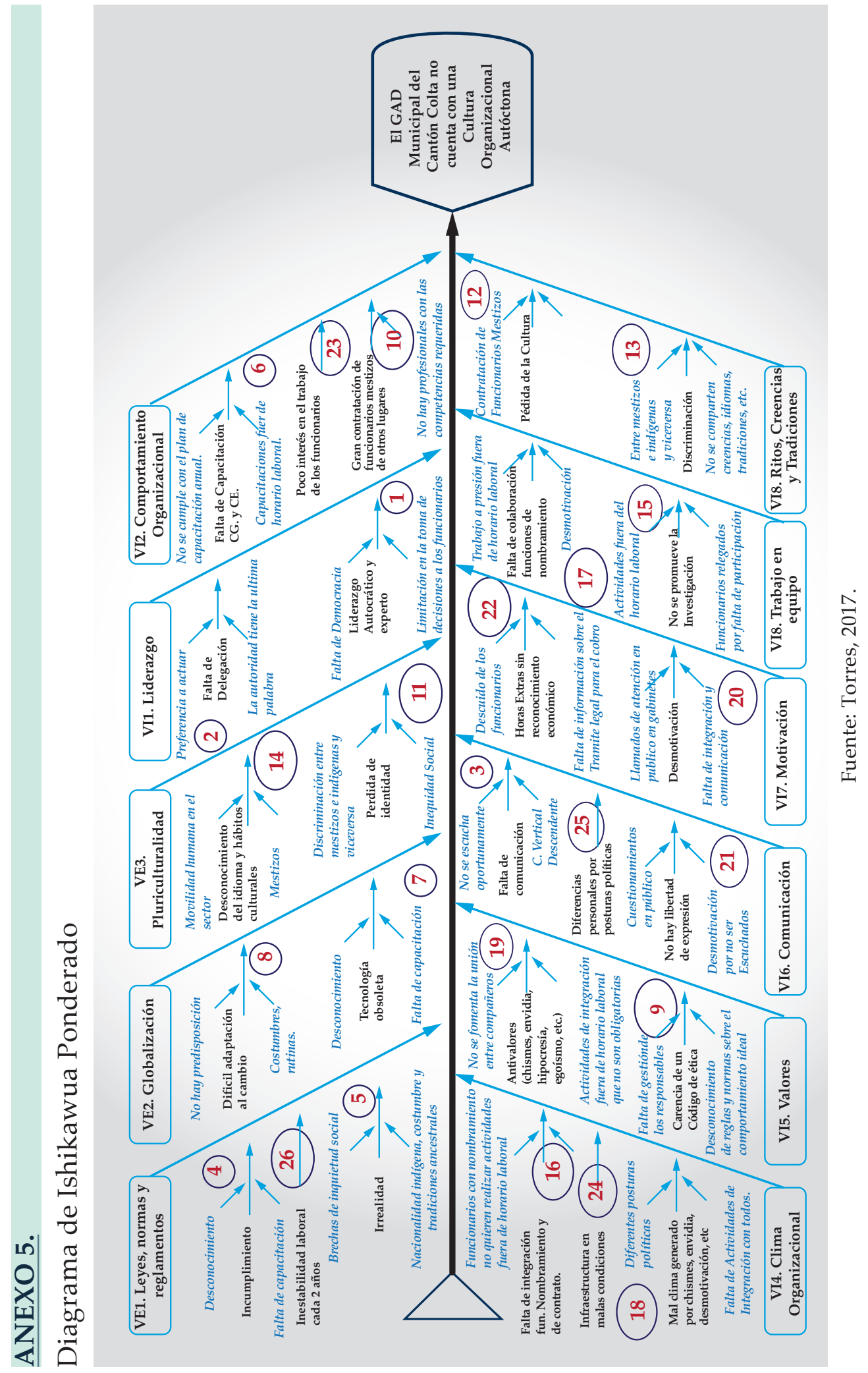




\section{Ponderaciones de causas (En base al diagrama de Ishikawa)}

Según Cuesta (2005), el objetivo de las ponderaciones de las causas es "buscar el consenso en el orden no mediante votación publica sino de manera privada o individual, mediante hojas donde se den numeradas las causas y después se solicite a cada experto su orden de importancia desde 1 hasta $n$, siendo 1 la causa más importante, 2 la que sigue en importancia, hasta la n, la menos importante" (p.47).

\section{- $\quad$ Sumatoria de las ponderaciones $\mathbf{R j}$ \\ $\mathrm{Rj}=\mathrm{D}_{1}+\mathrm{D}_{2}+\mathrm{D}_{3}+\mathrm{D}_{4}+\mathrm{D}_{5}+\mathrm{D}_{6}+\mathrm{D}_{7}$ \\ $\mathrm{Rj}>=$ Causa Menos importante \\ $\mathrm{Rj}<=$ Causa Más importante}

Ponderaciones de causas

\begin{tabular}{|c|c|c|c|c|c|c|c|c|c|}
\hline $\mathbf{N}^{\circ}$ & Directores departamentales & $\mathrm{D}_{1}$ & $\mathrm{D}_{2}$ & $\mathrm{D}_{3}$ & $\mathrm{D}_{4}$ & $\mathrm{D}_{5}$ & $\mathrm{D}_{6}$ & $\mathrm{D}_{7}$ & $\mathbf{R j}$ \\
\hline 1 & Falta de comunicación & 11 & 1 & 3 & 13 & 1 & 9 & 11 & 49 \\
\hline 2 & $\begin{array}{l}\text { Mal clima organizacional generado por } \\
\text { chismes, envidia, desmotivación, etc. }\end{array}$ & 8 & 6 & 13 & 8 & 2 & 5 & 12 & 54 \\
\hline 3 & $\begin{array}{l}\text { Gran contratación de funcionarios mestizos } \\
\text { de otros lugares }\end{array}$ & 24 & 14 & 5 & 1 & 6 & 3 & 13 & 66 \\
\hline 4 & Desmotivación & 10 & 4 & 9 & 10 & 4 & 23 & 4 & 64 \\
\hline 5 & Carencia de un Código de Ética & 4 & 15 & 1 & 23 & 8 & 4 & 3 & 58 \\
\hline 6 & $\begin{array}{l}\text { Antivalores (chismes, envidia, hipocresía, } \\
\text { egoísmo, etc.) }\end{array}$ & 9 & 5 & 14 & 9 & 3 & 6 & 20 & 66 \\
\hline 7 & $\begin{array}{l}\text { Liderazgo autocrático y experto con } \\
\text { participación de funcionarios, pero sin toma } \\
\text { de decisiones conjuntas. }\end{array}$ & 1 & 17 & 2 & 12 & 16 & 1 & 9 & 58 \\
\hline 8 & $\begin{array}{l}\text { Falta de capacitación en competencias } \\
\text { generales y especificas }\end{array}$ & 3 & 23 & 24 & 7 & 7 & 2 & 8 & 74 \\
\hline 9 & No se promueve el trabajo en equipo & 5 & 7 & 10 & 6 & 13 & 12 & 5 & 58 \\
\hline 10 & Pérdida de la cultura & 23 & 10 & 6 & 3 & 10 & 16 & 1 & 69 \\
\hline 11 & $\begin{array}{l}\text { Discriminación entre mestizos e indígenas y } \\
\text { viceversa }\end{array}$ & 17 & 11 & 7 & 4 & 11 & 13 & 10 & 73 \\
\hline 12 & Horas extras sin reconocimiento económico & 21 & 3 & 16 & 11 & 5 & 8 & 14 & 78 \\
\hline 13 & $\begin{array}{l}\text { Desconocimiento del Idioma y hábitos } \\
\text { culturales }\end{array}$ & 18 & 12 & 8 & 5 & 12 & 15 & 15 & 85 \\
\hline
\end{tabular}




\begin{tabular}{|c|c|c|c|c|c|c|c|c|c|}
\hline 14 & Pérdida de identidad & 15 & 13 & 19 & 2 & 9 & 14 & 7 & 79 \\
\hline 15 & $\begin{array}{l}\text { No se promueve la integración entre } \\
\text { funcionarios de nombramiento y contrato }\end{array}$ & 6 & 8 & 11 & 17 & 14 & 22 & 16 & 94 \\
\hline 16 & Falta de delegación & 12 & 18 & 4 & 16 & 17 & 17 & 4 & 88 \\
\hline 17 & Incumplimiento de leyes & 2 & 19 & 23 & 18 & 18 & 10 & 17 & 107 \\
\hline 18 & $\begin{array}{l}\text { Falta de colaboración por parte de los } \\
\text { funcionarios de nombramiento. }\end{array}$ & 7 & 9 & 22 & 15 & 15 & 21 & 21 & 110 \\
\hline 19 & No hay libertad de expresión & 22 & 2 & 15 & 22 & 19 & 24 & 18 & 122 \\
\hline 20 & $\begin{array}{l}\text { Irrealidad en la aplicación de leyes para el } \\
\text { GAD }\end{array}$ & 20 & 20 & 18 & 24 & 22 & 11 & 19 & 134 \\
\hline 21 & Difícil adaptación al cambio & 13 & 16 & 21 & 21 & 20 & 19 & 22 & 132 \\
\hline 22 & Tecnología obsoleta & 19 & 22 & 20 & 20 & 21 & 18 & 6 & 126 \\
\hline 23 & Poco interés en el trabajo & 16 & 21 & 17 & 14 & 23 & 7 & 24 & 122 \\
\hline 24 & Infraestructura en malas condiciones & 14 & 24 & 12 & 19 & 24 & 20 & 23 & 136 \\
\hline
\end{tabular}

- Cálculo de la concordancia Cc

$\mathrm{Cc}=(1-\mathrm{Vn} / \mathrm{Vt}){ }^{*} 100$

Donde:

C : concordancia expresada en porcentaje

Vn : cantidad de directores en contra del criterio predominante

$\mathrm{Vt}$ : cantidad total de directores

\begin{tabular}{|c|c|c|}
\hline & Contra del criterio predominante & Favor del criterio predominante \\
\hline$D_{1}$ & $X$ \\
\hline$D_{2}$ & $X$ & $X$ \\
\hline$D_{3}$ & & $X$ \\
\hline$D_{4}$ & & $X$ \\
\hline$D_{5}$ & & \\
\hline$D_{6}$ & & $X$ \\
\hline$D_{7}$ & $X$ \\
\hline
\end{tabular}

$\mathrm{Cc}=(1-\mathrm{Vn} / \mathrm{Vt}){ }^{*} 100$

$\mathrm{Cc}=(1-1 / 7) * 100$

$\mathrm{Cc}=85,71 \%$ Porcentaje de concordancia de los directores en la ponderación de las causas del diagrama de Ishikawa. 


\section{ANEXO 6.}

Gráfico de Influencias MIC-MAC

\section{Grafico de influencias directas}

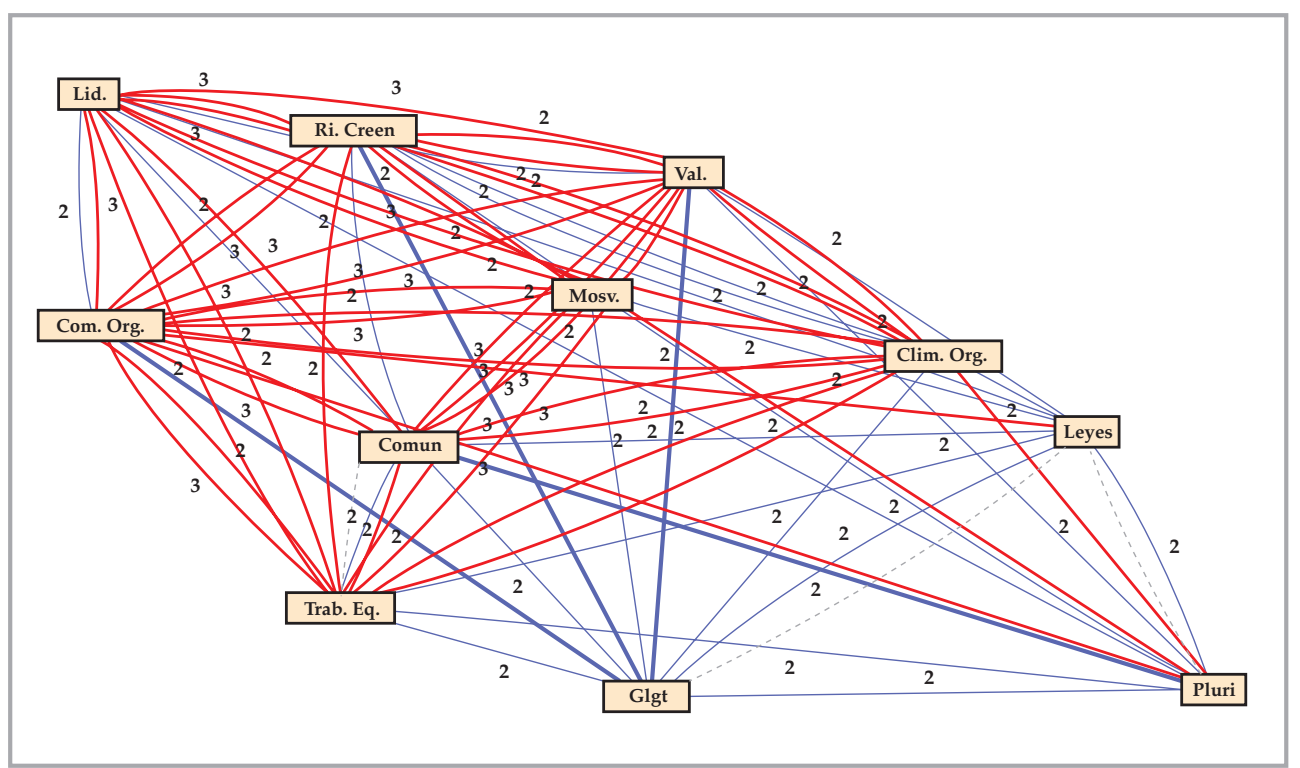

Influencias más débiles

Influencias débiles

- Influencias medias

Influencias relativamente importantes

_ Influencias más importantes

Fuente: Torres, 2017.

\section{ANEXO 7.}

\section{ENCUESTA A LOS EXPERTOS - IDENTIFICACIÓN DE ESCENARIOS FUTUROS}

Experto: E1

Objetivo de la Investigación: Diseñar un procedimiento que permita proponer acciones para fomentar una Cultura Organizacional Autóctona en aras de una mejor gestión en los Gobiernos Autónomos Descentralizados Municipales de la provincia de Chimborazo. 
Introducción: Su colaboración es muy importante para esta investigación, pues al considerarlo como experto, Ud. formará parte de la misma. Su apoyo en esta actividad, radica en la evaluación de las siguientes hipótesis proyectadas; todo esto con el objetivo de fijar los escenarios futuros que permitan establecer las estrategias más adecuadas para Fomentar una Cultura Organizacional Autóctona en el Gobierno Autónomo Descentralizado Municipal del cantón Colta.

Instrucción: Atendiendo al grupo de hipótesis, resultantes del proceso metodológico que se desarrollado en la investigación, evalúe las mismas en las siguientes matrices: califique en base a cada rango, la probabilidad, que usted considera, de que ocurra $\mathrm{Hi}$, atendiendo a la siguiente clasificación:

H1. Se trabaja en base a un liderazgo participativo, democrático e incluyente, que motiva e incentiva a los funcionarios del GAD en un $94,09 \%$.

H2. Se logra el trabajo en minga en un 93,07\% respetando la cosmovisión indígena ancestral de Ama Quilla, Ama Shua, Ama Llulla (no mentir, no robar, no ser ocioso).

H3. Se logra una imbricación entre la Universidad, el GAD Municipal y la población del cantón Colta para realizar programas y planes de capacitación para promover el desarrollo de competencias y conocimientos requeridos por la organización local en un $94,09 \%$.

H4. Se realiza capacitación con las instituciones de regulación y control de los GAD, en lo referente al cumplimiento de la normativa vigente y cambios admirativos en un $90 \%$.

H5. Se implementan acciones para rescatar la identidad y la cultura en el GAD Municipal del cantón Colta un 94,09\%. 


\section{EVALUACIÓN}

A. Probabilidades Simples

Rangos de medición

1-Evento casi imposible

2-Evento improbable

3- Evento medianamente probable

4-Evento probable

5-Evento casi cierto

Tabla: Cruzamiento de hipótesis para las probabilidades simples

\begin{tabular}{|c|c|c|c|c|c|}
\hline Hipótesis & 1 & 2 & 3 & 4 & 5 \\
\hline $\mathrm{H}_{1}$ & & & & \\
\hline $\mathrm{H}_{2}$ & & & & \\
\hline $\mathrm{H}_{3}$ & & & & \\
\hline $\mathrm{H}_{4}$ & & & \\
\hline $\mathrm{H}_{5}$ & & & & \\
\hline
\end{tabular}

B. Cruzamientos de las hipótesis para las probabilidad de ocurrencia de la hipótesis Hi dado que ocurra $\mathrm{Hj}$.

En base a su consideración, determine la probabilidad de ocurrencia de la hipótesis Hi dado que ocurra Hj. Atendiendo a la siguiente clasificación:

Rangos de medición

1-Evento casi imposible

2-Evento improbable 
3-Evento medianamente probable

4-Evento probable

5-Evento casi cierto

6- Eventos independientes

Tabla: Cruzamientos de las hipótesis para las probabilidad de ocurrencia de la hipótesis Hi dado que ocurra $\mathrm{Hj}$.

\begin{tabular}{|c|c|c|c|c|c|}
\hline $\mathrm{Hi} / \mathrm{Hj}$ & $\mathrm{H}_{1}$ & $\mathrm{H}_{2}$ & $\mathrm{H}_{3}$ & $\mathrm{H}_{4}$ & $\mathrm{H}_{5}$ \\
\hline $\mathrm{H}_{1}$ & $\mathrm{x}$ & & & & \\
\hline $\mathrm{H}_{2}$ & & $\mathrm{x}$ & & & \\
\hline $\mathrm{H}_{3}$ & & & $\mathrm{x}$ & & \\
\hline $\mathrm{H}_{4}$ & & & & $\mathrm{x}$ & \\
\hline $\mathrm{H}_{5}$ & & & & & $\mathbf{x}$ \\
\hline
\end{tabular}

C. Cruzamientos de las hipótesis para la probabilidad de ocurrencia de la hipótesis $\mathrm{Hi}$ dado que no ocurra $\mathrm{Hj}$

Determine la probabilidad de ocurrencia de la hipótesis Hi dado que no ocurra $\mathrm{Hj}$.

Rangos de evaluación

1-Evento casi imposible

2-Evento improbable

3-Evento medianamente probable

4-Evento probable

5-Evento casi cierto

6-Eventos independientes 
Tabla: Cruzamientos de las hipótesis para la probabilidad de ocurrencia de la hipótesis Hi dado que no ocurra $\mathrm{Hj}$

\begin{tabular}{|c|c|c|c|c|c|}
\hline $\mathrm{Hi} / \mathrm{Hj}$ & $\mathrm{H}_{1}$ & $\mathrm{H}_{2}$ & $\mathrm{H}_{3}$ & $\mathrm{H}_{4}$ & $\mathrm{H}_{5}$ \\
\hline $\mathrm{H}_{1}$ & $x$ & & & & \\
\hline $\mathrm{H}_{2}$ & & $x$ & & & \\
\hline $\mathrm{H}_{3}$ & & & $x$ & & \\
\hline $\mathrm{H}_{4}$ & & & & $x$ & \\
\hline $\mathrm{H}_{5}$ & & & & & $x$ \\
\hline
\end{tabular}

Recomendaciones:

¡Gracias por su colaboración 


\section{Informe SMIC - Escenarios Futuros}

\section{Informe Smic-Prob-Expert}

\section{Fomento de una Cultura Organizacional Autóctona GAD Colta}

Histograma de los estremums (Cultura Organizacional Autoctona)

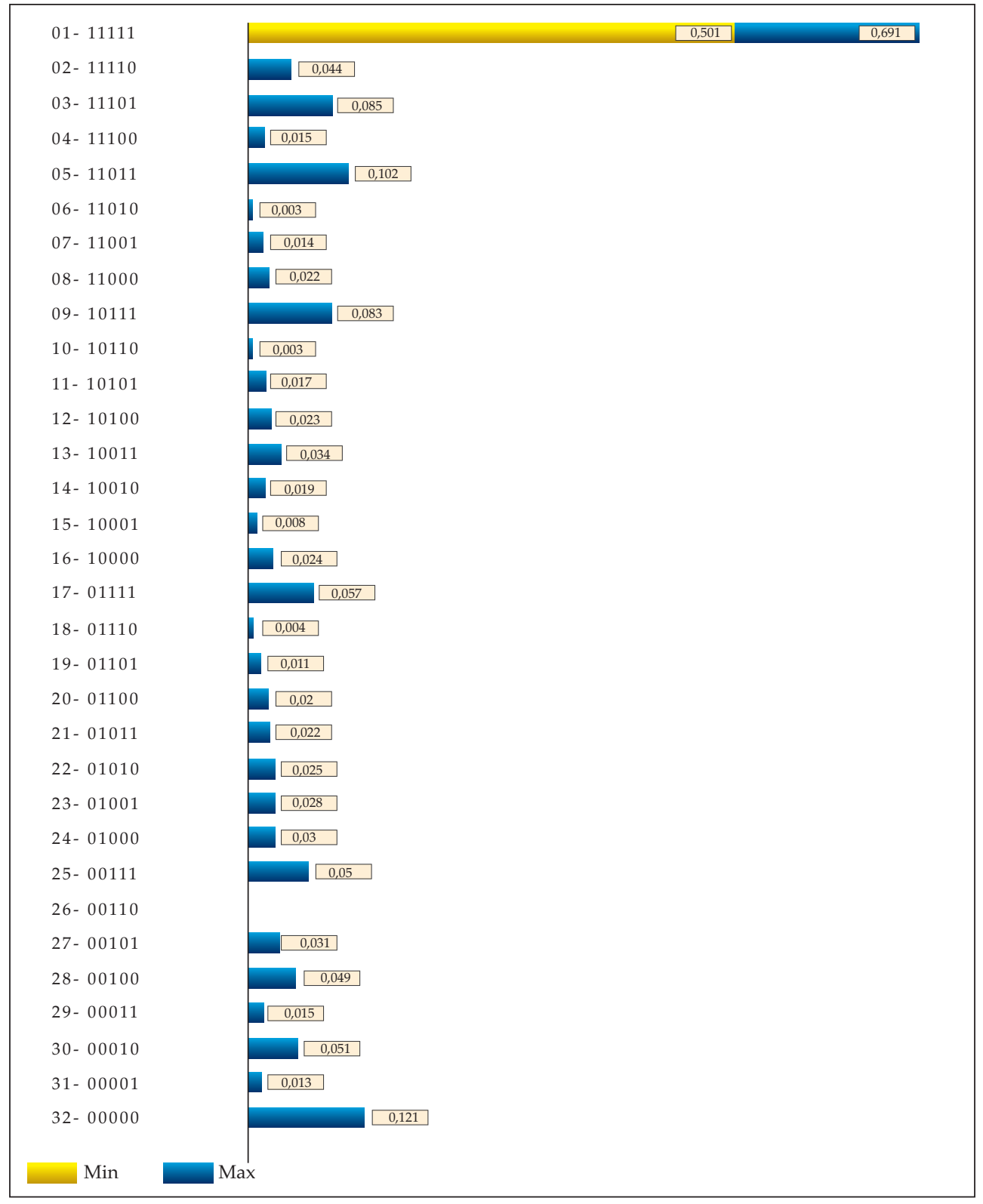





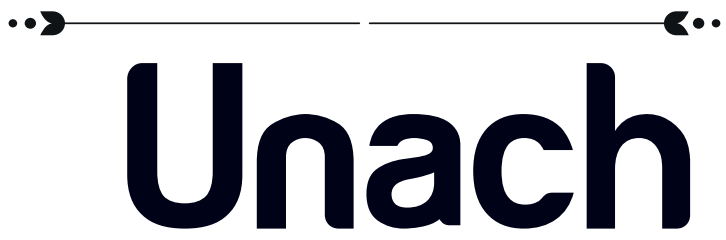

UNIVERSIDAD NACIONAL DE CHIMBORAZO

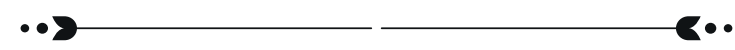

Gestión del Conocimiento y Propiedad Intelectual

HACIA UNA CULTURA ORGANIZACIONAL AUTÓCTONA QUE FOMENTE EL DESARROLLO ECONÓMICO; se publicó en el mes de noviembre de 2020 en la Universidad Nacional de Chimborazo. 


\section{HACIA UNA CULTURA ORGANIZACIONAL AUTOCTONA \\ QUE FOMENTE EL DESARROLLO ECONÓMICO}

Esta obra contempla resultados importantes que parten del proyecto de investigación titulado "Lineamientos para Fomentar una Cultura Organizacional exitosa" de la Universidad Nacional de Chimborazo (Unach) y de la investigación "Fomento de una Cultura Organizacional Autóctona en aras de una mejor gestión para los Gobiernos Autónomos Descentralizados Municipales de la provincia de Chimborazo", los cuales contribuyen a las ciencias administrativas y económicas, pues la fundamentación teórica de esta investigación, se centra en concebir una Cultura Organizacional que rescata cualidades y características propias de los territorios, con culturas ancestrales, que reconozcan el accionar de los actores locales, en los cantones del Ecuador.

El objetivo de esta investigación es establecer las acciones para que, a través del fomento de una Cultura Organizacional Autóctona en los Gobiernos Autónomos Descentralizados Municipales del Ecuador, y el enfoque de trabajo de los funcionarios públicos, dé como resultado un impacto positivo promoviendo el desarrollo de los pueblos.
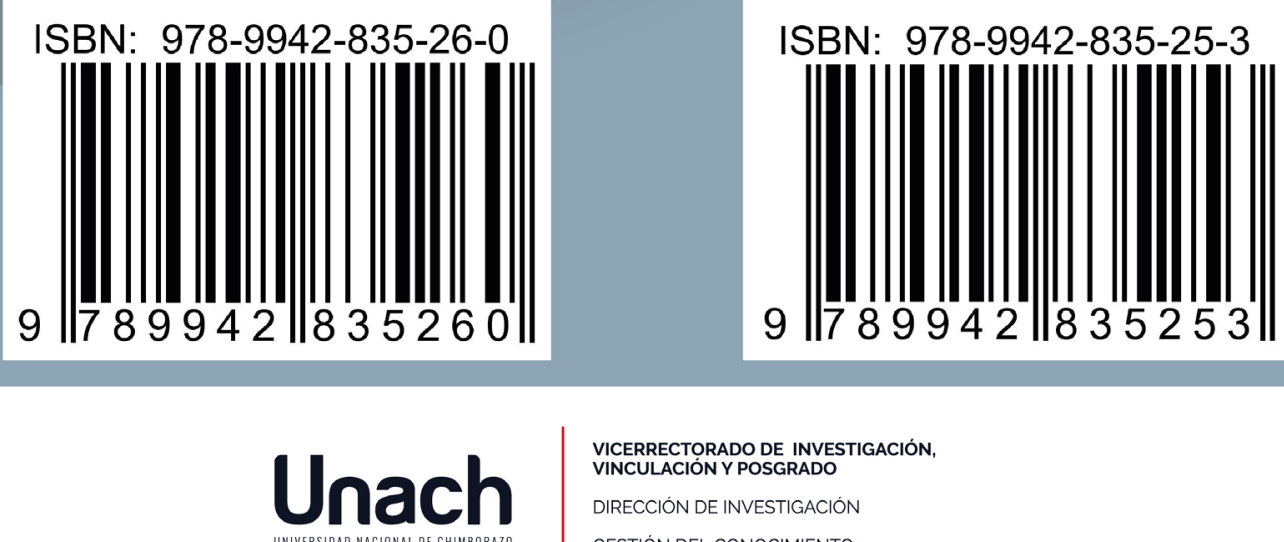